\title{
ACADEMIC AND NURSING APTITUDE AND THE NCLEX-RN IN BACCALAUREATE PROGRAMS
}

\author{
by \\ Mary Ann McCarthy \\ B.S.N. (Mount St. Joseph College) 1984 \\ M.S.N. (California State University, Fresno) 2008
}

\begin{abstract}
A dissertation
submitted in partial fulfillment of the requirements for the degree of
\end{abstract}

Doctorate in Education

Doctoral Program in Educational Leadership at Fresno State Kremen School of Education and Human Development

California State University, Fresno

2012 
Mary Ann McCarthy

April 2012

Educational Leadership

\title{
ACADEMIC AND NURSING APTITUDE AND THE NCLEX-RN IN BACCALAUREATE PROGRAMS
}

\begin{abstract}
Predicting NCLEX-RN success has a positive impact on all stakeholders of nursing education. The focus of this study is on the ability to predict NCLEX-RN pass rates based on prenursing academic aptitude variables and the Assessment Technologies Institute (ATI) nursing aptitude program. The prenursing variables consisted of the prenursing GPA, a prerequisite communication course, and the ATI Test of Essential Academic Success (TEAS) composite subscores of TEAS Reading, TEAS Math, TEAS Science, and TEAS English. The ATI assessment included Nursing Fundamentals, Medical/Surgical, Pediatrics, Psychology, and Maternal/Child. This study included 794 participants from four baccalaureate nursing programs in the California State University system. Results of canonical correlation, multiple linear regression, and logistic regression revealed a significant correlation between prenursing, ATI scores, and NCLEX-RN first-try pass rates. Prediction of NCLEX-RN success rate using standardized testing data is supported, with the strongest predictors being the ATI Medical/Surgical and ATI Psychology tests.
\end{abstract}


Copyright by

MaryAnn McCarthy

2012

iii 


\section{California State University, Fresno \\ Kremen School of Education and Human Development \\ Doctoral Program in Educational Leadership}

This dissertation was presented

by

Mary Ann McCarthy

It was defended on

April 19, 2012

and approved by:

\begin{tabular}{c}
\hline Debra Harris, Chair \\
Social Work Education \\
\hline $\begin{array}{c}\text { Sharon Brown-Welty } \\
\text { Educational Research and Administration }\end{array}$ \\
\hline Susan Tracz \\
Educational Research and Administration
\end{tabular}




\section{ACKNOWLEDGMENTS}

Upon completing this educational milestone there are many individuals who deserve appreciation, more than I can ever put into words, for their help and support over the past three years.

The first and foremost is my family who have endured this process with me even though we had no idea what we were actually getting into three years ago. My husband, Bob, and two daughters, Britney and Jenae, have sacrificed and suffered in ways that I cannot ever begin to heal or repay. Thank you to Bob for picking up the slack at home and putting up with me. Thank you to Britney for her constant love and encouragement. Thank you to Jenae for her love and forgiveness when I was not there when she needed me most. That will remain my only regret in pursuing a doctoral education.

Thank you to my dissertation committee, Dr. Harris, Dr. Tracz, and Dr. Brown-Welty for their endless time, knowledge, and support. Thank you to my faculty mentors, Dorothy Frazer and Dr. Michael Russler, who believed in me and offered constant guidance and support in this three-year endeavor. Thank you to the Fresno State nursing department faculty, staff, and students for their encouragement, especially Carol Rayner, who was not only an amazing moral support but also extremely helpful in the data collection process.

Finally, I would like to thank CSU Bakersfield, Fullerton, and Sacramento for working with me to make this research possible.

"EdD in Three"... YES! 


\section{TABLE OF CONTENTS}

Page

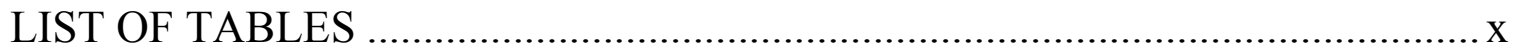

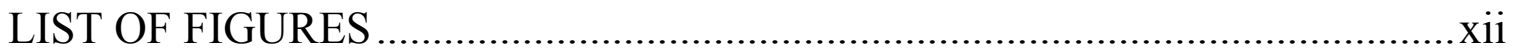

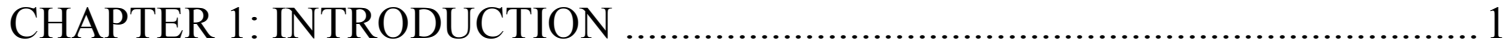

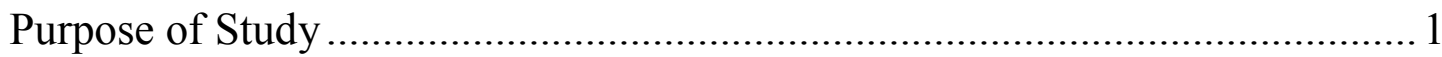

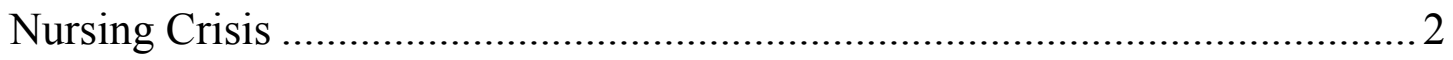

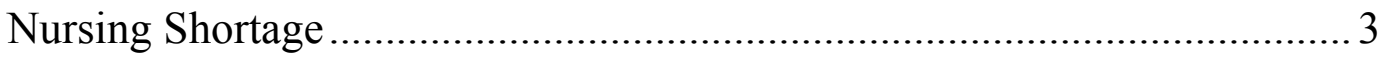

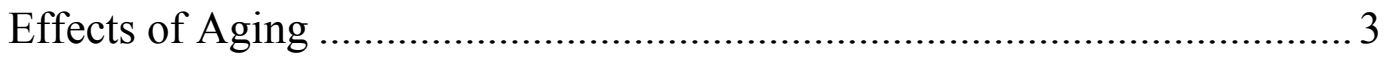

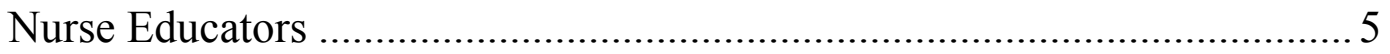

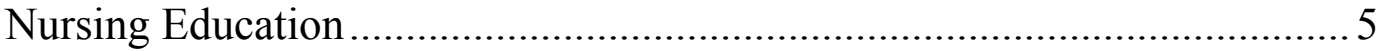

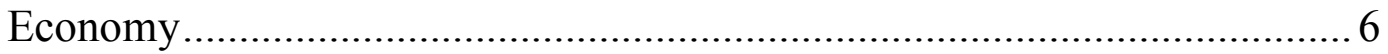

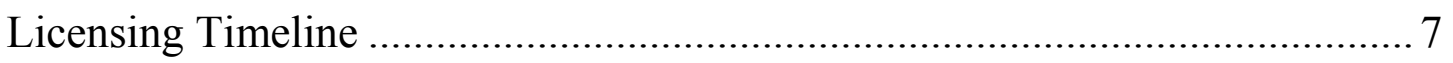

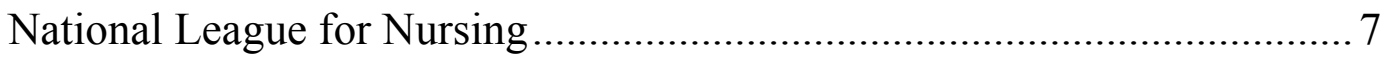

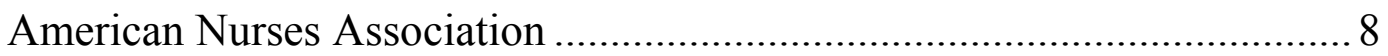

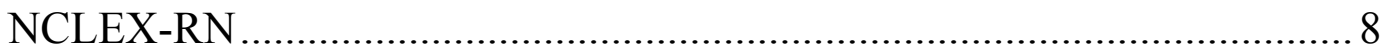

National Council of State Boards of Nursing .................................................. 10

Computerized Adaptive Testing.............................................................. 11

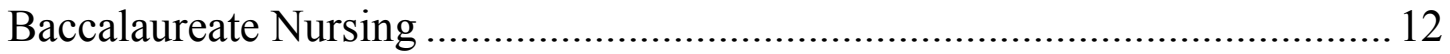

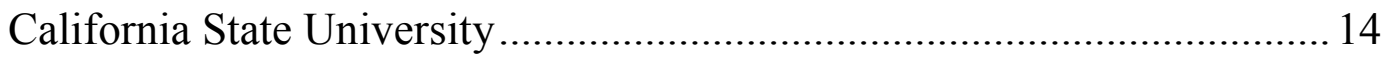

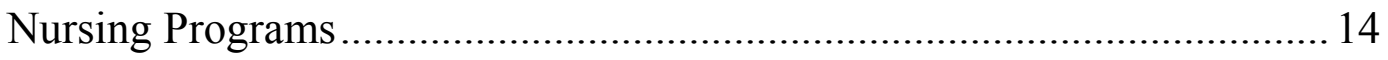

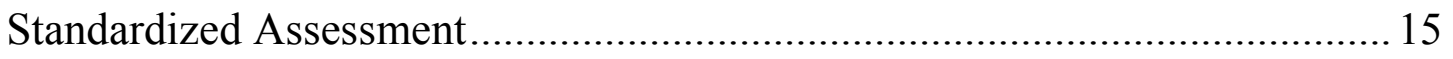

National League Readiness Examination.................................................... 15

Assessment Technologies Institute ........................................................... 16 
Entrance Examination for Schools of Nursing........................................... 18

Nursing School Aptitude Examination RN ................................................. 18

Health Education Systems Incorporated .................................................. 18

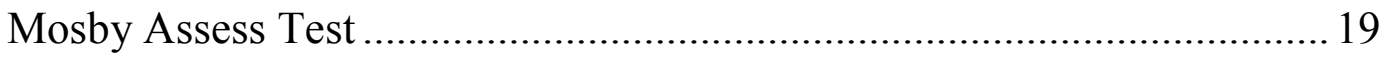

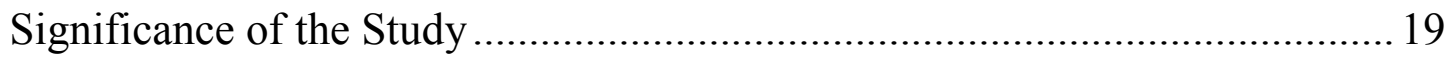

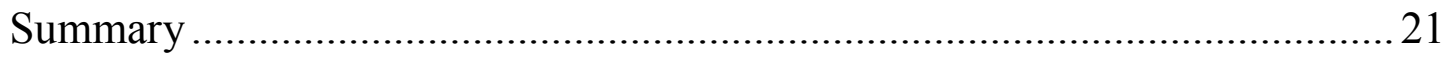

CHAPTER 2: REVIEW OF THE LITERATURE …………............................... 23

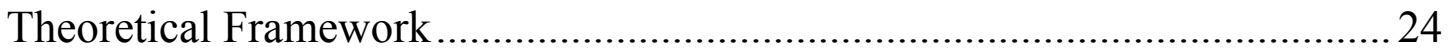

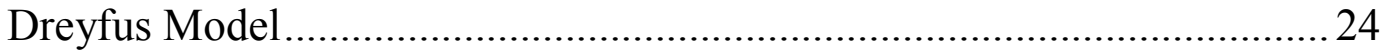

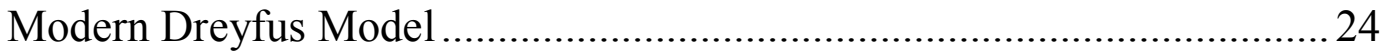

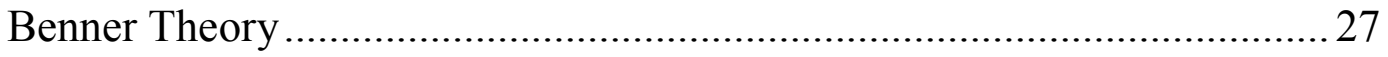

Adaptation of Dreyfus/Benner Model/Theory ...........................................22

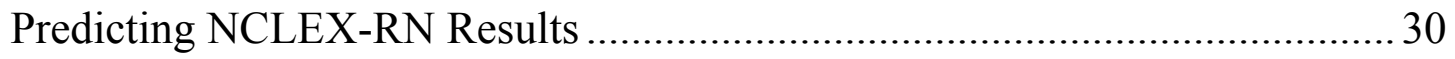

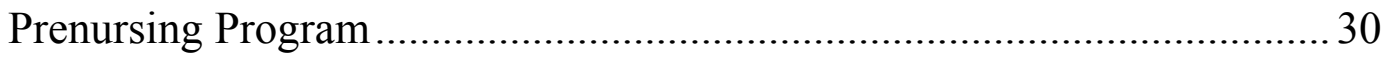

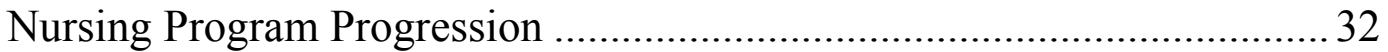

Prenursing and Programs Progression......................................................... 38

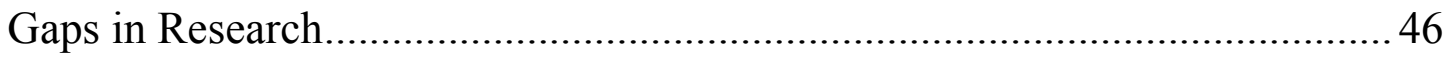

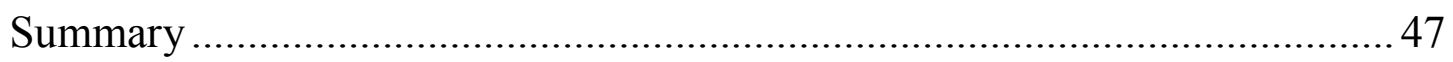

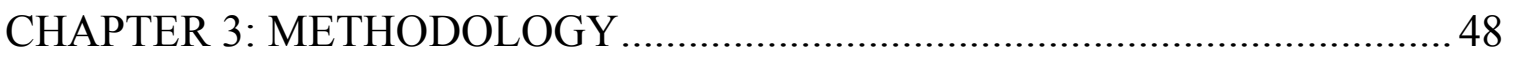

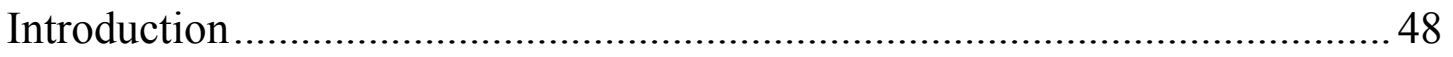

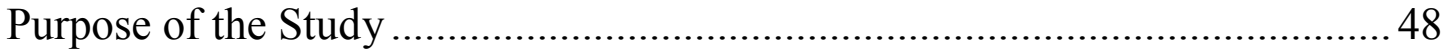

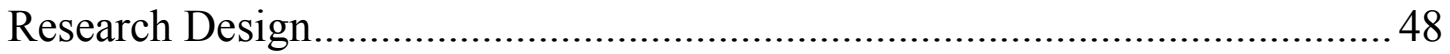

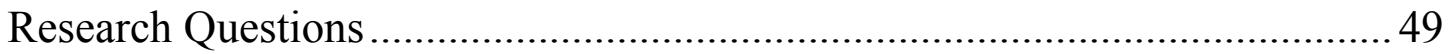

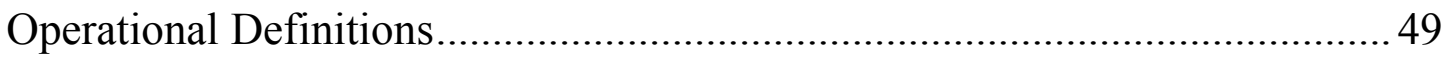

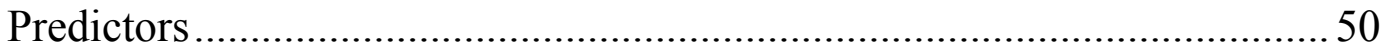




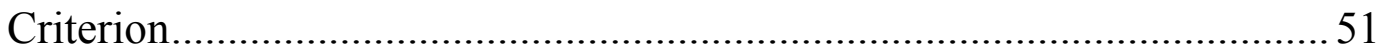

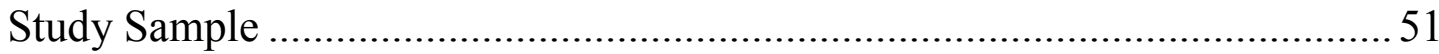

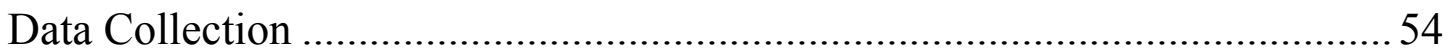

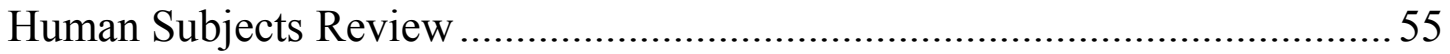

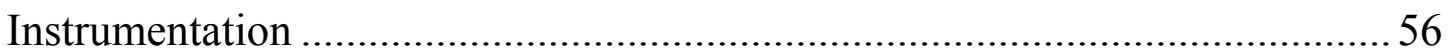

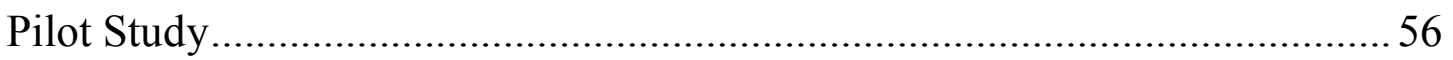

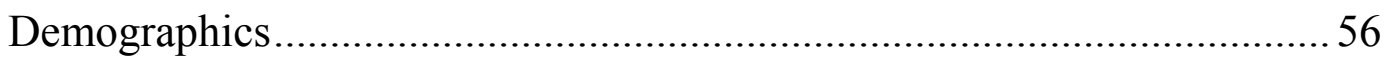

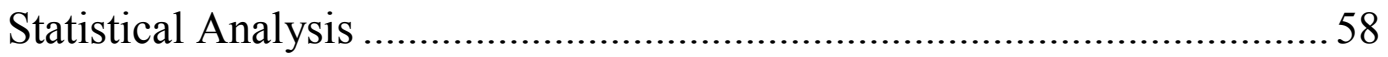

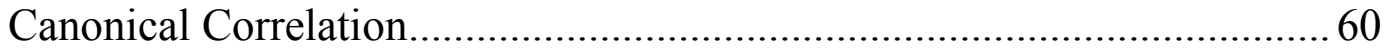

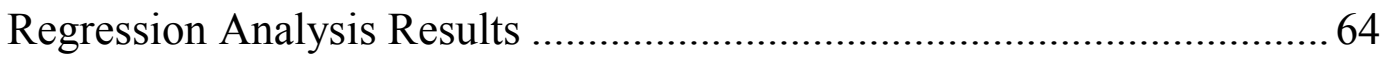

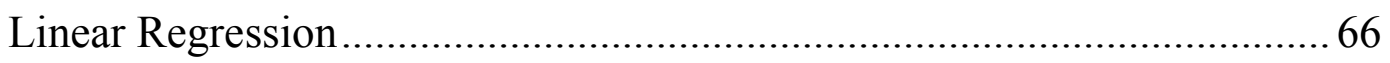

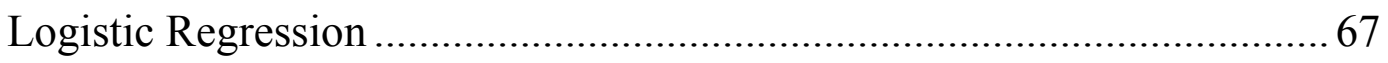

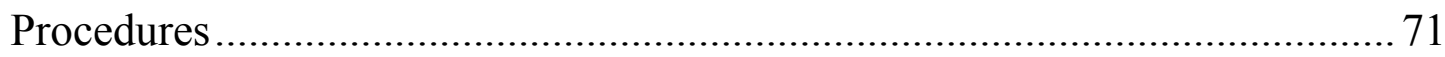

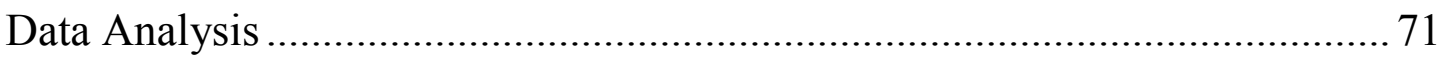

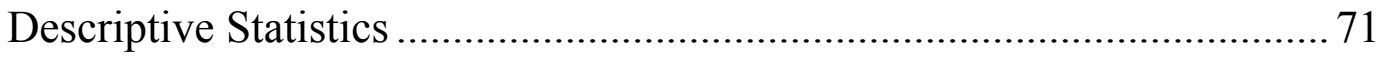

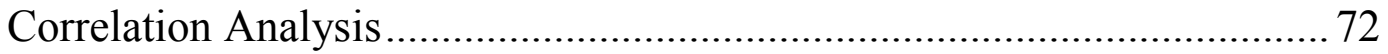

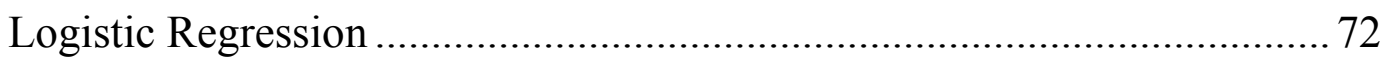

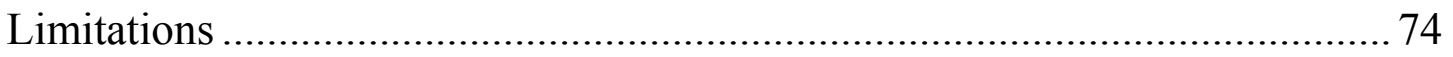

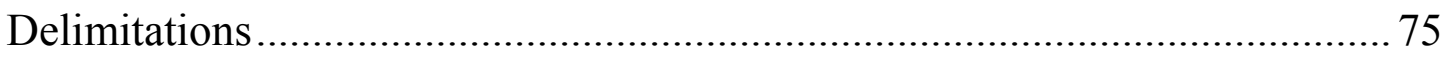

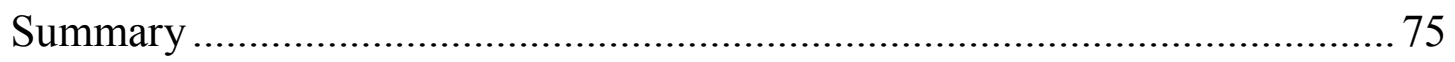

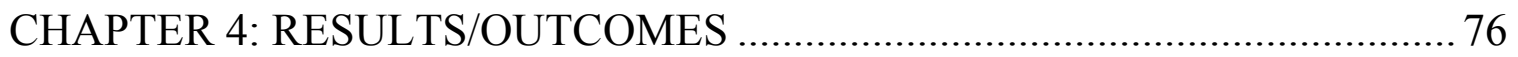

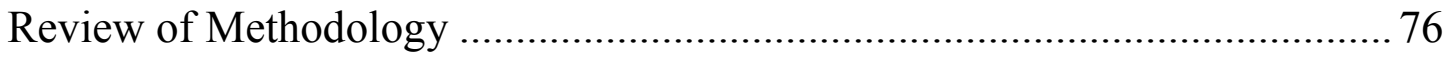

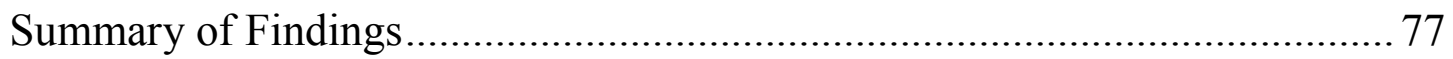

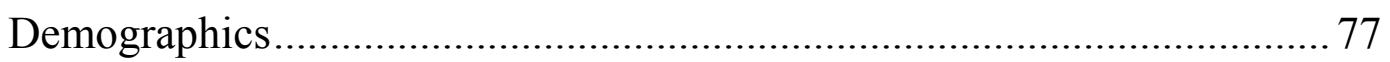

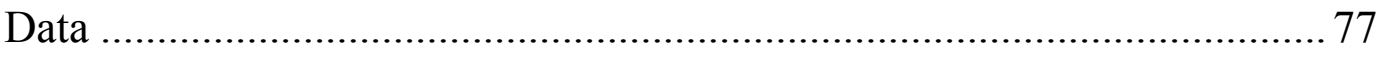




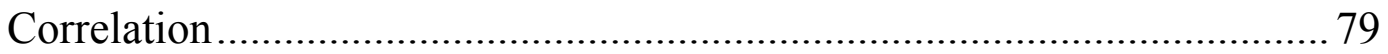

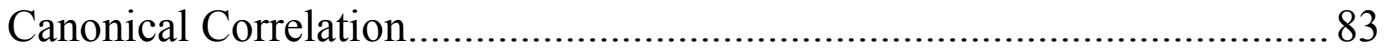

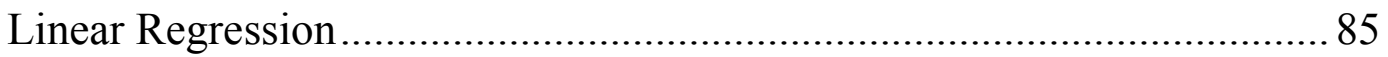

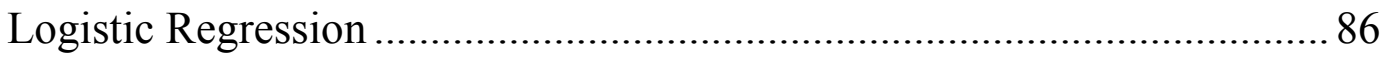

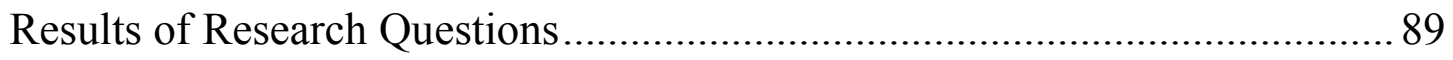

CHAPTER 5: DISCUSSION/SUMMARY/CONCLUSION .............................. 91

Discussion of Research Variables................................................................. 92

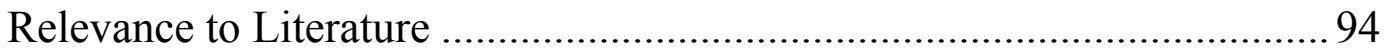

Pilot Study - Full Study ............................................................................ 96

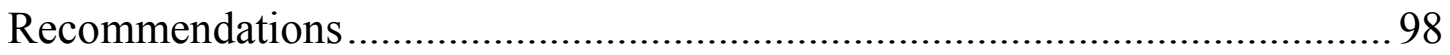

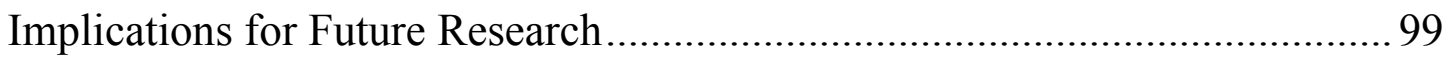

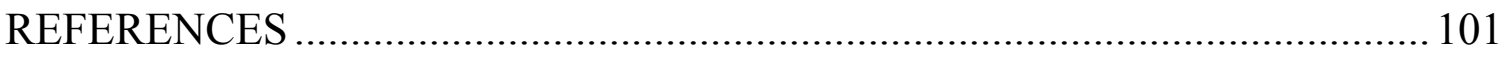

APPENDIX A: LITERATURE REVIEW FINDINGS ...................................111

APPENDIX B: PILOT STUDY COMPLETE CORRELATION ........................ 112 


\section{LIST OF TABLES}

Page

Table 1 California State University Basic Undergraduate Tuition Fees.............. 20

Table 2 California State University Nursing Completion and Retention Data for All Campuses ...................................................................................... 21

Table 3 A Five-Stage Model of Mental Activities Involved in Directed Skill Acquisition ............................................................................................... 24

Table 4 California State University Nursing Programs ..........................................53

Table 5 Pilot Population Demographic Information ........................................... 57

Table 6 Canonical Solution for Nursing Aptitude Predicting Academic Aptitude for Functions 1 and 2

Table 7 T-values and Probabilities of the Regression Coefficients for the Nine Models Using Nursing Variables as Dependent Variables and Academic as Predictors

Table 8 Results of Full, Restricted, and Change Model to Predict NCLEX-RN...67

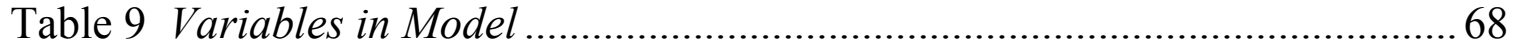

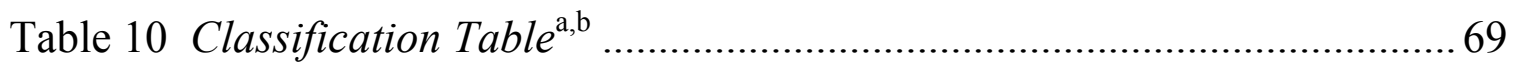

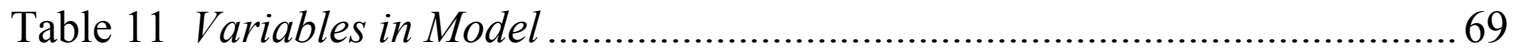

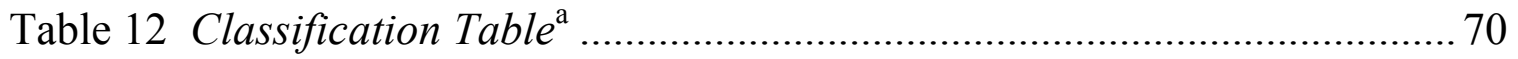

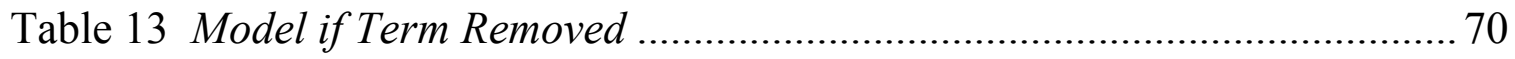

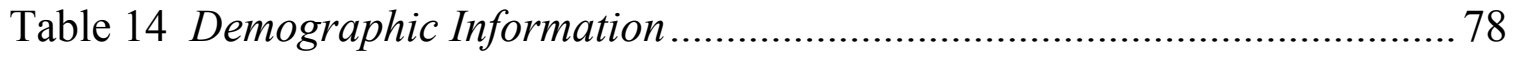

Table 15 Data Available for Each CSU Nursing Program ................................... 80

Table 16 Correlations Among NCLEX and Academic Variables .........................81

Table 17 Correlations Among NCLEX and Nursing Variables ............................ 81

Table 18 Correlations Among Academic and Nursing Variables ........................ 82

Table 19 Canonical Solution for Nursing Aptitude Predicting Academic Aptitude Function 1 
Table 20 Results of Full, Restricted, and Change Model to Predict NCLEX-

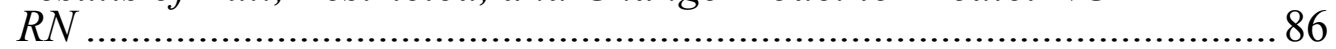

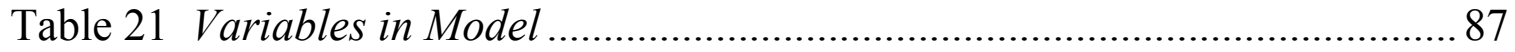

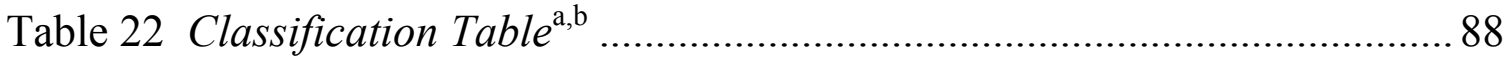

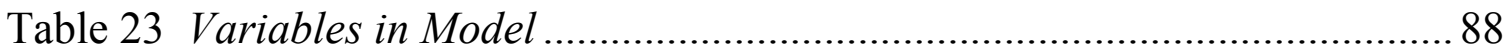

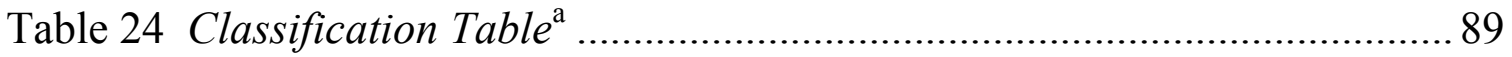

Table 25 Meta-analysis of Current Literature Review and Research Study

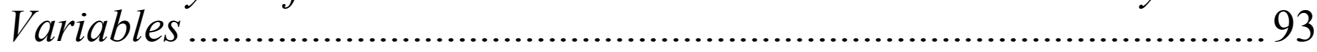




\section{LIST OF FIGURES}

Page

Figure 1. Nursing shortage.................................................................... 4

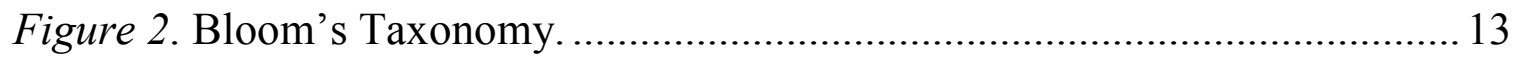

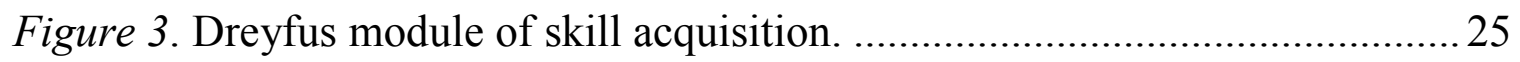

Figure 4. Theory Novice to Expert. ....................................................... 28

Figure 5. Adaptation of Dreyfus/Benner Theory Novice to Expert. ....................29

Figure 6. Canonical correlation............................................................ 73

Figure 7. Adaptation of canonical correlation. ............................................. 73

Figure 8. Parts of the analysis process. ...................................................... 73

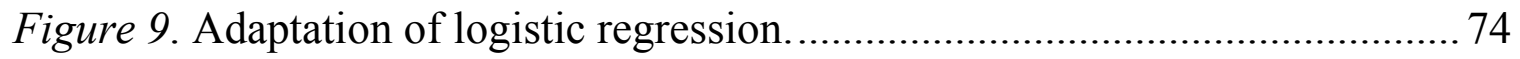




\section{CHAPTER 1: INTRODUCTION}

In the United States, in order to practice in the profession of registered nursing, a candidate must pass the National Council Licensure Examination Registered Nurses (NCLEX- RN) (Board of Registered Nursing [BRN], 2010a). This exam determines a student's eligibility to practice as a licensed registered nurse (RN). Since the first registered nurse licensing exam, nursing programs and faculty have evaluated student performance on this exam, and the effects of formal education on student preparation and pass rates. Nursing students must successfully complete a nursing education followed by a recommendation to the State BRN from an accredited nursing school to be eligible to take the licensing exam (BRN, 2010a).

A licensing exam for nurses is in place to protect the public and hold a minimum standard of safety and competency on the graduating nursing student entering the nursing profession. In the paragraphs that follow, the constructs included in this study will be introduced along with background information directly related to the profession of registered nursing. These constructs include (a) the nursing shortage crisis; (b) timeline of nursing licensure; (c) the NCLEX$\mathrm{RN}$, which is the national licensing exam; (d) prenursing program information which includes undergraduate academics and standardized testing prior to admission to a nursing program; (e) standardized testing, available through several test preparation companies, while in the nursing program; and (f) the significance of this research.

\section{Purpose of Study}

The importance of this licensing exam raises questions about the content of nursing curriculum, how students are educated, if there are effective measures that 
can be used to correlate student NCLEX-RN results, and what early interventions could be implemented to improve the test outcomes. The purpose of this study is to explore whether academic aptitude and nursing aptitude are correlated with each other and with first-attempt pass rates on the NCLEX-RN in baccalaureate nursing programs. This research has the potential to investigate nursing admission criteria and assist in the identification of students who may struggle with the academic rigor of a nursing education. This research also has the potential to assist nursing faculty in determining which students to provide early intervention or academic remediation to help ensure success in nursing education and in passing the NCLEX-RN on the first try. Specifically, this research will do the following:

1. Present correlations between academic aptitude and nursing aptitude.

2. Assess how well preadmission academic aptitude variables correlate with first-try NCLEX-RN pass rates of nursing students in the California State University system.

3. Assess how well in-program nursing aptitude variables correlate with first-try NCLEX-RN pass rates of nursing students in the California State University system.

4. Determine how well academic aptitude variable and nursing aptitude variables correlate with first-try NCLEX-RN pass rates of nursing students in the California State University system.

\section{Nursing Crisis}

Experts have been projecting a nursing shortage for many years. The United States is projecting a nursing crisis, a shortage of qualified nurses that could reach the 1 million mark by 2020 (U.S. Department of Health and Human Services [USDHHS], 2000). The timeline projected in the early 2000s marked 2011 as the year expected to initially feel the effects of this shortage. This 2011 
projected outcome has not been realized due to the recent downturn of the national economy forcing nurses, who were planning to retire, to continue working to meet unexpected financial needs (Hader, Saver, \& Steltzer, 2006).

\section{Nursing Shortage}

Projections in labor growth by the Bureau of Labor Statistics (BLS) included new RN positions in excess of 500,000 by the year 2018. This growth is expected to be the fastest growth prediction of any profession (U.S. Department of Labor, 2010). The decline in the economy, which has delayed the onset of the impending crisis, has caused some to believe that the nursing shortage has passed or will not occur. In July of 2010, the Tri-Council for Nursing released a statement cautioning stakeholders against prematurely stating an end to the crisis. The council suggested that the arrest of the predicted nursing shortage is temporary, secondary to the U.S. economy, and although delayed, the crisis will occur with nursing being the profession most affected (Rother \& Lavizzo-Mourey, 2009). The BLS reported again in April of 2011 that in spite of significant job losses in almost every other area, health care continued to grow, adding 37,000 new jobs in 1 month and totaling 283,000 new health care positions in the past year (Bureau of Labor Statistics, 2011) (see Figure 1).

\section{Effects of Aging}

In spite of this downward economic turn, the Baby Boomer generation continues to age and will require more health care for age and disease related problems in the not-so-distant future. This aging generation also encompasses a large majority of the nursing workforce who are reaching and surpassing retirement age: "The resources of health care organizations will be strained as this 


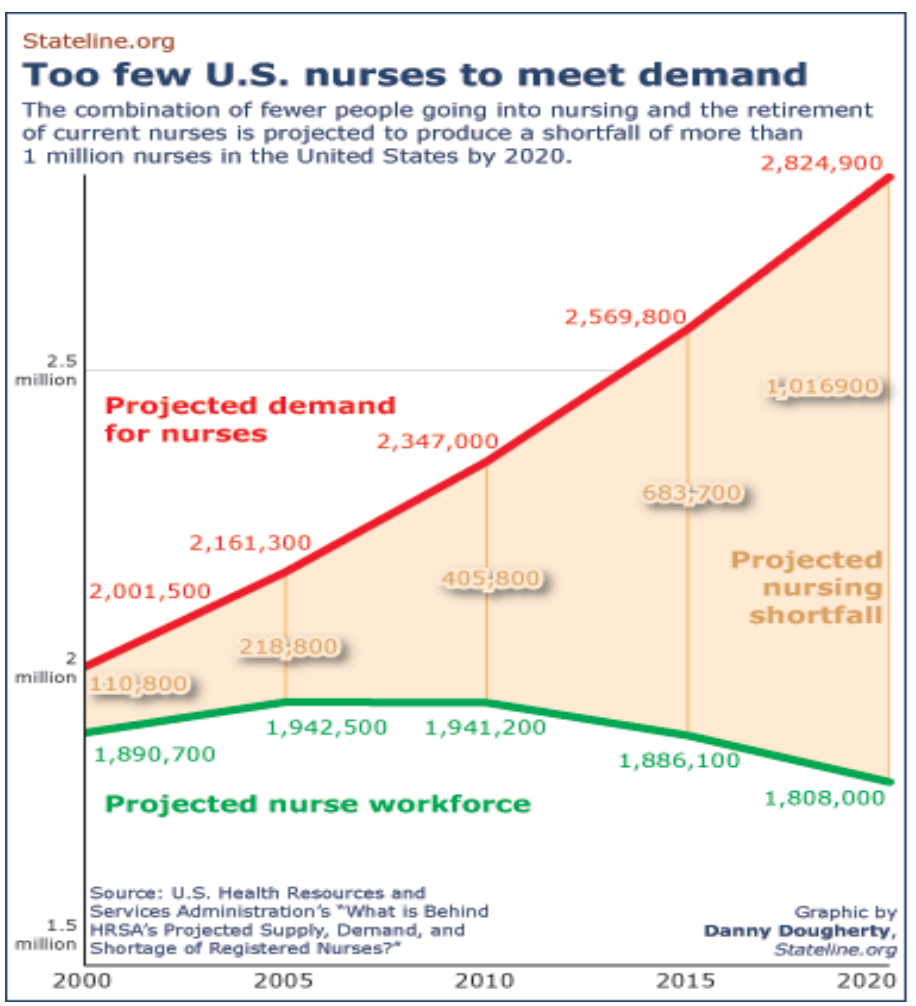

Figure 1. Nursing shortage.

Source: http://www.usnnursing.com/sandiego/San-Diego-Images/Nurshing-Shortage-Graphic.aspx

large demographic cohort moves eventually into old age" (Val Palumbo, McIntosh, Rambur, \& Naud, 2009, p. 229).

In May of 2001, the University of Illinois College of Nursing reported that there would not be enough caregivers to care for this growing elderly population. It also suggested that the changes in demographics across America may limit needed access to health care (Stone \& Wiener, 2001). According to a government report in 2001, a significant nursing shortage, due to an imbalance of supply and demand, is projected to leave many individuals without adequate available health care (Government Accountability Office, 2001).

Not only are the clients who need care aging, but so are the current registered nurses available to care for them. In a 2002 study of nursing faculty, it was revealed that there are $12 \%$ fewer nursing faculty available than the minimum 
needed to educate future nurses. The shortage in this study included 16 states and the District of Columbia. This shortage of faculty as a result of retirement is predicted to cause a ripple effect for years to come (Hodges \& Williams, 2002). In 2008, the Federal Division of Nursing conducted a survey sampling registered nurses to determine the average age of the current $\mathrm{RN}$ population. The survey results indicated that the average age of the $\mathrm{RN}$ population had slightly increased from 46.8 in 2004 to 47 in the 2008 survey, an expected trend predicted to continue (USDHHS, 2010).

\section{Nurse Educators}

As these nurses and educators retire, the most experienced professionals are leaving a new generation without mentors and teachers. In many areas there is a challenge to find and keep nurse educators when salaries are nearly double if the same nurses work in the clinical setting. New faculty has little to no teaching experience, and the seasoned faculty does not have the time or energy to teach these novice nurse educators. Graduate programs often do not introduce or educate nurses for teaching roles, and few nursing faculty are scholars integrating teaching, learning, and research. Nursing educators are responsible for high quality teaching, which is also the best way to interest students in education, teaching, and scholarship (Benner, Sutphen, Leonard, \& Day, 2010).

\section{Nursing Education}

The Institute of Medicine (IOM) report regarding the future of nursing called for an increased education level of nurses entering the workforce to meet the needs of society. In order to raise the entry-level of nursing practice, the IOM included the intention to double the number of nurses holding doctoral degrees and expand the nursing workforce of baccalaureate prepared nurses to at least $80 \%$. 
Advancing nursing education to these levels would increase the statistics which earlier reported that only $50 \%$ of the employed registered nurses hold a baccalaureate or more advanced degree (Robert Wood Johnson Foundation, 2010).

The American Association of Colleges of Nursing (AACN) reported that in 2010 nursing programs in the United States were unable to admit over 67,000 qualified student applicants due to a lack of faculty, resources, clinical space, and budget issues. Of the nursing schools surveyed by the AACN, two-thirds reported a nursing faculty shortage as the number one reason for being unable to accept more students into the nursing program. The AACN also reported an increase in the number of students entering baccalaureate programs in 2010; however, even with this increase the demands for nursing, service will not be met, especially with the Patient Protection and Affordable Care Act in place. The Act will allow millions of Americans who did not have access to health care in the past the ability to gain access to healthcare therefore increasing the need for health care workers, especially nurses (Tracy \& Fang, 2011). The AACN is working with all stakeholders including colleges, universities, legislators, professional organizations, and the media to bring attention to this issue in hopes of identifying collaborative strategies to address this crisis (AACN, 2011).

\section{Economy}

In recent years the downturn of the U.S. economy has wreaked havoc on higher education across the nation. This great recession has resulted in rising unemployment and a drop in real estate values, affecting nearly every population. This situation has also reared its ugly head in the higher education arena, which is where the practice of nursing originates. In a recent statement by the CSU Chancellor's office, 
The $\$ 2.1$ billion in state funding allocated to the CSU in the 2011-12 budget will be the lowest level of state support the system has received since the 1998-99 fiscal year ( $\$ 2.16$ billion), and the university currently serves an additional 90,000 students. If the system is cut by an additional $\$ 100$ million, state support would be at its lowest level since 1997-98. (Uhlenkamp \& Fallis, 2011, p. 1)

These budgetary decisions mean that all CSU campuses in the system will continue to feel deep cuts in academic services provided and a continued increase in student tuition and fees. With most nursing programs already using waiting lists, and the nursing shortage looming overhead, it is imperative that students know what is expected to enter and succeed in a nursing program. It is also crucial that nursing programs look carefully at admission and promotion policies to ensure that the most qualified students enter nursing school with the potential to survive the program, pass the NCLEX-RN on the first try, and enter the workforce ready to care for the community.

\section{Licensing Timeline}

\section{National League for Nursing}

Licensure to practice in the profession of nursing came about in the early 19th century. Before 1944, each state took responsibility to establish its own rules, regulations, and licensing exam requirements. The state exams were typically essay questions one of which was answered orally by the candidates (Iowa Board of Nursing, 2003). As interstate travel became more common, this licensing process became a concern for nurses attempting to move and work in other states. To address the issue of licensure recognition in all states, the National League for Nursing (NLN) began a program to establish a nation-wide testing system (Matassarin-Jacobs, 1989).

By 1949, most states had converted to a multiple-choice version of the exam and by 1952 all states were using the national multiple-choice state board 
test but still imposed a state-determined passing score (Iowa Board of Nursing, 2003). The NLN continued to administer the five subjects: (a) medical, (b) surgical, (c) obstetrics, (d) pediatrics and (e) psychiatry, paper and pencil test (Damgaard, Hohman, \& Karpiuk, 2000).

\section{American Nurses Association}

In 1955, the American Nurses Association (ANA) took control of managing the test in its original format, while the NLN continued administration. In 1978, the ANA gave the responsibility of test development and administration to the National Council of State Boards of Nursing (NCSBN). This transfer of the testing process was done to give state boards autonomy over the process of licensure within the state and allow for more effective regulation of nursing practice to protect nurses and the public (NCSBN, 2010). The test remained relatively unchanged until 1982. At this time the test changed from a five part subject related test (geriatrics, medical surgical, obstetrics, pediatrics, and psychology) to encompass an overall nursing approach crossing and integrating these topics using the nursing process: assessment, diagnosis, planning, implementation, and evaluation. The reason behind this change was to ensure that minimal standards required for entry-level into the profession were being upheld (Matassarin-Jacobs, 1989).

\section{NCLEX-RN}

In 1986, a new graduate job analysis survey completed by the NCSBN was used to assess whether the licensing exam was consistently evaluating the responsibilities of entry-level nursing practice. Following this study, the test focus changed again, this time to focus on the health needs of the client. The four categories of health needs that new nurses were most expected to perform in were 
(a) safe, effective care environment, (b) physiological integrity, (c) psychosocial integrity, and (d) health promotion (Matassarin-Jacobs, 1989).

In 1988, the numeric scoring system of the exam was replaced by pass/fail results because all candidates who achieved a passing score earned a license to practice nursing regardless of the actual numerical value. The biggest change came in 1991, when the NCLEX-RN was reformatted from the traditional paper and pencil exam to a computer adaptive testing (CAT) model (NCSBN, 2010; Wall, Miller, \& Widerquist, 1993). The NCSBN became the first organization in the nation to use this technological adaptive test format in order to further individualize the test in relationship to the standards of nursing practice (NCSBN, 2010).

Throughout the history of nursing practice, the licensing exam has evolved to meet the changing dynamics of the nursing profession in order to protect those individuals who use the medical system in the United States. As medical research advances the care and treatment of individuals in the healthcare system and the face of the health consumers continue to evolve with global travel and cultural diversity, the nursing profession must keep pace (Potter \& Perry, 2009). Job performance analysis surveys, completed every 3 years by nurses who are in the first 5 years of nursing practice, keep the NCLEX-RN focus up to date on what knowledge and skills novice nurses are using most in the nursing profession.

The importance of this licensing exam raises the question of how students are educated, if valid measures can be used to correlate students' data, and how early interventions may improve program and test outcomes. Consequences ride on this high-stakes exam not only for nursing programs, but candidates as well. Nursing students must pass the NCLEX-RN to obtain a license to practice and nursing programs cannot stay in business without successful graduates. Nursing 
program accreditation is in jeopardy if first-time success rates do not remain above $75 \%$, adding pressure to the faculty, department, and institution. Students who have invested many years of hard work and financial resources yet still fail, have a loss of income because they cannot be employed as a $\mathrm{RN}$, and also experience added physical and psychological stress. The gravity of professional licensing is extensive with strong regulation by legislature.

State professional licensing agencies are charged with protecting consumers from harm resulting from illegal or incompetent practitioner's acts. They carry out their mission by ensuring that candidates for professional and occupational licensure, certification or registration meet all criteria mandated through statutes and regulations. Licensure, the most restrictive form of state regulation specifies that it is illegal to practice a state-licensed profession without meeting state-defined standards, usually consisting of at least educational and additional examination requirements. No one without a license may practice the profession as defined in a scope of practice act. (Brinegar, 2005, p. 495)

\section{National Council of State Boards of Nursing}

The NCSBN is the governing board for the NCLEX-RN as well as an advocate, liaison, and consultant to the individual state boards in 50 states, the District of Columbia, and four U.S. territories. It is made up of an executive director, support staff, and a representative from each of the individual state boards. This group is responsible for writing, managing, and administering the NCLEX-RN and to provide test research and statistical information to its nursing program members. The NCSBN is also a resource for policy makers and the general public for educational nursing information (NCSBN, 2010). The mission of the NCSBN is "to provide leadership to advance regulatory excellence by assisting member boards, collectively and individually, and to promote safe and effective nursing practice in the interest of protecting public health and welfare" (Kenward, Woo, Gross, \& Lui, 2010, p. 1). 


\section{Computerized Adaptive Testing}

Computerized adaptive testing (CAT) is an innovative way to administer high stakes testing using modern theories of measurement and sophisticated computer technology. The use of CAT is unlike other forms of testing because each test is individualized to the student taking the exam. The CAT interacts specifically with the candidate through recording answers and adapting future questions to past responses (Kenward et al., 2010).

The NCLEX-RN, the national licensing exam for registered nurses, uses this testing format. Each student test begins with a baseline question at or around the line of minimal safety and competence. Then, as the individual answers correctly, the computer displays a more difficult question. When a question is answered incorrectly an easier question follows. The level of difficulty this exam holds is evident in that the NCSBN expects students to answer only half of the questions correctly. The test continues until the student remains above or below the competent and safe level for $95 \%$ of the testing time (Kenward et al., 2010).

Once the computer establishes a pattern above or below this minimal level, the test ends. Those above the level of safety and competence pass the exam; those below fail. The minimum number of questions a student must answer is 75 , the maximum is 265 . Students have 6 hours to complete the test. If a student has not completed the test after the 6-hour mark, the last 60 questions are evaluated to determine if the individual was above or below the safe and competent level to determine a pass or fail result. Nursing students must pass the NCLEX-RN in order to practice nursing in the United States. Ideally, students succeed on the first attempt; however, if first or subsequent attempts fail, there is a 45-day waiting period between tries (Kenward et al., 2010). 


\section{Baccalaureate Nursing}

The change in health care in recent years has been dramatic, changing the face and role of the nursing profession at almost the same pace. Clients who are hospitalized today are older, sicker, and often have options of being cared for in multiple settings outside routine medical centers. Technology is also expanding at an incredible rate, prolonging life and requiring higher skill levels of nurses at the bedside. Registered nurses are the frontline of the medical profession, often the first health care professional to make contact with the client and the team member to spend the most time caring for them (Campbell, 1997).

Baccalaureate nursing programs provide education and experience for more than bedside practice. A Baccalaureate of Science in Nursing (BSN) degree also aligns nurses for leadership, management, and graduate education in advanced practice. Baccalaureate education will need to continue its hold in nursing, through the foundation of practice and embracing deeper levels of knowledge related to health promotion and disease prevention. In addition, increasing expectations are growing in the areas of genetic counseling and areas related to the dynamic cultural changes of the health care recipient. The possibilities are endless; however, the responsibilities are too. Only this type of preparation will allow nursing to keep up with medicine and technology in the next century (Amos, 2005).

Baccalaureate nursing programs, like all programs educating registered nurses, must meet minimum standards, preparing students with the skill and knowledge needed to take the licensing exam. These programs are also expected to give students experience and knowledge of technology used in the work setting and in computer adaptive testing (BRN, 2009). As students progress through nursing education, it is helpful for them to gain experience taking tests with 
questions that resemble those on the licensing exam and computerized tests instead of paper and pencil, again to model the NCLEX-RN. Complex, higherlevel thinking skills are required to pass the NCLEX-RN (Oermann \& Gaberson, 2009). This higher-level thinking is explained by the difficulty of the NCLEX-RN. This exam is based on Bloom's taxonomy for the cognitive domain (Wendt, Kenny, \& Schultz, 2010). The six learning categories are to remember, understand, apply, analyze, evaluate, and create. Bloom's model appears as a triangle, beginning at the base with knowledge which includes remembering and understanding cognitive skills (see Figure 2).

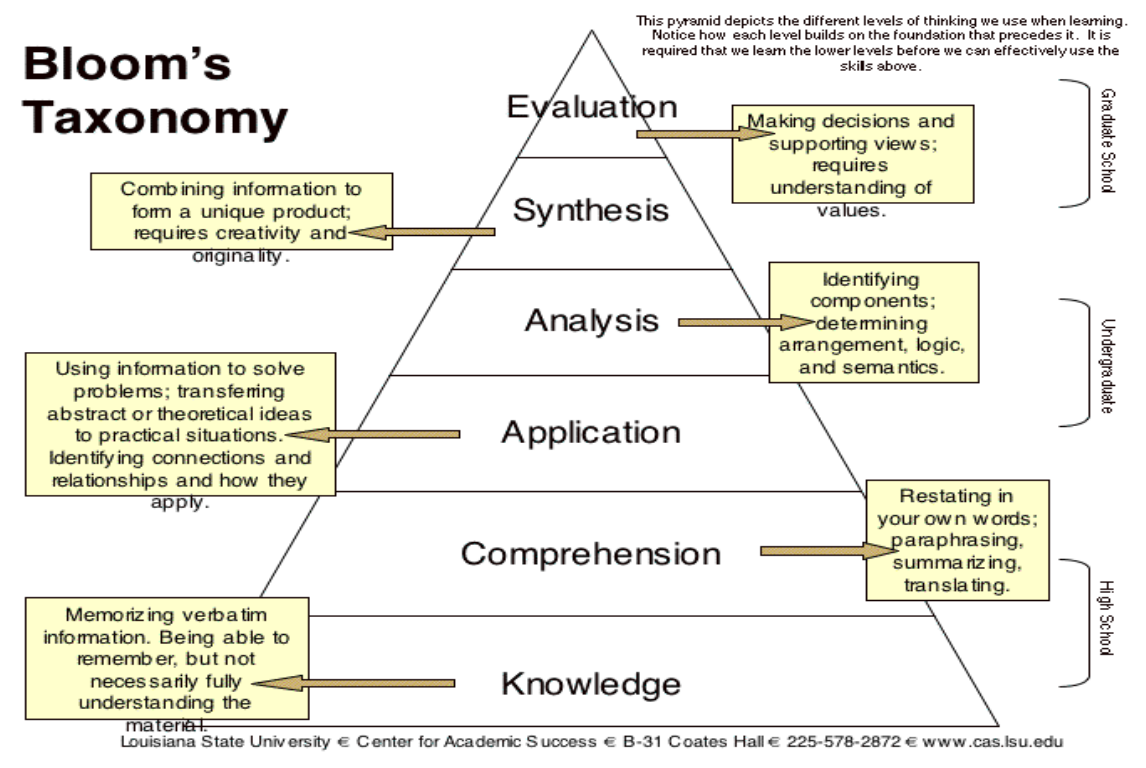

Figure 2. Bloom's Taxonomy.

Source: http://4.bp.blogspot.com/_zSktzKGEi4g/TTM337JfAuI/AAAAAAAABMs/3D1aGWKMKEo/s1600/bltax.gif

As student learning moves upward, the level of thinking becomes more complex, progressing to comprehension, application, analysis, synthesis, and finally, evaluation. Since nursing programs do not typically test at this level, standardized testing is frequently used to guide admission and provide this kind of testing experience throughout the education process. Graduating more nurses to 
meet the increased needs, while maintaining the safety of society is a delicate balance (Allen, Higgs, \& Holloway, 1988):

Society has the right to expect that each professional nurse will be a safe, competent practitioner. Baccalaureate programs that accept a large number of at-risk students may unintentionally lower their internal standards and thus the quality of their product. (p. 113)

\section{California State University}

The California State University (CSU) system is the largest of its kind in the United States. It comprises 23 campuses and educates more than 400,000 students yearly. Campuses stretch as far north as Chico and as far south as San Diego, employing over 40,000 faculty and staff. In 1960, under the state of California Master Plan for Higher Education, the CSU system was created and today draws university admission from the top third of California High Schools. CSU leads the state in baccalaureate graduates, preparing California communities with 95,000 job-ready graduates each year. The system also reaches out to underserved communities, enabling all students to succeed in gaining access to education. A 25-member Board of Trustees, most of whom are appointed by the governor, hold responsibility for the system (CSU, 2011).

\section{Nursing Programs}

The CSU system is made up of 23 campuses statewide. Of those 23 campuses, 18 of them offer baccalaureate nursing programs. Two campuses are on the quarter system, with the remainder on a semester plan. CSU Channel Islands is the newest program, graduating its first nursing class in 2011. Thirteen of the programs are considered to be at impacted status, meaning there are far more students who apply to enter the program than there are seats to fill. All programs consider college and prerequisite grade point average (GPA) during the admission process. All programs use the ATI system with the TEAS in some manner before 
or in the program (CSU, 2011). For example, all schools require students to take the TEAS test; however, they may or may not use the results to determine admission to the program. They may use the results as a precursor to determine areas of academic weakness.

\section{Standardized Assessment}

Over the years, many standardized testing models have been introduced into the academic arena of nursing in an attempt to determine student standing and progress in programs as well as determine preparedness for taking the NCLEX$\mathrm{RN}$. This area of interest and research is yet to unveil which of these tests is the best predictor of nursing program and NCLEX-RN success. Standardized tests have been researched frequently for accuracy in predicting NCLEX-RN success. This type of testing, before and throughout the nursing program, is another way to monitor progress in the program and identify students at risk of NCLEX-RN failure. Identification of these students prior to admission and early in the curriculum enables nursing faculty to offer and encourage remediation and intervention to improve chances of NCLEX-RN success (Daley, Kirkpatrick, Frazier, Chung, \& Moser, 2003). The following paragraphs list and describe the standardized assessments available to nursing programs and students.

\section{National League Readiness Examination}

There are several preadmission and pregraduation tests available in the United States that nursing programs may require students to take as a prerequisite to admission to, or graduation from, an academic nursing education. One such exam, the National League Readiness Examination, is produced and given by the NLN. The NLN is a professional organization for nursing faculty and other professionals involved in nursing education. This test is designed to assess student 
knowledge in academic areas that are essential to nursing education. It is a 75question online or paper/pencil exam that is available to the general public. Due to the nonrestrictive availability, reliability and validity are considered low. The purpose of this test is to measure entry-level professional nursing knowledge; therefore, it is recommended that this exam be given at the end of a student's nursing education (NLN, 2004).

\section{Assessment Technologies Institute}

ATI offers packages to nursing schools only for student purchase. Each student ATI box includes a complete content book set, online access, and standardized testing from preadmission through postprogram NCLEX-RN preparation. The book set, which is in hard copy and fully available online, covers the subject areas of nursing education: (a) adult medical surgical nursing, (b) community health, (c) fundamentals, (d) leadership, (e) maternal newborn, (f) mental health, (g) pediatrics, (h) pharmacology, and (i) nutrition. Each ATI box also comes with a full online access code and proctored exam access in each content area. ATI also offers a prenursing skills exam (ATI, 2007b).

Test of Essential Academic Skills. The preadmission test, the TEAS, is designed to measure entry-level skills in (a) math, (b) verbal reading, (c) written reading, and (d) science. The test has 179 questions, is computer-based, and multiple choice. It is formulated by experts in nursing curriculum to help programs identify the readiness of student nurse candidates to enter a nursing program. Internal consistency, computed by Cronbach's alpha, estimated TEAS reliability of all four test scores totaled above 0.90 for the 2007 ATI sample (ATI, 2007b).

Benchmark Evaluations. The ATI package also offers eight content-based proctored tests to assess nursing content knowledge during progression through a 
nursing program. All exams are secured multiple choice and come in two different forms. The Adult Medical-Surgical exam consists of 95 questions; and the remainder, Fundamentals, Pharmacology, Nutrition, Maternal Newborn, Leadership, Mental Health, and Pediatrics, all have 65 questions. Through ongoing research, ATI establishes benchmark scores that are suggested to nursing programs to determine student proficiency. These score ranges are placed into levels from level 1 to level 3, lowest to highest, respectively. Program faculty are then able to decide what benchmark scores and level of achievement are required for intervention, remediation, and progression from a nursing program. Nursing programs that purchase the package can use any or all the tests, benchmarks, and levels in ways that meet the needs of the program. Updates are made corresponding to NCLEX-RN test plan updates with the latest updates beginning in 2010 with the April 2010 NCLEX-RN changes (ATI, 2007b).

RN Comprehensive. Completing the ATI package is the 3-hour, 180question, RN Comprehensive Assessment test, also available in two proctored formats that are most like the NCLEX-RN. This test integrates all content areas into this culminating exam to assess content knowledge, clinical reasoning, and NCLEX-RN readiness. This test is not leveled in the same way that the other benchmark tests are because of its close relationship to the NCLEX-RN. The RN comprehensive does provide benchmarks to the percentage of probable licensing exam success. The RN Comprehensive is available, from a password protected site, for nursing programs in paper/pencil or online format. Online formats are encouraged due to the similarity to the NCLEX-RN (ATI, 2007a). 


\section{Entrance Examination for Schools of Nursing}

The Psychological Corporation (TPC) offers the Entrance Examination for Schools of Nursing (RNEE). Predicative validity of this test, when measured against grades in high school was found to be predictive of success. This screening tool assesses numerical and verbal ability, physical and life science, and reading comprehension (Gallagher, Bomba, \& Crane, 2001).

\section{Nursing School Aptitude Examination RN}

Psychological Services Bureau (PBS), a private testing organization for multiple health related fields, offers the Nursing School Aptitude Examination $\mathrm{RN}$. This preadmission evaluation is designed to measure a student's potential capability of success in a nursing program (Evangelist, Orr, \& Unrein, 2009).

\section{Health Education Systems Incorporated}

The Health Education Systems Incorporated (HESI) organization, an examination product by the Elsevier book company, has also developed diagnostic and summative evaluation tests for nursing students and students of other health fields. The diagnostic preadmission test evaluates (a) English grammar, (b) English vocabulary; the sciences of (c) anatomy, (d) physiology, (e) chemistry, (f) biology; and (g) math, considered academic factors and two nonacademic factors; including (a) motivation and (b) learning styles. The HESI exit exam offers a 160question computerized exam that follows the NCLEX-RN test plan. Upper level thinking questions are formulated by educators in the nursing profession from across the nation. It is a secure test only available for purchase by nursing programs (Morrison, Free, \& Newman, 2002). Validity of the content, construct, and criterion referenced validity are assessed to determine the exit exam, and the Kuder Richardson formula 20 (KR-20) is used to measure reliability. This test 
averages a KR-20 of 0.79 (Nibert, Young, \& Adamson, 2008). In the same manner as the other testing options, the HESI measures basic knowledge levels to provide feedback to students and faculty regarding preparedness for the rigor of a nursing program (Westra, 2006).

\section{Mosby Assess Test}

The Mosby Assess Test is another computerized study tool which allows a nursing student to evaluate knowledge and skill. This 300 -question exam is comparable to the NCLEX-RN content and is often given near the end of nursing school to help determine student readiness to take the licensing exam. Questions are designed to resemble situations in nursing practice, assessing students' abilities to manage clients with multiple health issues (Saxton, Pelikan, \& Green, 1999).

\section{Significance of the Study}

The findings of this study will have a broad impact on all stakeholders of the nursing profession. First, for students and the parents of those students, solid evidence-based research to outline a significant roadmap on what is needed to prepare and be admitted to a nursing program would be extremely helpful. With the rising cost of higher education and the competitive admission process, the more informed and prepared students and parents are, the more cost and time effective it would be. For example, in Fresno, tuition has increased from \$3,687 in 2008-2009 to $\$ 5,089$ in 2010-2011 (see Table 1).

Second, nursing programs will be more prepared to admit the students who will be most likely to succeed in a nursing program, graduate from it, pass the NCLEX-RN, and enter the nursing workforce. Many publically-funded baccalaureate programs have been pressured and given financial resources to market and enroll a greater number of nursing students in an attempt to graduate 
Table 1

California State University Basic Undergraduate Tuition Fees

\begin{tabular}{lrrrc}
\hline \multicolumn{1}{c}{ Program } & $2008 / 09$ & $2009 / 10$ & $2010 / 11$ & $2011 / 12$ \\
\hline Bakersfield & $\$ 4,077$ & $\$ 5,091$ & $\$ 5,524$ & $\$ 6,682$ \\
Fresno & 3,687 & 4,673 & 5,089 & 6,263 \\
Fullerton & 3,682 & 4,662 & 5,076 & 6,120 \\
Sacramento & 3,854 & 4,901 & 5,405 & 6,573 \\
\hline
\end{tabular}

more nurses (Seldomridge \& DiBartolo, 2004; Symes, Tart, \& Travis, 2005).

Increased enrollment is counterproductive if student quality and faculty effectiveness is lost. Another value to these rigorous programs will be the experience of less attrition by students ignorant of the expectations and rigor of the nursing profession, failing out of the nursing program, or dropping from the program due to failing grades. Nursing programs strive to admit, retain, and graduate all accepted students. Attrition and retention data allow programs to visualize those students who might leave the program or fall behind (see Table 2).

Third, nursing educators will find significance in this study. Educators are in a position to assist colleges and universities in the education of potential students, parents, high schools, and the communities. Offering a clear framework for admittance and success into a nursing program, candidates hold the information needed to reach career goals. Nursing faculty will also be acutely aware of those students who are in need of intervention and remediation early and throughout the program since it will be mandatory to insure the success of at-risk students (Crow, Handley, Shawmorrison, \& Shelton, 2004; Symes et al., 2005). The nursing workforce and community at large will be impacted in a positive way as well. With a nursing shortage on the horizon, the changing demographics in the 
Table 2

California State University Nursing Completion and Retention Data for All Campuses

\begin{tabular}{lccc}
\hline & \multicolumn{3}{c}{ Academic Years } \\
\cline { 2 - 4 } \multicolumn{1}{c}{ Variable } & $2007 / 08$ & $2008 / 09$ & $2009 / 10$ \\
\hline Students & 1051 & 1056 & 850 \\
Completed & 804 & 803 & 745 \\
Still enrolled & 96 & 138 & 30 \\
Attrition & 151 & 115 & 75 \\
Retention rate (\%) & 76.5 & 76.0 & 87.6 \\
Attrition rate (\%) & 14.4 & 10.9 & 8.8 \\
\% Still enrolled & 9.1 & 13.1 & 3.5 \\
\hline
\end{tabular}

United States related to the growing population of Americans over the age of 65, and the condition of the state and national economy, it is essential that students be prepared to enter a nursing program, be successful in the program of choice, and pass the NCLEX-RN on the first try. Advances in medicine and the expanding role of the baccalaureate prepared registered nurse no longer allows for careless admission or the social promotion and graduation of students who are unable to pass the licensing exam and enter a chosen profession. The challenge is to graduate NLCEX-RN-prepared students and not simply admit a greater number of students into nursing programs (Sayles, Shelton, \& Powell, 2003). Standardized testing of academic and nursing aptitude as admission and progression criteria are solid variables that could predict outcomes in nursing education.

\section{Summary}

The primary purpose of this study is to explore whether academic aptitude and nursing aptitude are related to first-attempt pass rates on the NCLEX-RN in 
baccalaureate nursing programs. This research has the potential to investigate nursing admission criteria, assist in the identification of struggling students in need of early intervention or remediation, and determine who will be successful nursing graduates who pass the NCLEX-RN on the first try. The findings of this study will have a broad impact on all stakeholders of the nursing profession.

Chapter 2 reviews literature and includes the NCLEX-RN predictors in nursing research in the categories of the prenursing program, nursing program progression, and those with research inclusive of both prenursing program and progression. This literature review will add depth, illuminate gaps, and assist in the conceptualization of this research. 


\section{CHAPTER 2: REVIEW OF THE LITERATURE}

Nursing is considered an art and a science. A professional nurse is expected to deliver care "artfully" with compassion and respect for the dignity of all clients. As a science, nursing is based on a foundational body of knowledge that is continually changing as the profession, medicine, and client populations evolve. Nursing education curriculum builds on basic reading, comprehension, math, and sciences. Although education in these areas begins in childhood, the focus converges in higher education as prerequisite courses to further build knowledge in those four key educational areas (Potter \& Perry, 2009). With a solid foundation in place, nursing school curriculum builds from that prerequisite base and adds to it with each course and level of development through the program. In nursing education, this includes laboratory and clinical experience as an added component of situational learning theory or "learning by doing" (Lave \& Wenger, 2009).

The literature review is made up of the following headings: (a) theoretical framework, (b) predicting NCLEX-RN results, pre and postadmission to a nursing program, and (c) gaps in research. The theoretical framework that follows will form a foundation for this research. It will demonstrate the relationship between situational learning, skills acquisition, and nursing practice. This theoretical framework will progress forward into this research study adding an additional link to nursing education. The section titled predicting NCLEX-RN results will address existing studies in literature that have attempted to predict student results on the licensing exam. Included are those studies that include only preadmission to a nursing program data, only data after admission to a nursing program, during nursing school education, and those that include both. Finally, gaps in these studies that necessitate further research will be addressed. 


\section{Theoretical Framework}

\section{Dreyfus Model}

In 1984, Patricia Benner introduced a nursing theory based on the Dreyfus Model of Skill Acquisition. S.E. Dreyfus, mathematician/engineer and H.L. Dreyfus, philosopher, conducted a study of airline pilots in flight education and training. The study concluded that each pilot in training went through five stages of development from novice to expert. Table 3 depicts the early work of Dreyfus and Dreyfus (1980) as they began the study and progression of the learning outcomes of airline pilots. Figure 3 is the result of years of research where the original concepts, with further study were condensed and streamlined with some refinement of each stage (see Figure 3).

Table 3

A Five-Stage Model of Mental Activities Involved in Directed Skill Acquisition

Skill Level

\begin{tabular}{lccccc}
$\begin{array}{c}\text { Mental } \\
\text { Function }\end{array}$ & Novice & Competent & Proficient & Expert & Master \\
\hline Recollection & Non-situational & Situational & Situational & Situational & Situational \\
Recognition & Decomposed & Decomposed & Holistic & Holistic & Holistic \\
Decision & Analytical & Analytical & Analytical & Intuitive & Intuitive \\
Awareness & Monitoring & Monitoring & Monitoring & Monitoring & Absorbed \\
\hline
\end{tabular}

(Dreyfus \& Dreyfus, 1980, p. 15)

\section{Modern Dreyfus Model}

In Dreyfus's model the novice stage pilots were found to be strict rule followers with little perception of the actual situation and no discretionary judgment. The progression followed to the advanced beginner stage. Advanced 


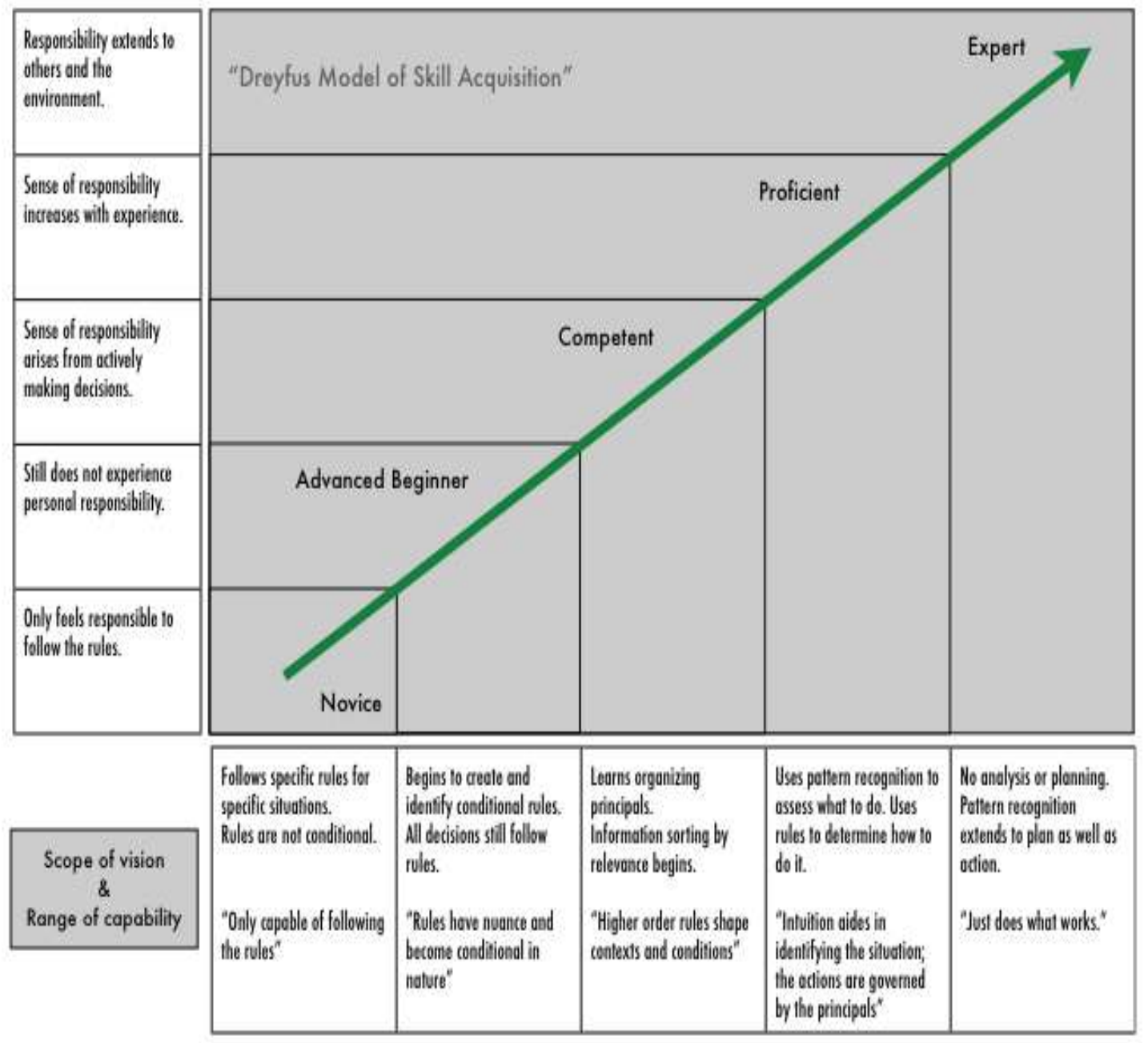

Figure 3. Dreyfus module of skill acquisition.

Source: http://www.coderfriendly.com/wp-content/uploads/2009/05/dreyfus_model.jpg

beginner was added into the newer model when the stages were adjusted to add advanced beginner and eliminate mastery. These researchers determined that the jump from novice to competent was too great and, therefore, added advanced beginner. They also were not convinced that true mastery could be achieved, as the learning process is dynamic. In the advanced beginner stage, the pilots were found to be able to move slightly from strict guidelines with still limited perception of the situation but differentiating between items of equal importance. Third, the learning transferred into what Dreyfus and Dreyfus (1980) referred to as 
the competent stage of skill acquisition. Pilots in this stage had the ability to see forward with long-term goals and make conscious deliberate planning. Procedures at this stage were more routine and standardized. Next, in the proficient state the pilots entered a holistic phase including the ability to see complete aspects and importance of some situations over others. Decision making at the proficient stage is much more fluid. As the pilots moved past the proficiency, they entered the final stage of the skill acquisition, expert. The expert does not rely on rules but instead uses intuition and analytical thinking only in new or problem situations (University of Medicine and Dentistry of New Jersey, n.d.). According to Dreyfus $\&$ Dreyfus, "The pilot, when he stops concentrating all thoughts on features and rules, at first begins to feel he is flying the plane, and finally comes to feel that he is flying" $(1979$, p. 73).

These researchers arrived at this theory model by first taking a look at the work of several other researchers in behavioral, cognitive, psychology, philosophy, situational, and nonsituational learning environments. These included stages of improvised jazz performance by David Sudnow (1978), whose ideas the Dreyfus brothers used to look at the learning of a second language. Work by psychologist Adriaan de Groot (1978), who studied how chess players learn the game of chess, suggested that they go from following the rules of the game strictly, to the ability to look multiple moves ahead and anticipate possible future moves in the game. The chess playing study most resembles the study of the airline pilots and the explanation of the progression process in leaning used in the Dreyfus model. Dreyfus and Dreyfus (1980) also referred to legal psychology work by Konečni and Ebbesen (1979), who studied judges inside the courtroom and out. The differences they observed were that outside the courtroom judges were guided by rules, whereas in the courtroom they were guided more by 
intuition (Dreyfus \& Dreyfus, 1980). In the article about the five-stage model, Dreyfus and Dreyfus, (1980) made a summation as follows:

Our approach is to take the reliance on everyday familiarity in problem solving not as an anomaly, but as a pervasive and essential feature of human intelligent behavior... in skills acquisition concrete experience play a paramount role... we argue that skill in its minimal form is produced by following abstract formal rules, but that only experience with concrete cases can account for higher levels of performance. (p. 5)

\section{Benner Theory}

Benner (2001) visualized this model in the nursing world. From novice to expert, Benner's nursing theory model described the same stages of growth in a new, novice nurse beginning a nursing career all the way to becoming a seasoned, expert nurse with years of experience and training in the nursing profession. In the same manner as the Dreyfus and Dreyfus (1980) model, beginners or novice nurses have limited or no work experience in the profession, and learning is by memorization of a set of rules that have no meaning. Advanced beginner nurses demonstrate marginally with limited experience, mostly recognized only after a mentor calls attention to it. Competence, according to Benner (2001), comes into existence after a nurse has worked consistently in a similar job for a period of time enabling speed, flexibility, and deliberate long-term planning to begin to form. Proficient nurses see and understand the situation as a whole, and decision making come easier and with more confidence. Finally, the expert nurse no longer relies on the original information that allowed entry into the profession, but instead has become one with the information gained from extensive practice (see Figure 4).

\section{Adaptation of Dreyfus/Benner Model/Theory}

This nursing theory can also be applied to students entering and progressing through a nursing program. Students are admitted into a program as novices of 


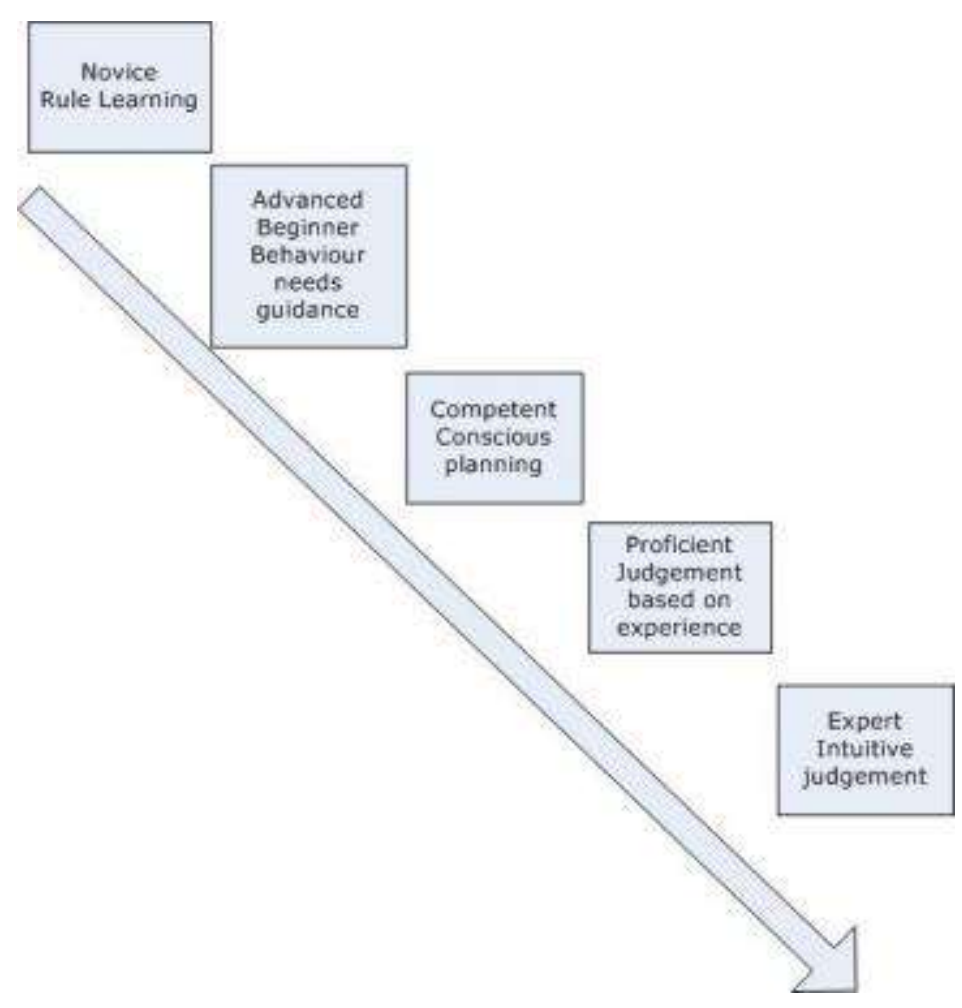

Figure 4. Theory Novice to Expert.

Source: Benner (1984), http://pd.nottingham.ac.uk/var/ezwebin_site/storage/images/media/images/bennersreflective-model/28891-1-eng-GB/Benners-reflective-model_large.jpg

nursing education. Most students have little or no experience in the field and minimal understanding of what the profession itself involves. From day one of nursing education, each course or set of courses build on prior courses on a stair step path from novice nursing student to expert nursing student ready to graduate and take the NCLEX-RN (see Figure 5, Dreyfus/Benner Theory, 1984).

Dreyfus would recognize this progression through the nursing program in three major steps that encompass the theory model. The first step involves a movement from reliance on the abstract, bookwork, or "know it" phase, to the use of concrete experience which adds the "do it" phase. In the second step, the learning is less fragmented and takes on a more holistic approach, with the ability to pull out the most relevant experience for each setting. Finally, in step 3 the 


\section{NURSING STUDENT PROGRESSION THROUGH DREYFUS/BENNER THEORY MODEL}

\section{Novice $\rightarrow$ Advanced Beginner $\rightarrow$ Competent $\rightarrow$ Proficient $\rightarrow$ Expert}

Pre Admit $\rightarrow$ Admission $\rightarrow$ End of 1 st year $\rightarrow$ End of 2 nd year $\rightarrow$ End of 3 rd year $\rightarrow$ Graduation (1st Nursing Courses)
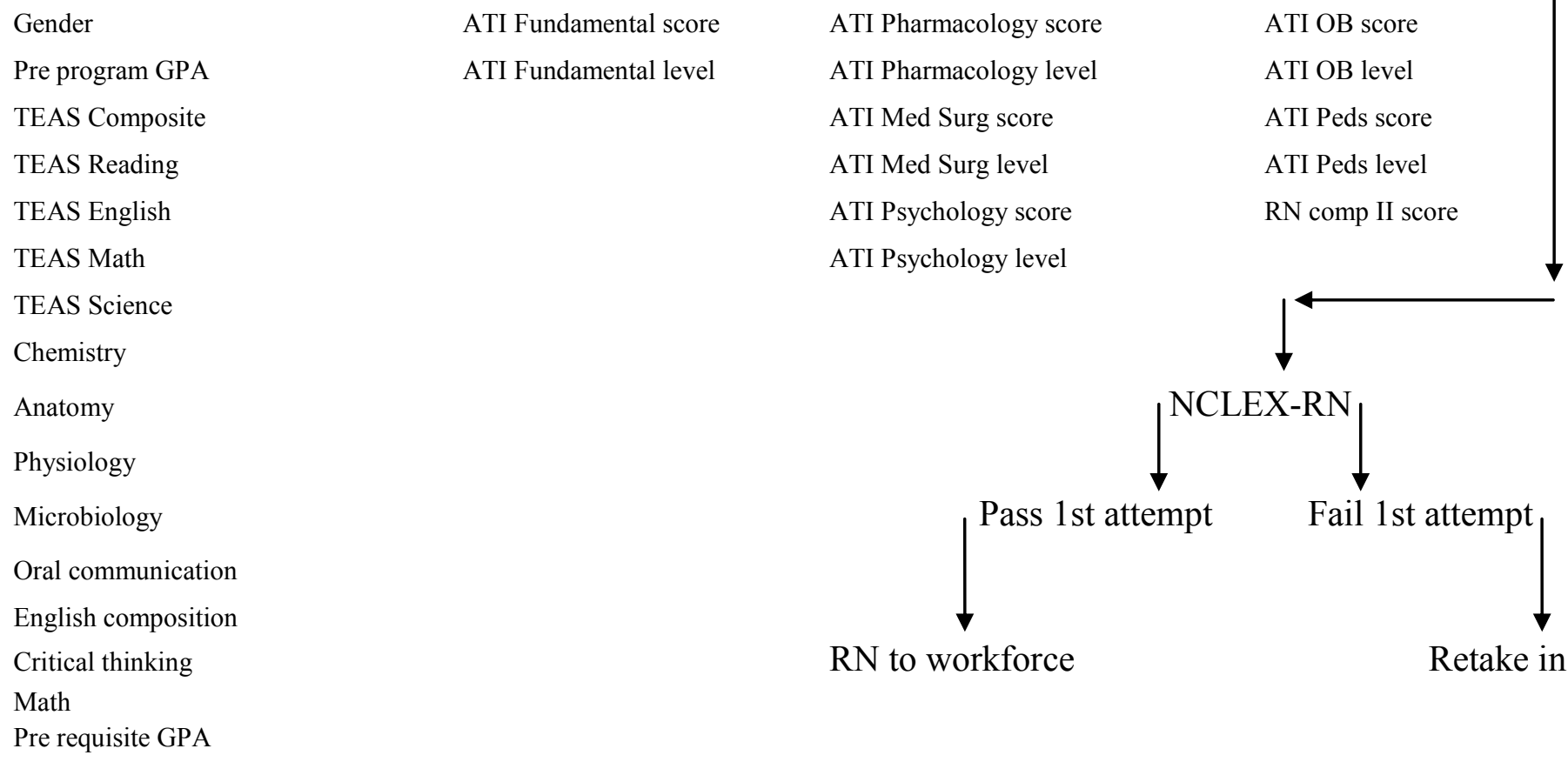

$\mathrm{RN}$ to workforce

Retake in 45days 
transition is from "detached observer to involved performer," therefore ending at the expert level (Benner, 2001).

The literature review that follows includes NCLEX-RN predictors in nursing research in the categories of the prenursing program, nursing program progression, and those with research inclusive of both prenursing program and progression throughout the program to graduation. In an attempt to clarify the data of this literature review, a table located in Appendix A is included. The header of this table lists the author and year of the research data. The far right column lists the independent variables used in the corresponding studies that the researchers found to predict NCLEX-RN outcomes. This table also allows the reader to readily see studies with overlapping findings (see Appendix A).

\section{Predicting NCLEX-RN Results}

\section{Prenursing Program}

Prior to admission to an accredited nursing program, students are required to successfully complete several prerequisite courses needed to build a solid base of information in preparation for the rigor of a nursing program. Students are often also required to take one of several standardized admission testes of math, science, reading, and writing skills. Many researchers contend that preadmission courses and standardized testing reflect evidence of success in programs and on the licensing exam.

Allen et al. (1988) conducted a study of 296 BSN students in one nursing program between 1979 and 1981 to determine success in a nursing program using 40 variables including academic and nonacademic factors related to success. Depending on the variable, chi-square, $t$-tests, Analysis of Variance (ANOVA), Pearson correlation, and multiple regression were used to determine relationships 
between variables and outcomes. Success was defined by remaining in the program, and attrition by failing out of the program due to not holding the required grades/GPA, or dropping out of the program due to poor grades before actually receiving failing grades on college transcripts. Of the 40 academic and nonacademic variables, only prenursing grade point average (PGPA) and grade point average (GPA) in the program were significant to progression and completion of the program. None of the nonacademic variables were found to be significant. These nonacademic variables included (a) personal references, (b) age, (c) marital status, (d) previous experience as a licensed practical nurse or health aide, (e) the amount of time working (job), (f) full-time or part-time student status, (g) previous upper division courses, (h) number of colleges attended, and (i) traditional versus transfer students (Allen et al., 1988).

Newton, Smith, Moore, and Magnan (2007) used an exploratory descriptive design to study a sample of 164 first semester nursing students in two cohorts admitted in fall and winter session. Each student took the TEAS at the beginning of the first semester. The composite TEAS score along with the PGPA, which included the final grades in the required prenursing courses of the program, were evaluated to determine if these outcomes predict early achievement in nursing. The researchers used these items because both PGPA and TEAS measure aptitude identified for predicting academic success. The fall and winter cohorts varied greatly; however, each group was found to have significant findings related to the TEAS test and PGPA. In the fall cohort, the PGPA was significant to success in the program as well (Newton et al., 2007).

A study by Wolkowitz and Kelley (2010) used a multiple regression model to look at student TEAS test scores to determine if TEAS subtest scores in reading, math, science, and English had any correlation to success early in a 
nursing program as determined by the Assessment Technologies Institute fundamental assessment criteria. In this study the science subscore was the strongest predictor. The study population was a large multi-program sample with data from 4,105 RN students in multiple nursing programs. Results concluded program success is best predicted by TEAS subscores in this order: science, written reading, verbal reading, and math. This study demonstrated a low to moderate correlation between science subscores and ATI fundamental assessment (Wolkowitz \& Kelley, 2010).

The monitoring of prerequisite criteria of nursing programs in order to predict successful outcomes benefits both nursing students and nursing programs. This prerequisite monitoring allows schools of nursing to set admission standards that increase the chances of student program success. Successful nursing students who complete the program, pass the NCLEX-RN, and join the nursing profession reflect positively on the academic institution of study and the profession as a whole. In the next section, research on performance predictors from within a nursing program will be reviewed.

\section{Nursing Program Progression}

Academic performance in the years of nursing school appears to give some foresight into what the future may hold for nursing students. Once students who are at risk of dropping out of the program due to poor grades or failing out of a program for the same reason are confirmed, strategies to assist these students could be available through intervention and remediation. Much of the literature reflecting NCLEX-RN success makes reference to the need to monitor students before and during nursing education to implement intervention and remediation for students in a timely manner if identified as at risk for program or NCLEX-RN success. Determining which constructs predict academic and NCLEX-RN success 
enables nursing faculty the opportunity to provide students with strategies to accomplish the goal of becoming a registered nurse. Student achievement and progress during the nursing program may also indicate positive NCLEX-RN results. Studies of predictor variables within a nursing program will be addressed in the following section.

Nursing researchers have also studied sectors within nursing programs, postadmission to the program, to predict program and NCLEX-RN success. Gross, Takazawa, and Rose (1987) studied a sample size of 108 Associate Degree in Nursing (ADN) and BSN students at one nursing program in Hawaii. The independent variables included age, years of college, ethnicity, NLN entrance test score, and a critical thinking ability test. The dependent variables, considered predictors of program success, were GPA, completion of the nursing program, and NCLEX-RN results. Through correlation and multiple regression $(p<.01-.05)$ the study results revealed that of the variables studied, NLN test scores, (a) verbal, (b) math, (c) science, (d) composite, (e) years of education after high school, and (f) GPA within the nursing program, were found to be the best and only predictors of performance on the NCLEX-RN (Gross et al., 1987).

Friedemann and Valentine (1988) studied 159 BSN students at Eastern Michigan University. The dependent variable was the result of the licensing exam. Independent variables included age, prenursing credits, GPA, medical experience as a licensed practical nurse (LPN), grades in the prerequisite courses, chemistry, psychology, sociology, anthropology, grades in six in-program nursing courses, and exit GPA. This study, using one-way ANOVAs, found that GPA in the nursing program, reflective of course grades, was the best predictor of whether or not students would pass the licensing exam. Students with higher GPAs (>3.5) were found to have greater NCLEX-RN pass rates than those with GPAs below 
3.5. These researchers found older students, above age 21, often had higher GPAs and higher NCLEX-RN pass rates. However, of traditional students, those aged 18 to 21 years who held a GPA of greater than 3.5 did just as well as their older colleagues in passing the licensing exam (Friedemann \& Valentine, 1988).

Dell and Valine (1990) completed a research study on 78 BSN graduates from three small schools in the southwestern U.S. The dependent variable was the results of the licensing exam and the independent variables included (a) GPA, (b) SAT, (c) ACT, (d) age, and (e) self-esteem. In a Spearman-Brown correlation ( $p<$ .001 ), the results produced data supporting GPA in the nursing program as the best predictor of success on the national licensing exam in this small study. These researchers acknowledged that self-esteem was not a cognitive concept, thus making it difficult to predict "cognitive scores with non-cognitive measures" (Dell \& Valine, 1990, p. 161).

In a study by Horns, O'Sullivan, and Goodman (1991), a sample of 408 BSN graduates correlated 11 predictor variables and the NCLEX-RN in a forward regression analysis, correlation coefficient $(p<.01)$. This inquiry not only examined academic achievement but also the demographic information of age, gender, and race. The conclusions were significant for preadmission to the nursing program GPA and the GPA of all nursing courses completed by the end of the second year in the nursing program as predictive of NCLEX-RN success. This study found no significant correlation in the demographic variables as related to the national licensing exam pass rates (Horns et al., 1991).

Mills, Sampel, Pohlman, and Becker (1992) and Wall et al. (1993) both achieved similar results to Horns et al., (1991). Subsequent research revealed that a nursing student's GPA in the second out of 4 years for this BSN program is most significant to predicting program and NCLEX-RN success. Mills et al.'s (1992) 
research included 534 nursing graduates between 1982 and 1990 from a private university in the Midwest. The research looked at demographic and academic information. NCLEX-RN success or failure was the dependent variable; the independent variables included (a) age; (b) gender; (c) high school GPA; (d) American College Testing (ACT) subscores in math, English, social science, and natural science; (e) traditional versus transfer student; and (f) cumulative GPA at the end of each of the 4 academic years. Stepwise logistic regression $(p<.05)$ found the GPA following the second year of nursing school predictive of NCLEXRN success. Age in this study was found to be inversely related to success, meaning that students' age $>22$ years upon admission to the program had higher GPAs (Mills et al., 1992). Wall et al. (1993) also identified the nursing student's GPA in the second year of the nursing program as a predictor as well. These researchers included a sample of $92 \mathrm{BSN}$ graduates from four consecutive cohorts from 1988 to 1991 at a small, private, religiously-affiliated nursing program in the Midwest. The NCLEX-RN results were the dependent variable, and the independent variables included (a) SAT, (b) high school rank, (c) GPA from each of the 4 years of baccalaureate study, (d) NLN diagnostic readiness score, and (e) the Mosby Assessment Test (MAT). Using $t$-tests and discriminate function analysis $(p<.01-.15)$, the study identified four of the five academic variables, all except high school rank, were found to have significance in licensure exam results (Mills et al., 1992; Wall et al., 1993).

Sutherland, Hamilton, and Goodman (2007) studied the effects of implementing an At-Risk Minorities for Success Program (ARMS) to determine if an intervention program, implemented within the program itself, would improve the grades in the last semester of nursing school and NCLEX-RN pass rates for atrisk students. At-risk in this study were students from the following categories: 
African American, Hispanic, and Asian Pacific students, first generation college students, students from rural communities, and students with a $\mathrm{C}$ grade or failing a nursing course. The study, supported by a 3-year grant, enabled the researchers to admit 64 at-risk students into a predominately White baccalaureate nursing program in the south central region of the U.S. The program also allowed for mentoring and tutoring of these at-risk students throughout the program. Descriptive statistics, $t$-tests and chi-square analysis resulted in a small, nonsignificant change in the final semester grades or on NCLEX-RN pass rates of the at-risk student group receiving the ARMS educational support. These results were not significantly different from students not in the ARMS program (Sutherland et al., 2007).

Morris and Hancock (2008) looked at a nursing program at a large, urban, public university in the southeastern part of the U.S. There were 53 students in the study from two cohorts. The study compared NCLEX-RN results before and after a curriculum change. The HESI nursing program exit examination was also studied in this research since the HESI exam is often used by nursing programs to help predict students' readiness to take the licensing exam. Morris and Hancock found no significant change in NCLEX-RN pass rates before or after the curriculum change and no significance between the new curriculum versus the old curriculum on HESI scores. The HESI, however, did show significance in predicting students who would pass the NCLEX-RN. The researchers used a HESI score of 900 or above to attempt to predict licensure exam success. Although those students with a score of 900 or above did pass the NCLEX-RN, 36 students scored below 900 and passed the NCLEX-RN as well. The researchers stated that in this study, significance for predicting students who pass the NCLEX-RN exists; 
however, at a score of 900 predicting NCLEX-RN failure was not as reliable (Morris \& Hancock, 2008).

Spurlock and Hunt (2008) also looked at the HESI exam as related to NCLEX-RN results. Using a retrospective descriptive, correlational design data were collected from 179 graduate records. The setting of this study was a nursing college in a large Midwestern town. The researchers did not use other academic or demographic data due to the retrospective nature of the study and because the progression policy at the college is based only on the HESI score. The researchers found no relationship between the HESI and NCLEX-RN results; however, this nursing program allowed students to retake the HESI to meet the minimum 850 score required. Even with the option of multiple attempts on the HESI, the results of the study did not change the risk of failing the NCLEX-RN (Spurlock \& Hunt, 2008).

Alameida, Davis, and Renwanz-Boyle (2011) in a recent study at San Francisco State University, looked at predicting NCLEX-RN success in the nursing program at this large diverse urban university. A sample of 589 students graduating between 2003 and 2009 were included. The dependent variable was success or failure on first-attempt NCLEX-RN. The independent variables included (a) nursing courses GPA, (b) cumulative GPA, (c) program type, (d) ATI RN comprehensive predictor test score, (e) ATI predictor probability of first time NCLEX-RN pass, (f) nursing course grades, (g) age (h) gender, and (i) race. Using $t$-tests, one-way ANOVAs, and Pearson's correlations, the researchers found a significant relationship between NCLEX-RN success on the first try and the ATI. The study found no significant relationship between first-time NCLEX-RN success and age, race, or gender, and no significance between the ATI RN comprehensive predictor test score and age, race, or gender. The only other 
significance found was between nursing course grades in medical surgical nursing and nursing pathophysiology (Alameida et al., 2011).

\section{Prenursing and Programs Progression}

In a study by Beeman and Waterhouse (2001), 21 variables containing both pre and postadmission items were evaluated using discriminant function analysis and Pearson correlation. This analysis was used to examine first-time NCLEX-RN pass fail rates in one nursing program. Of the 21 variables, (a) year of graduation, (b) gender, (c) age, (d) type of program, (e) SAT math, (f) SAT verbal, grades in biology (g) I \& (h) II, grades for (i) physiology, (j) pathophysiology, (k-r) eight didactic nursing courses, $(\mathrm{s})$ clinical grades, GPA at $(\mathrm{t})$ end of sophomore year, and $(\mathrm{u})$ the first semester or the senior year. Results were found to be significant only for the grades in the eight didactic nursing courses. Ninety-four percent of students were predicted correctly in passing the NCLEX-RN, and $92 \%$ of students were predicted correctly to fail the licensing exam (Beeman \& Waterhouse, 2001).

Beeson and Kissling (2001) conducted a study of 505 baccalaureate nursing students from a college in the southeastern U.S. to define variables to predict NCLEX-RN success or failure. The independent variables were (a) type of student, (b) age, (c) gender, prenursing grades in (d) anatomy, (e) physiology, (f) microbiology, (g) psychology, (h) sociology, (i) lifespan, and (j) family development, as well as all (k) nursing course grades, (l) scores on the Mosby standardized predictive test, and (m) cumulative GPA at graduation. Methods including nonparametric Mann-Whitney test, $t$-tests, chi-square, and logistic regression found that those students who passed the NCLEX-RN had higher biology grades and prenursing or prerequisite GPA. These students also had a higher overall GPA, and higher scores on the Mosby standardized predictive test (Beeson \& Kissling, 2001). 
Daley et al. (2003) also analyzed variables as potential predictors of NCLEX-RN success in BSN programs. The study included 224 undergraduate BSN seniors in two cohorts graduating in 1999 and 2000. The independent variables included in this study were (a) age, (b) gender, (c) ethnic background, (d) American College Testing (ACT) score, (e) prerequisite GPA, (f) prerequisite course grades, (g) grades from nursing program courses, (h) HESI test score, and (i) MAT test score. NCLEX-RN success or failure was the dichotomous dependent variable. Only two of these variables consistently showed significant association with NCLEX-RN success. Those were the senior level medical surgical nursing course and cumulative program GPA. When the HESI and MAT predictors were compared, the HESI exam was also found to be a better predictor of NCLEX-RN results than the MAT (Daley et al., 2003).

Crow et al. (2004) sent a 32-item questionnaire to BSN program directors across the United States. The goal of this descriptive correlation national study was to answer five questions regarding BSN nursing programs and the ability to promote and predict NCLEX-RN success. The first question in the study asked what baccalaureate programs used most often with regard to admission criteria. The study showed most BSN nursing programs used college cumulative GPA most often for admission criteria. The second question in the survey asked what data is used by BSN programs to predict NCLEX-RN success. The most common response was the use of a comprehensive exam. The third question inquired as to what specific interventions were used to assist NCLEX-RN success. The answer was academic referrals. The next question asked how admission and progression requirements predicted NCLEX-RN success in BSN programs. In the findings, most responses under admission criteria referred to standardized entrance exams. The graduation criteria cited most were clinical proficiency and standardized exit 
exams. Finally, this research team inquired as to what influence specific interventions had on NCLEX-RN performance. The findings determined that only the use of commercial review was significant in relationship to NCLEX-RN success. This study supports nursing program use of standardized entrance and exit exams to help assess NCLEX-RN readiness success (Crow et al., 2004).

Haas, Nugent, and Rule (2004) orchestrated a study of 368 students in one nursing program in southeastern United States. The retrospective study over a 10year span from 1991 to 2001 was composed mostly of White female students from 22 to 50 years of age. The independent variables included (a) gender, (b) race, (c) prenursing GPA, (d) nursing GPA, and the location of the campus where courses are taken either on the (e) main campus or at a (f) satellite campus. NCLEX-RN results were the dependent variable. Methods included discriminant function analysis, chi square, and $t$-tests to attempt to predict nursing student success on the NCLEX-RN. The researchers of this study deliberately set a Type I error rate (alpha) at 0.10 instead of 0.05 because they were willing to take a $10 \%$ Type I Error rate in the study results. In other words, studies often have students who pass but were expected to fail, and students who are expected to pass yet fail the exam. The Type I Error rate, in the researcher's opinion, could account for this phenomenon. The results of this study found that the men in this study failed the licensing exam at a higher rate than women. The study consisted of 39 men and 312 women. However, even though the groups were not evenly distributed, the failure rate for men was proportionately greater than for the women. Second, although the majority of the students were Caucasian, the pattern of class NCLEXRN success by race ranked in the following order: Hispanic, Caucasian, African American, and Asian. This was not deemed significant since there were only two Hispanic students in the study. Third, GPA in the nursing program was significant 
for NCLEX-RN success; however, the location of instruction was not significant. Students who studied on campus and at satellite sites had nearly the same pass rates. These researchers concluded that existing student data can predict first-try success on the NCLEX-RN (Haas et al., 2004).

A study by Seldomridge and DiBartolo (2004) included 184 BSN students over a 4-year period between 1998 and 2002. The sample was obtained from one rural BSN program in the mid-Atlantic region, and the researchers looked to uncover the best way to predict NCLEX-RN success. This study focused on three specific time frames in nursing education to attempt to predict results. The first time frame was the examination of student academic standings at preadmission to the program, the second time frame was after the completion of the first year of nursing school, and the third time frame was just prior to graduation from the program. The dependent variable was NCLEX-RN success. The independent variables, (a) traditional or transfer student, (b) PGPA, (c) prerequisite course grades, (d) GPA after one semester of nursing program, (e) grades in core nursing courses, (f) test scores in beginning and advanced medical surgical nursing courses, (g) scores on the NLN Comprehensive Achievement Test for Baccalaureate Students (NLN-CATBS), and (h) graduation GPA. This study concluded that specific items in each time frame predicted success on the NCLEXRN. According to these researchers, student grades in pathophysiology as a prerequisite course to admission to the nursing program correlated to successful NCLEX-RN results. While in the nursing program, the average grade of two medical surgical courses gave the strongest relationship to national exam results. The results of the NLN-CATBS exit exam given prior to graduation from the nursing program as an evaluation of NCLEX-RN readiness was significant in this study (Seldomridge \& DiBartolo, 2004). 
Newton et al. (2007) studied early academic achievement defined as overall first semester GPA, which consisted of student grades from four didactic nursing courses. This sample came from admission into the program each of the two semesters of the academic year. One-hundred eight mostly White female students were admitted in the Fall and 70 in the winter. The independent variables were scholastic aptitude (PGPA from seven prerequisite courses including biology, anatomy, physiology, chemistry, biochemistry, psychology, and composition I \& II) as well as nursing aptitude measured by the ATI TEAS test. Exploratory descriptive analysis found that both scholastic and nursing aptitude were significant predictors of early academic achievement. The study also found that the ATI TEAS test, which was used to measure nursing aptitude, predicted slightly higher than the scholastic aptitude variables. These researchers contended that the strongest prediction of NCLEX-RN success lay in scholastic and nursing aptitude together (Newton et al., 2007).

Uyehara, Magnussen, Itano, and Zhang (2007) studied 224 graduates from University of Hawaii at Manoa generic BSN program for a 5-year period after implementation of a new nursing curriculum. The purpose was to identify factors of program success versus withdrawal and NCLEX-RN passing data. The dependent variables were program completion and NCLEX-RN results. Success was defined as completion of the nursing program and passing the NCLEX-RN. Nonsuccess was defined as failing out due to poor grades, withdrawal from the nursing program for any reason, or failure on the NCLEX-RN. The study consisted of descriptive statistics, correlations, and regression analysis in three time settings: preadmission, in program, and end of program. Preadmission independent variables included (a) GPA from all prerequisite courses, (b) cumulative college GPA, NLN prenursing readiness test, (c) composite scores as 
well as (d) verbal and (e) math subscores, (f) ethnicity, and (g) age. In-program independent variables included (a) grades in seven nursing courses, (b) achievement test scores on four NLN program standardized tests, and (c) a critical thinking appraisal. End-of-program independent variables were the Mosby Assessment test score, GPA in nursing courses, and GPA at graduation. Results of this study showed significant correlations between NCLEX-RN success and (a) the Mosby Assessment test score, (b) three of the four NLN program standardized tests, (c) GPA in nursing courses, and (d) fundamentals nursing course grade. However, after the completion of logistic regression analysis, only the NLN program standardized tests in adult health showed the most significance for success on the NCLEX-RN. Age and ethnicity were not significant in this study.

Ukpabi (2008) studied 39 graduates from North Carolina Central University generic BSN program. The purpose of the study was to find specific variables that would predict NCLEX-RN success for future students in the program. NCLEX-RN pass/fail results comprised the dichotomous dependent variable. The independent variables included (a) 13 ATI test score categories, including the TEAS, (b) five NLN test categories, and (c) GPA in the nursing curriculum. Using discriminate analysis, the researcher found that six of the eight prenursing categories were significant $(p<.05)$. Of the NLN testing variables, three of the five were significant, and three of the six ATI tests used during the program were also significant. In this study, student GPA was not found to be predictive of NCLEX-RN success. The researcher found standardized testing to be a good predictor in the nursing program studied (Ukpabi, 2008).

Korvick, Wisener, Loftis, and Williamson (2008), in a retrospective, quasiexperimental study, evaluated the success of first semester nursing students in one nursing program. The students, although all beginning nursing students, were 
admitted either as traditional students in search of a primary degree or on track for an accelerated BSN degree; meaning, these students are admitted to the BSN program already holding a baccalaureate degree in another field of study. The setting for this study was a nursing program at a mid-sized, private, urban university in the heart of America. The sample included 29 second baccalaureate candidates and 32 traditional BSN students. The study purpose was to determine if either sample performed better in the nursing program than the other. Program success was measured on a faculty made point system. The independent variables included age and PGPA for science courses only. The researchers found that age had no significance on first semester success; however, when looking at PGPA of those already holding a baccalaureate degree in another subject, it correlated to first semester success. The study also determined that when traditional BSN students with a grade of B or better in prerequisite courses were isolated from the other traditional BSN students in the group with lower prerequisite grades, the B grades correlated with first semester success.

Yucha, Kowalski, and Cross (2009) did a quasi-experimental study with two groups of nursing students from one nursing program. The differences in the groups were based solely on the placement of their clinical practice courses. Seventy-eight students were placed at the traditional hospital that educated students from this Las Vegas nursing program for years. Seventy-nine students were placed in new alternate hospital sites for the study. This alternate hospital site placement was done to determine if clinical placement would make a difference in students' outcomes due to the added stress of clinical placement at sites outside the traditional program hospital. NCLEX-RN success rate on the first try was the dependent variable. Independent variables included (a) GPA in nursing courses, (b) Nurse Entrance Test (NET), and (c) data from the Registered Nurse 
Computerized Adaptive Test (RN-CAT). The RN-CAT is a mock NCLEX-RN assessment test typically given in the last weeks of a nursing program to determine NCLEX-RN readiness. The results of the study concluded that GPA was significant in predicting the results of the NET and RN-CAT tests. The NET and RN-CAT tests were not found to be associated to each other in this study. Finally, as far as passing the NCLEX on the first try, these researchers found that the higher the NET score, RN-CAT scores, and GPA in nursing courses, the more students were prone to passing the NCLEX-RN on the first try.

Newton and Moore (2009) studied a nursing program in a large Midwestern state supported BSN program. The purpose of the study was to look at BSN readiness for the NCLEX-RN and attrition late in the nursing program. The dependent variables leave the program or take the NCLEX-RN. The independent variables in the study fell under the categories of scholastic and nursing aptitude similar to Newton et al. (2007). Scholastic aptitude included prenursing GPA from seven prerequisites including (a) biology, (b) anatomy, (c) physiology, (d) chemistry, (e) bio-chemistry, (f) composition I, and (g) composition II. Nursing aptitude variables included (a) TEAS composite score as well as subscores of (b) math, (c) science, (d) reading, and (e) English. Logistic regression was used to examine effects of scholastic aptitude variables and nursing aptitude variables first on attrition, and neither was found to be predictive. Stepwise regression analysis was used to assess effects of scholastic and nursing aptitude on NCLEX-RN readiness. This part of the study indicated scholastic aptitude was predictive but nursing aptitude was not predictive. Of all the variables, these researchers found first semester nursing GPA to be the most predictive of NCLEX readiness. 


\section{Gaps in Research}

In the preceding literature review, many studies were dedicated to the attempt to find program and NCLEX-RN success predictors either before admission to a nursing program, after admission, during the progression stages throughout the program, or both before and after admission individually, or in comparison. Standardized testing has been studied as a possible predictor before and on admission to a program as a gauge of readiness for the content and rigor of nursing education and professional practice. Standardized testing has also been a popular assessment at the conclusion of the nursing education process as a predictor of readiness to sit for the licensing exam. Other variables have been visible in research at pre and postadmission as well such as course grades, GPA, and nonacademic criteria. However, missing in the research is standardized testing throughout nursing education. Progressive standardized topic-related tests like those offered to nursing programs by ATI, are available to evaluate not only nursing content knowledge throughout the education process but also computerized testing (not adaptive) with NCLEX-RN style questions. These tests give simulated NCLEX-RN practice with benchmark and potential percent of NCLEX-RN success for each student as immediate feedback at the end of the test (see Figure 5, p. 29).

Many nursing programs in the California State University system use the ATI system. The ATI "box," as it is referred to, may only be purchased through a nursing program by students in that program. The box contains a set of books, online access for 3 years with secured codes, and proctored tests for each of the following subject areas: TEAS, Adult Medical-Surgical, Fundamentals, Pharmacology, Nutrition, Maternal Newborn, Leadership, Mental Health, Pediatrics, and the RN comprehensive exam. Although the pre or admission TEAS 
test and the end of program RN comprehensive exam are becoming visible in nursing research, there is no sign of the full use of the "boxed" program, as it was designed to assist students, faculty, and nursing programs to meet the demand for safe, competent, practice-ready, registered nurses who graduate from accredited institutions. Research in the complete use of the ATI testing program is the focus of this dissertation. Information in this area would address this gap in the research and provide insight to the strength, or lack of strength, that comes with progressive standardized testing before, throughout, and at the end of nursing education.

\section{Summary}

The theoretical framework, Dreyfus and Dreyfus's (1980) model, and Benner's (2001) nursing theory, were applied to this study. This framework assumes that the principals of nursing theory, taught in the educational setting, will prepare graduates to be safe, competent nurses, armed with the knowledge needed to master skills while using upper level thinking. In nursing practice this would include the use of critical thinking and clinical reasoning to ask the right questions and problem solve effectively (Benner, 2001). Nursing education is responsible for providing the groundwork of this model in the nursing school experience. Implementation of this model is completed by giving students the knowledge and theoretical framework needed to pass the NCLEX-RN and practice under the nursing scope of practice in the current workforce. Using Benner's nursing theory in the education realm keeps the focus on building upon past education and experience to advance to the next level of academic and clinical training.

Chapter 3 discusses the methodology of the dissertation research and the procedures used to conduct this study. 


\section{CHAPTER 3: METHODOLOGY}

\section{Introduction}

The importance of this licensing exam raises questions about the content of nursing curriculum, how students are educated, if there are effective measures that can be used to correlate student results, and what early interventions will improve the test outcomes. Chapter 3 includes (a) study purpose, (b) research design, (c) research questions, (d) operational definitions, (e) study sample, (f) data collection, (g) human subjects review, (h) instrumentation, (i) pilot study, (j) procedures, (k) data analysis, and (1) limitations and delimitations.

\section{Purpose of the Study}

The purpose of this study is to explore whether academic aptitude and nursing aptitude are correlated with first-attempt pass rates on the NCLEX-RN in baccalaureate nursing programs. This research has the potential to (a) investigate admission criteria of baccalaureate nursing programs, (b) assist in the identification of students that will struggle in nursing education and would benefit from early intervention and/or remediation, and (c) better prepare senior nursing students as successful graduates who will pass the NCLEX-RN on the first try.

\section{Research Design}

The research in this study will be nonexperimental, retrospective, quantitative, and correlational. It will examine independent variables prior to admission to a nursing program as well as independent variables within the education of a professional nurse. The study will look for correlations among these variables separately, together, and how they relate to student outcomes on the NCLEX-RN licensing exam. What distinguishes the study as nonexperimental is 
that the data will not be manipulated in any way, nor will there be randomization. Both randomization and manipulation would need to be present in an experimental study, and manipulation would be present only in a quasi-experimental design (Pedhazur \& Schmelkin, 1991). This study will be retrospective, also known as ex post facto, because the data are archival or in the past (Polit \& Hungler, 1995). This research will be correlational due to the variation in the criterion variable, and the NCLEX-RN outcome which will be examined for its relationship to the variables (Kerlinger \& Lee, 2000). The criterion variable (NCLEX-RN) results are reported as pass or fail, rendering them dichotomous.

\section{Research Questions}

This study is guided by the following research questions.

1. How do academic aptitude and nursing aptitude correlate?

2. How does nursing aptitude correlate with first-try NCLEX-RN pass rates, controlling for academic aptitude of BSN students?

3. How do academic aptitude and nursing aptitude predict first-try NCLEX-RN pass rates for BSN students in the CSU system?

\section{Operational Definitions}

The following definitions are explained to provide understanding and clarification of specific terms that will be included in this paper.

Bachelor of Science in Nursing (BSN) or Baccalaureate degree - awarded after typically a 4-year period of study at a university or private college. The degree requires a more expansive range of study besides that required for nursing practice and prepares students for leadership and management roles along with readiness for advanced practice education (BRN, 2010). 
Benchmark - "A statement of expected achievement, frequently inspirational in nature, posed generally by a group or organization; a means by which a program can compare themselves with a larger group" (NLN, 2006, p. 76).

Board of Registered Nursing (BRN) - state legislative body responsible for regulating nursing practice with a mission to protect the public as defined by the nurse practice act, to uphold standards of safe, competent nursing practice, and manage issues of its licensees (BRN, 2010).

National Council Licensure Exam for Registered Nurses (NCLEX-RN) national licensing exam available to nursing students who have graduated from an accredited school of nursing. Graduates must pass this licensing exam in order to practice in the profession of nursing. Reliability reported at Cronbach's alpha .91 in a national study of 31,036 nurses (NCSBN, 2010).

National Council of State Boards of Nursing - an independent nonprofit organizational board represented by members from each state that are responsible for development and monitoring of the NCLEX-RN (NCSBN, 2010).

NCLEX-RN pass rates - percentage of nursing student candidates passing the licensing exam (Woo, 2011). In this study only students who have taken the NCLEX-RN for the first time will be included. The rationale for this decision is, although students have up to six months after graduation to take the NCLEX-RN, should they fail the exam, they must wait 45 days between subsequent attempts.

\section{Predictors}

Academic aptitude - preadmission data, including no nursing content (a) preprogram GPA, (b) TEAS composite, (c) TEAS reading, (d) TEAS English, (e) TEAS math, (f) TEAS science, (g) chemistry, (h) anatomy, (i) physiology, (j) 
microbiology, (k) oral communication, (l) English composition, (m) critical thinking, (n) math, and (o) prerequisite GPA.

ATI Test of Essential Academic Skills (TEAS) - a preadmission assessment test to measure entry-level skills in math, verbal and written reading, as well as science (ATI, 2010). Reliability reported at Cronbach's alpha 0.90 for a national sample of program using ATI (ATI, 2009).

\section{Criterion}

ATI RN Comprehensive Assessment - a 180-question test, typically given to nursing students in the final semester of nursing school, as an assessment of safety and competence for entrance into the nursing profession. Upon completion of this exam, students receive feedback regarding the probability of passing the NCLEXRN (ATI, 2007). Reliability reported at Cronbach's alpha 0.79 in a national study (ATI, 2009).

ATI RN Content Mastery Series Online Practice Assessments - contentbased proctored tests to assess nursing content knowledge during progression through a nursing program (ATI, 2007).

Nursing aptitude - in nursing school progression, all nursing content (a) ATI fundamental score, (b) ATI fundamental level, (c) ATI pharmacology score, (d) ATI pharmacology level, (e) ATI medical/surgical score, (f) ATI medical/surgical level, (g) ATI psychology score, (h) ATI psychology level, (i) ATI OB score, (j) ATI OB level, (k) ATI pediatrics score, (l) ATI pediatrics level, and (m) RN comp II score.

\section{Study Sample}

The study will include California State University baccalaureate nursing programs that are willing to participate and have the data available for the time 
frame presented. There are 23 CSUs in the system. Three of these universities do not have nursing programs. One school has an RN to BSN program only, another school offers only the prerequisites to a nursing education, a third has a new program, with the first class graduating in 2011, and a fourth has cancelled the nursing program altogether. These seven will not be included in the study.

An informative invitation email was sent to the remaining 16 CSUs. All student data from the university nursing programs, who agree to participate, and have available data within the time frame, will be included in the study. The study will look at specific variables over two academic years, including 2009-2010 and 2010-2011. Of the 16 CSU schools invited, four nursing programs had the needed data in the study time frame and were willing to participate (see Table 4). In order to determine the population size and the need for a power analysis, an estimate has been made as follows. Of the four participating programs, program number 1 has 245 participants, program number 2 has 255 participants, program number 3 has 146 participants, and program number 4 has 203 participants. This provides a sample population of 864 participates in the study, an adequate sample confirmed by prior power analysis.

The research sample was estimated from graduation statistics of the four CSU baccalaureate nursing programs in the study: CSU Fresno, CSU Sacramento, CSU Bakersfield, and CSU Fullerton. This estimated sample was 794 nursing graduates posted as statistical data on the CSU website; however, when the data were collected for the academic years of 2009-10 and 2010-11 for students who completed the NCLEX-RN exam once, not all data were complete from each school. The decision was made to keep all four schools in the study and eliminate variables with incomplete data from all four schools. This left only 11 of the 23 initial variables in the study intact and the number of participants dropped to 532 . 
Table 4

California State University Nursing Programs

\begin{tabular}{|c|c|c|}
\hline CSU & Study status & Response \\
\hline Bakersfield & Invitation extended & Accepted $\mathrm{N}=146$ \\
\hline Channel Islands & New program - 1st grad 2011 & N/A \\
\hline Chico & Invitation extended & No response \\
\hline Dominguez Hills & RN-BSN program only & N/A not 4-year BSN \\
\hline East Bay & Invitation extended & No response \\
\hline Fresno & Invitation extended & Accepted N=245 \\
\hline Fullerton & Invitation extended & Accepted N=203 \\
\hline Humboldt & Program discontinued & N/A \\
\hline Long Beach & Invitation extended & No response \\
\hline Los Angeles & Invitation extended & No response \\
\hline Maritime Academy & No program & N/A \\
\hline Monterey Bay & $\begin{array}{c}\text { No program - prerequisites } \\
\text { only }\end{array}$ & N/A \\
\hline Northridge & Invitation extended & No response \\
\hline Pomona & No program & N/A \\
\hline Sacramento & Invitation extended & Accepted $\mathrm{N}=255$ \\
\hline San Bernardino & Invitation extended & No response \\
\hline San Diego & Invitation extended & No response \\
\hline San Francisco & Invitation extended & No response \\
\hline San Jose & Invitation extended & Denied \\
\hline San Luis Obispo & No program & N/A \\
\hline San Marcos & Invitation extended & No response \\
\hline Sonoma & Invitation extended & No response \\
\hline Stanislaus & Invitation extended & Denied \\
\hline
\end{tabular}


It was the decision of this researcher to include more schools and fewer variables in order to make the study more generalizable. A quantitative, retrospective, correlational design was used to analyze the relationship of the independent prenursing program predictor variables of prenursing GPA, communication 3, reading TEAS, math TEAS, science TEAS, English TEAS, and independent in-program criterion variable of ATI fundamentals, ATI medical surgical, ATI pediatrics, ATI psychology, and ATI maternal child. The dependent dichotomous NCLEX-RN pass/fail variable was also used.

\section{Data Collection}

The variables for this study were determined using the Dreyfus/Benner (1984) theoretical framework adapted for this research study in the theoretical framework section of chapter 2 (see Figure 5, p. 29). Since students are admitted into nursing programs as novices of nursing education, each course or set of courses builds upon prior courses on a stair-step path from novice nursing student to expert nursing student prepared to graduate and take the NCLEX-RN. Dreyfus and Dreyfus (1980) would recognize this progression through the nursing program in three major steps: (a) Encompasses the theory model reliance on the abstract, bookwork, or "know it" phase; (b) The use of concrete experience, which adds the "do it" phase; and (c) Less fragmented learning that takes on a holistic approach of the "detached observer to involved performer" (Benner, 2001) (see Figure 4 in the theoretical framework section of chapter 2, p. 28). These three steps as related to nursing education are preadmission, in-program progression, and NCLEX-RN results. The variables for this study fit under these theoretical framework headings. First, preadmission (a) preprogram GPA, (b) TEAS composite, (c) TEAS reading, (d) TEAS English, (e) TEAS math, (f) TEAS science, (g) chemistry, (h) anatomy, (i) physiology, (j) microbiology, (k) oral communication, (l) English composition, 
(m) critical thinking, (n) math, and (o) prerequisite GPA. Second, in-program progression (a) ATI fundamental score, (b) ATI fundamental level, (c) ATI pharmacology score, (d) ATI pharmacology level, (e) ATI medical/surgical score, (f) ATI medical/surgical level, (g) ATI psychology score, (h) ATI psychology level, (i) ATI OB score, (j) ATI OB level, (k) ATI pediatrics score, (l) ATI pediatrics level, and (m) RN comp A and B scores. Third, NCLEX-RN results (a) pass, (b) fail. Each CSU nursing program in the study will complete a data collection sheet for the students from that institution. The data tool included the input of all variables into the Microsoft Excel formatted data collection tool that was imported into SPSS.

\section{Human Subjects Review}

Institutional Review Board (IRB) permission was obtained from all participating universities and nursing programs as well as the university of this doctoral dissertation. All of the participating nursing programs were asked to complete a data collection tool containing only the information requested, free of any personal information, to maintain anonymity. The study was deemed exempt at the four campuses in the study due to the use of only archival data and no psychological risk. Information received by this researcher, for general research security, was secured on password protected computers and flash drives and locked in a key-entry office. Any identification information will be deleted at the end of the study. Individual school findings will be reported to each participating program through the faculty or staff involved with this researcher during the study. Complete findings of all participating school data will be reported in aggregate fashion to each participating CSU nursing department. 


\section{Instrumentation}

To collect and record student data for this study, a separate Microsoft Excel document was created for each school in the study initially and then merged. All 28 preadmission and in-program variables are categorical or continuous. There will be 13 preadmission academic aptitude variables, 18 in-program nursing aptitude variables, and one dichotomous criterion variable. Many variables in this study have been previously identified in nursing literature as having some significance to NCLEX-RN success in baccalaureate nursing graduates (see Appendix A). Additional variables have been added to address gaps in the literature and research.

\section{Pilot Study}

\section{Demographics}

A pilot study was completed using the assessment tool and all variable data from one volunteer CSU nursing program, California State University, Fresno. The pilot study had 245 participants and data available for the 28 variables in the time frame of academic years of 2009-10 and 2010-11 (see Table 5). The participant population was made up of $83 \%$ females and $17 \%$ males. Majority ethnic groups represented were White $42 \%$, Mexican 11\%, and Filipino $10 \%$. Ten percent of the population did not respond to the ethnicity question. The remaining $27 \%$ fell between $0.4 \%$ and $4.1 \%$ of the remaining CSU system ethnic classification choices: American Indian/Alaskan Native, African American, Other Caribbean, Other Asian, Other Pacific Islander, Other, Chinese, Decline to State, Japanese, Korean, Laotian, Puerto Rican, Asian Indian, Other Southeast Asian, Thai, and Vietnamese. 
Table 5

Pilot Population Demographic Information

\begin{tabular}{|c|c|c|}
\hline Category & $\mathrm{N}$ & $\%$ \\
\hline \multicolumn{3}{|l|}{ Gender } \\
\hline Male & 42 & 17.1 \\
\hline Female & 203 & 82.9 \\
\hline \multicolumn{3}{|l|}{ Ethnic group } \\
\hline Amer Indian/Alaskan & 1 & .4 \\
\hline African American & 7 & 2.9 \\
\hline Mexican & 28 & 11.4 \\
\hline Other Caribbean & 5 & 2.0 \\
\hline Other Asian & 4 & 1.6 \\
\hline White & 103 & 42.0 \\
\hline No response & 24 & 9.8 \\
\hline Chinese & 2 & .8 \\
\hline Decline to State & 9 & 3.7 \\
\hline Filipino & 25 & 10.2 \\
\hline Japanese & 3 & 1.2 \\
\hline Korean & 1 & .4 \\
\hline Laotian & 3 & 1.2 \\
\hline Puerto Rican & 2 & .8 \\
\hline Asian Indian & 10 & 4.1 \\
\hline Other SE Asian & 7 & 2.9 \\
\hline Thai & 1 & .4 \\
\hline Vietnamese & 10 & 4.1 \\
\hline \multicolumn{3}{|l|}{ Family income } \\
\hline Less than $\$ 24,000 / \mathrm{yr}$ & 33 & 13.5 \\
\hline$\$ 24,000$ to $\$ 35,999$ & 13 & 5.3 \\
\hline$\$ 36,000$ to $\$ 47,999$ & 16 & 6.5 \\
\hline$\$ 48,000$ to $\$ 59,999$ & 8 & 3.3 \\
\hline$\$ 60,000$ to $\$ 71,999$ & 11 & 4.5 \\
\hline$\$ 72,000$ or more & 41 & 16.7 \\
\hline Cannot estimate & 9 & 3.7 \\
\hline No response & 114 & 46.5 \\
\hline \multicolumn{3}{|l|}{ Mother's education } \\
\hline No high school & 39 & 15.9 \\
\hline Some high school & 12 & 4.9 \\
\hline High school graduate & 47 & 19.2 \\
\hline Some college & 38 & 15.5 \\
\hline 2-year college grad & 22 & 9.0 \\
\hline 4-year college grad & 47 & 19.2 \\
\hline Postgraduate & 16 & 6.5 \\
\hline No response & 24 & 9.8 \\
\hline \multicolumn{3}{|l|}{ Father's education } \\
\hline No high school & 36 & 14.7 \\
\hline Some high school & 12 & 4.9 \\
\hline High school graduate & 45 & 18.4 \\
\hline Some college & 43 & 17.6 \\
\hline 2-year college grad & 9 & 3.7 \\
\hline 4-year college grad & 46 & 18.8 \\
\hline Postgraduate & 26 & 10.6 \\
\hline No response & 28 & 11.4 \\
\hline
\end{tabular}


In the area of family income, $47 \%$ of the population did not respond. Seventeen percent reported a family income $\$ 72,000$ or greater, followed by $14 \%$ who reported less than $\$ 24,000$. The remaining family income categories each had less than $7 \%$ representation. These categories are $\$ 24,000$ to $\$ 35,999, \$ 36,000$ to $\$ 47,999, \$ 48,000$ to $\$ 59,999, \$ 60,000$ to $\$ 71,999$, and cannot estimate.

For information regarding the students' mother's education, 19\% reported their mother's education as high school graduate, 19\% 4-year college graduates, $16 \%$ had no high school education, and $15 \%$ had some college. Ten percent did not respond in this area, 9\% were 2-year college graduates, post-graduate education made up 7\%, and the remaining 5\% had some high school.

In the category of father's education, 19\% said their father was a 4-year college graduate, $18 \%$ high school graduate, and 18\% some college. Fourteen percent had no high school, $11 \%$ did not respond, $10 \%$ had postgraduate degrees, $5 \%$ had some high school, and 5\% were 2-year college graduates.

\section{Statistical Analysis}

Correlation coefficients were run between all the academic aptitude independent variables of (a) pre-program GPA, (b) TEAS composite, (c) TEAS reading, (d) TEAS English, (e) TEAS math, (f) TEAS science, (g) chemistry, (h) anatomy, (i) physiology, (j) microbiology, (k) oral communication, (1) English composition, (m) critical thinking, (n) math, and (o) prerequisite GPA with all of the nursing independent variables of (a) ATI fundamental score, (b) ATI fundamental level, (c) ATI pharmacology I score, (d) ATI pharmacology I level, (e) ATI pharmacology II score, (f) ATI pharmacology II level, (g) ATI medical/surgical score, (h) ATI medical/surgical level, (i) ATI psychology score, (j) ATI psychology level, (k) ATI OB score, (l) ATI OB level, (m) ATI pediatrics score, (n) ATI pediatrics level, (o) RN comp A score, (p) RN comp A probability 
score, (q) RN comp B score, (r) RN comp B probability score, and (s) the dichotomous dependent variable NCLEX-RN.

Correlating these 34 variables resulted in 561 correlation coefficients. These correlations ranged from -.374 to -.798 . They are not reported here due to the volume of these statistics; however, all correlations and their probabilities appear in Appendix B. It was determined that some of the nursing variables would not provide useful information in this study for several reasons. These variables included the ATI test proficiency levels, 1-3, for each of the individual ATI subject. The ATI test scores are reported levels as percentages from $0 \%$ to $100 \%$, while ATI levels represent the blocking of ATI test scores into four levels. Although the level simplifies goal setting and proficiency for nursing faculty and students, the actual student score is a higher statistical measure than the ATI proficiency levels of 1-3. Only ATI test scores were retained in this data set as the ATI level consisted of duplicated information with less variability. The same is true for the probability of passing the NCLEX-RN percentages based on the RN comprehensive exam A and the RN comprehensive exam B individual student scores. Therefore, the level data would be a duplication of the individual test scores, and the probability percentage is a duplication of the individual exam score. The decision was made to use only one set of variables to eliminate duplication and avoid multicolinearity.

The nursing aptitude independent variables included in the study are (a) ATI fundamental score, (b) ATI pharmacology I score, (c) ATI pharmacology II score, (d) ATI medical/surgical score, (e) ATI psychology score, (f) ATI OB score, (g) ATI pediatrics score, (h) RN comp A scores, and (i) RN comp B scores. It was also determined that there were multiple variables measuring the same constructs more than once. For example, the prerequisite GPA is an average of the 
eight prerequisite course grades. Since both the grades for each prerequisite course and the prerequisite GPA were available and the actual grades are more specific, the prerequisite GPA variable was removed. In addition, correlations would be inflated if both were used since that information would be included in the statistical analysis twice. The same was found to be true regarding the comprehensive TEAS score and the four subtest scores of math, reading, science, and English. The four subtest scores are averaged and reported as the comprehensive score, therefore multiples provide redundant information. The comprehensive TEAS were removed from the study. The final pilot study included 13 academic variables, 9 nursing variables, and the dichotomous NCLEX-RN pass/fail dependent variable.

\section{Canonical Correlation}

Question 1 - How do academic aptitude and nursing aptitude correlate? Canonical Correlation (CC) analysis was conducted for the nine nursing aptitude criterion variables and the 13 academic aptitude variables as predictors. CC evaluates the multivariate shared relationship between the two variable sets. The $\mathrm{CC}$ analysis yields a number of functions based upon the number of predictors or the number or criterion variables, whichever is smaller, in addition to the test of the overall model. Collectively, the model across all functions was statistically significant using the Wilk's Lambda criterion (Wilk's Lambda $=.208, F(117$, $1298.00)=2.60, p<.001)$. Because Wilk's Lambda represents the variance unexplained by the model, 1-Lambda yields the full model effect size in an $r^{2}$ metric. Thus, for this set of canonical functions, the $r^{2}$ type effect size was 1-.208 $=.792$, which indicates that the full model explained a substantial portion $(\sim 79 \%)$ of the variance shared between the sets of predictor and criterion variables. Although this $\mathrm{CC}$ yielded nine functions, a decision must be made regarding 
interpretation. This subjective decision is based on the significance of each of the nine functions and the magnitude of the structure coefficients.

The dimension reduction analysis allowed the researcher to test the hierarchal arrangement of functions for statistical significance. The models for the first three functions were statistically significant, as were the model functions for one to nine: $(F(117,1298.99)=2.60, p<001)$. The model for functions two to nine were significant $(F(96,1175.66)=1.74, p<.001)$, as was the model for functions three to nine $(F(77,1050.12)=1.46, p=.01)$. The next six functions were not statistically significant.

$\operatorname{CCs}\left(\left(R_{c}\right)\right.$ of $.701, .504, .404, .384, .347, .255, .214, .139$, and .059) were revealed for each successive function. The $\left(R_{c}^{2}\right)$ for the nine functions were .49 , $.25, .16, .15, .12, .06, .05, .02$, and .003 . The first two functions were considered noteworthy in the context of this study, $49 \%$ in function $1,35 \%$ in function 2 , and the remaining variance in the variable sets after the extraction of the prior functions leveled off and did not explain as much of the variance.

Table 6 presents the standardized canonical functions coefficient and structure coefficients for all variables across functions 1 and 2 . The squared structure coefficients $\left(r_{s}^{2}\right)$ are also given, which is the index of the percentage of shared variance between a predictor or criterion variable and the remaining predictor or criterion variables in the variable set or how much variance they share. The far right column lists the communality coefficients $\left(h^{2}\right)$, which represent the amount of variance in the academic and nursing aptitude that was explained across the functions. Structure coefficients above .40 are underlined, as are communalities above $40 \%$ to reveal the variables with the highest usefulness in the function. 
Table 6

Canonical Solution for Nursing Aptitude Predicting Academic Aptitude for Functions 1 and 2

\begin{tabular}{|c|c|c|c|c|c|c|c|}
\hline \multirow[b]{2}{*}{ Variable } & \multicolumn{3}{|c|}{ Function1 } & \multicolumn{4}{|c|}{ Function2 } \\
\hline & Coef & $\mathrm{r}_{\mathrm{s}}$ & $r_{s}^{2}(\%)$ & Coef & $\mathrm{r}_{\mathrm{s}}$ & $\mathrm{r}_{\mathrm{s}}^{2}(\%)$ & $h_{s}(\%)$ \\
\hline GPAb4Nsg & -.139 & -.379 & .144 & -.343 & -.296 & .088 & .232 \\
\hline Chem3A & .005 & -.003 & .000 & -.032 & .022 & .000 & .000 \\
\hline Anatomy & -.143 & -.361 & .130 & -.009 & -.045 & .002 & .132 \\
\hline Physiology & -.141 & -.200 & .040 & .123 & .027 & .000 & .040 \\
\hline Micro & -.090 & -.241 & .058 & -.384 &.- .406 & .165 & .223 \\
\hline Comm3 & -.078 & -.125 & .016 & -.339 & -.389 & .151 & .167 \\
\hline Eng $1 \mathrm{~A}$ & -.022 & -.124 & .015 & .008 & -.036 & .001 & .016 \\
\hline Math 11 & -.011 & .035 & .001 & -.477 & -.422 & .178 & .179 \\
\hline CritThink & -.032 & -.106 & .011 & .199 & .245 & .060 & .071 \\
\hline Read TEAS & -.245 & -.721 & .520 & -.639 & -.283 & .080 & .600 \\
\hline Math TEAS & -.194 & -.694 & .482 & .395 & .236 & .056 & .538 \\
\hline Scien TEAS & -.456 & -.817 & .667 & .214 & .181 & .033 & .700 \\
\hline Eng TEAS & -.221 & -.665 & .442 & .326 & .132 & .017 & .459 \\
\hline $\mathrm{R}_{\mathrm{c}}{ }^{2}$ & & 49.1 & & & 25.4 & & \\
\hline Comp A & .356 & -.869 & .755 & .155 & -.236 & .056 & .811 \\
\hline Comp B & -.213 & -.808 & .653 & .122 & -.189 & .036 & .689 \\
\hline ATI Fund & -.266 & -.783 & .613 & .223 & .007 & .000 & .613 \\
\hline ATI Pharm I & -.058 & -.654 & .428 & -.151 & -.231 & .053 & .481 \\
\hline ATI Pharm II & -.163 & $\underline{-.692}$ & .479 & .071 & -.246 & .061 & .540 \\
\hline ATI MedSurg & -.113 & $\underline{-.712}$ & .507 & -.150 & -.270 & .073 & .580 \\
\hline ATI Peds & -.314 & -.458 & .210 & -.557 & $\underline{-.552}$ & .305 & .515 \\
\hline ATI Psych & .313 & $\underline{-.732}$ & .536 & .576 & .148 & .022 & .558 \\
\hline ATI MatChi & -.023 &.- .483 & .233 & -.791 & $\underline{-.756}$ & .572 & .805 \\
\hline
\end{tabular}


In function 1 coefficients, the salient predictor variable with the highest structure coefficients were reading TEAS $\left(r_{\mathrm{s}}=-.721\right)$, math TEAS $\left(\mathrm{r}_{\mathrm{s}}=-.694\right)$, science TEAS $\left(r_{\mathrm{s}}=-.817\right)$, and English TEAS $\left(\mathrm{r}_{\mathrm{s}}=-.665\right)$. On the criterion side of function 1, all nine criterion variables had high structure coefficients: RN comp A $\left(r_{s}=-.869\right), R N$ comp B $\left(r_{s}=-.808\right)$, ATI fundamentals $\left(r_{s}=-.783\right)$, and ATI pharmacology I $\left(r_{s}=-.654\right)$, ATI pharmacology II $\left(r_{s}=-.692\right)$, ATI medical/surgical $\left(r_{s}=-.712\right)$, ATI pediatrics $\left(r_{s}=-.458\right)$, ATI psychology $\left(r_{s}=\right.$ -.732), and ATI maternal child $\left(r_{s}=-.483\right)$. In function 2 coefficients, the salient predictor variable with the highest structure coefficients were microbiology $\left(\mathrm{r}_{\mathrm{s}}=\right.$ -.406), math $11\left(r_{s}=-.422\right)$, microbiology $\left(r_{s}=-.406\right)$, ATI pediatrics $\left(r_{s}=-.522\right)$, and ATI maternal child $\left(\mathrm{r}_{\mathrm{s}}=-.756\right)$. In function 3 , the structure coefficient for only one variable reached the .40 cut-off level so that function and the others were deemed uninterruptable.

These results reveal that in function 1 it is known that if students score high on predictor variables, they will also score high on criterion variables because the sign for all structure coefficients is the same. All TEAS subscores are good predictors of ATI tests scores or nursing criterion. Function 2 reveals that if students score high on microbiology and math 11, they will do well in pediatrics and maternal child. These are relevant based on the importance of well child visits and prenatal visits for preventative care. Since both of these are considered states of wellness and not illness, when illness does arise microbiology becomes significant. Also, since medication calculations are based on weight and body surface area for infants and children, the significance of math can also be understood. Considering this statistical information, the decision was made to interpret only function 2 . 


\section{Regression Analysis Results}

One can think of regression analysis as a type of post hoc test for canonical correlation. Table 7 shows a separate regression analysis for each of the nine criterion variables with the 13 predictor variables. This table presents $t$ values and their significance levels for each predictor variable in the model for each dependent variable. Prenursing GPA, anatomy, reading TEAS, and science TEAS were significant predictors of the RN comprehensive A. Prenursing GPA, microbiology, reading TEAS, and science TEAS were significant predictors of the RN comprehensive B. Anatomy, reading TEAS, and science TEAS were significant predictors of the ATI fundamentals test. Physiology, microbiology, and science TEAS were significant predictors of the ATI pharmacology I test. Microbiology and science TEAS were significant predictors of the ATI pharmacology II test. Microbiology, reading TEAS, and the science TEAS were significant predictors of the ATI medical surgical test. Anatomy, microbiology, and reading TEAS were significant predictors of the ATI pediatrics test. Physiology, math TEAS, and science TEAS were significant for the ATI psychology test. Prenursing GPA, communication 3, math 11, and the reading TEAS were significant for the ATI maternal child test.

Of the predictor variables, the science TEAS was significant in seven regression modules. The reading TEAS was significant in six regression modules. Microbiology was significant in five regression modules. Prenursing GPA and anatomy each were significant in three regression models. Physiology was significant in two regression models, and math 11 and math TEAS were each significant in one regression model. 
Table 7

T-values and Probabilities of the Regression Coefficients for the Nine Models Using Nursing Variables as Dependent Variables and Academic as Predictors

Criterion Variables

\begin{tabular}{lrrrrrrrrr} 
Predict Variables & RN CompA & RN CompB & \multicolumn{1}{c}{ ATI Fund } & ATI Pharm1 & ATI Pharm2 & ATI MedSurg & ATI Peds & ATI Psych & ATI MatChild \\
\hline Pre nsg GPA & $(2.18, .03)$ & $(2.45, .02)$ & $(.19, .85)$ & $(1.30, .19)$ & $(1.59, .11)$ & $(.55, .58)$ & $(1.29, .20)$ & $(.48, .63)$ & $(3.04,<.001)$ \\
Chem 3A & $(.79, .43)$ & $(<.001, .99)$ & $(-.11, .91)$ & $(-.45, .65)$ & $(-.63, .53)$ & $(.13, .90)$ & $(.97, .34)$ & $(.51, .61)$ & $(.06, .95)$ \\
Anatomy & $(2.68,<.001)$ & $(.36, .72)$ & $(1.94, .05)$ & $(1.54, .12)$ & $(.88, .38)$ & $(.73, .47)$ & $(2.02, .04)$ & $(1.23, .22)$ & $(.06, .95)$ \\
Physio & $(1.10, .27)$ & $(-.92, .36)$ & $(1.27, .20)$ & $(2.30, .02)$ & $(.53, .60)$ & $(.16, .87)$ & $(.05, .96)$ & $(2.50, .01)$ & $(.51, .61)$ \\
Micro & $(-.056, .96)$ & $(1.98, .05)$ & $(1.67, .10)$ & $(2.69,<.001)$ & $(2.82,<.001)$ & $(2.98,<.001)$ & $(3.11,<.001)$ & $(.50, .62)$ & $(1.66, .10)$ \\
Comm 3 & $(1.64, .10)$ & $(-.50, .62)$ & $(-.89, .38)$ & $(1.67, .10)$ & $(1.28, .20)$ & $(.44, .66)$ & $(1.26, .21)$ & $(.07, .95)$ & $(2.08, .04)$ \\
Eng 1A & $(.07, .94)$ & $(-.1 .00, .32)$ & $(-.02, .98)$ & $(-.53, .58)$ & $(-.37, .71)$ & $(.69, .49)$ & $(-1.85, .07)$ & $(-.58, .56)$ & $(.64, .52)$ \\
Math 11 & $(1.11, .27)$ & $(.42, .68)$ & $(-1.84, .07)$ & $(.65, .52)$ & $(.87, .38)$ & $(1.56, .12)$ & $(1.39, .17)$ & $(.62, .54)$ & $(3.53,<.001)$ \\
Crit Think & $(.08, .94)$ & $(-.15, .88)$ & $(.33, .75)$ & $(.91, .36)$ & $(.75, .45)$ & $(-.24, .81)$ & $(.75, .45)$ & $(1.25, .21)$ & $(-1.54, .13)$ \\
Read TEAS & $(3.34, \underline{.001})$ & $(3.03,<. \underline{.001})$ & $(3.41,<.001)$ & $(.85, .40)$ & $(1.25, .21)$ & $(2.06, .04)$ & $(3.58,<.001)$ & $(.49, .63)$ & $(3.82,<.001)$ \\
Math TEAS & $(.90, .37)$ & $(.83, .41)$ & $(.86, .39)$ & $(-.63, .53)$ & $(-.10, .92)$ & $(.72, .47)$ & $(-.31, .76)$ & $(3.16,<.001)$ & $(-.30, .76)$ \\
Scien TEAS & $(2.88, .004)$ & $(3.83,<.001)$ & $(2.25, .03)$ & $(3.0,<.001)$ & $(3.67,<.001)$ & $(.05,<.001)$ & $(.41, .68)$ & $(2.55, .01)$ & $(.46, .64)$ \\
Eng TEAS & $(1.28, .20)$ & $(.75, .45)$ & $(1.28, .20)$ & $(1.42, .16)$ & $(.82, .41)$ & $(.06, .61)$ & $(-.96, .34)$ & $(1.18, .24)$ & $(-.55, .58)$ \\
\hline
\end{tabular}




\section{Linear Regression}

Question 2 - How does nursing aptitude correlate with first-try NCLEXRN pass rates controlling for academic aptitude of BSN students? To answer Question 2, linear regression analysis was run. To test for this question, three multiple linear regression models were run. The first model included all academic and nursing variables. The second model controlled for academic variables, so the regression weights for those academic variables were set equal to zero. The restricted model only included the nursing variables. The $R^{2}$ values from these two models are then used to calculate a change $F$ as follows:

$$
F=\frac{\left(R_{F}^{2} \frac{-R^{2}}{R}\right) /\left(m_{1}-m_{2}\right)}{\left(1-R_{F}^{2}\right) /\left(N-m_{1}\right)}
$$

Where

$$
\begin{aligned}
& m_{1}=\text { the number of weights in the full model } \\
& m_{2}=\text { the number of weights in the restricted model } \\
& R_{F}^{2}=R^{2} \text { in the full model } \\
& R_{R}^{2}=R^{2} \text { in the restricted model }
\end{aligned}
$$

This $F$ tests for the effects of the nursing variables controlling for the academic variables (McNeil, Newman, \& Kelly, 1996).

To do this analysis, a full model, a restricted model, and a change model are run. The full and restricted models appear in Table 8 . Both the full model $(F=$ 2.71, $d f=22,171, p=<.001)$ and the restricted model $(F=4.19, d f=9,184, p=$ $<.001)$ are significant, while the change model $(F=1.57, d f=13,171, p=.10)$, which answers the research question, is not significant. When the change model removes the variables of academic aptitude from the NCLEX-RN results, it is no longer significant. In practical terms, this means NCLEX-RN is better predicted from both academic and nursing variables or from nursing variables only. 
Table 8

\begin{tabular}{cccccc} 
Results of Full, Restricted, and Change Model to Predict & NCLEX-RN \\
\hline Model & $\mathrm{df}$ & $\mathrm{F}$ & $\mathrm{p}$ & $\mathrm{R}^{2}$ & $\Delta \mathrm{R}$
\end{tabular}

\begin{tabular}{lrrrrr}
\hline Full (academic + nursing) & 22,171 & 2.71 & $<.001$ & .258 & \\
Restricted (academic) & 9,184 & 4.19 & $<.001$ & .170 & \\
Change (nursing) & 13,171 & 4.57 & .100 & & .088 \\
\hline
\end{tabular}

\section{Logistic Regression}

Question 3 - How do academic aptitude and nursing aptitude predict firsttry NCLEX-RN pass rates for BSN students in the CSU system? Finally, to answer research Question 3, a logistic regression analysis was completed. Logistic regression allows for several variables, 13 academic aptitude variables and nine nursing aptitude variables, to predict one dichotomous pass-fail criterion, NCLEX$\mathrm{RN}$. To determine the best model, all predictors were included in the model, and then a backwards conditional stepwise solution was run to determine the best model.

When all 22 variables are included, the model is significant $\left(x^{2}=54.47, d f=\right.$ $22, p<.001$ ) and the Nagelkerke $\mathrm{R}^{2}$, which explains the amount of variance accounted for in the model, was .483. However, all variables are not significant. Table 9 presents the Wald statistical degrees of freedom, a significant level for all 22 variables in this model.

Also, the classifications appear in Table 10. All students were predicted to pass the NCLEX-RN, yet 22 failed, for an $88.7 \%$ correct percentage.

Nineteen models were fit to arrive at an optimal model, which included four variables and was significant $\left(x^{2}=38.90, d f=4, p<.001\right)$ and the Nagelkerke $\mathrm{R}^{2}$ for this model is .358. Table 11 presents the Wald Statistic, degrees of freedom, and probability for the four variables in the final model. 
Table 9

Variables in Model

\begin{tabular}{|c|c|c|c|}
\hline Step $1^{\mathrm{a}}$ & Wald & $\mathrm{df}$ & Sig \\
\hline RN Comp A & .031 & 1 & .860 \\
\hline RN Comp B & .928 & 1 & .335 \\
\hline Pre Nsg GPA & 1.004 & 1 & .316 \\
\hline Chemistry $3 \mathrm{~A}$ & 1.162 & 1 & .281 \\
\hline Anatomy & .430 & 1 & .512 \\
\hline Physiology & 2.342 & 1 & .126 \\
\hline Microbiology & .000 & 1 & .988 \\
\hline Communication 3 & 5.921 & 1 & .015 \\
\hline English 1A & .546 & 1 & .460 \\
\hline Math 11 & .518 & 1 & .472 \\
\hline Critical Thinking & 1.965 & 1 & .161 \\
\hline Reading TEAS & .062 & 1 & .804 \\
\hline Math TEAS & 3.487 & 1 & .062 \\
\hline Science TEAS & 1.093 & 1 & .296 \\
\hline English TEAS & 1.523 & 1 & .217 \\
\hline ATI Fundamentals & .100 & 1 & .751 \\
\hline ATI Pharmacology I & 1.104 & 1 & .293 \\
\hline ATI Pharmacology II & 2.367 & 1 & .124 \\
\hline ATI Med/Surg & .732 & 1 & .392 \\
\hline ATI Pediatrics & .130 & 1 & .718 \\
\hline ATI Psychology & .817 & 1 & .366 \\
\hline ATI Maternal Child & .162 & 1 & .687 \\
\hline
\end{tabular}


Table 10

\begin{tabular}{crcc} 
Classification Table & \multicolumn{4}{c}{ Predicted } \\
\cline { 2 - 4 } Observed & \multicolumn{4}{c}{ NCLEX 1st } & Percentage correct \\
\hline & \multicolumn{1}{c}{172} & 2 & 100.0 \\
Step 0 NCLEX 1st 1 & 22 & 0 & .0 \\
Overall percentage & 38.902 & 4 & 88.7 \\
\hline
\end{tabular}

a. Constant is included in the model

b. The cut value is .500

Table 11

Variables in Model

\begin{tabular}{lccc}
\hline \multicolumn{1}{c}{ Step 19 } & Wald & df & Sig \\
\hline RN Comp B & 4.136 & 1 & .042 \\
Physiology & 5.786 & 1 & .016 \\
Communication 3 & 8.051 & 1 & .005 \\
Pharmacology II & 5.363 & 1 & .021 \\
\hline
\end{tabular}

a. Variables entered on step 1: RNcompA, RNcompB, prensgGPA, Chem3A, Anatomy, Physiology, Microbiology, Comm3, Eng1A, Math11, CritThink, ReadTEAS, MathTEAS, ScienceTEAS, EngTEAS, ATIfund, ATIpharm1, ATIpharm2, ATIMedSurg, ATIPeds, ATIPsyche, ATIMatChild

The final classification Table 12 shows that 169 students were predicted to pass the NCLEX-RN and 13 were predicted to fail. In the overall model, correct percent was greater than $99.7 \%$. Both models are significant and, in the first, some variables are significant and some are not. In the second model, only the significant variables were retained which slightly improved the percent correct to $91.8 \%$.

Finally, in Table 13, the stepwise regression ends at Step 19, removing variables in each step. The results revealed that four variables were significant, two predictor academic aptitude variables, communication $3(p=.004)$, physiology $(p=.013)$ and two criterion nursing aptitude variables, $\mathrm{RN}$ comp B ( $p$ $=.038)$, and ATI pharmacology II $(\mathrm{p}=.016)$. 
Table 12

Classification Table

\begin{tabular}{ccccc}
\hline \multirow{2}{*}{ Observed } & \multicolumn{3}{c}{ Predicted } \\
\cline { 3 - 4 } Step 19 NCLEX 1st & 1 & \multicolumn{2}{c}{ NCLEX 1st } & Percentage correct \\
\cline { 2 - 4 } & & 1 & 2 & 98.3 \\
& 2 & 13.000 & 9 & 40.9 \\
\hline & & & \\
Overall percentage & 38.902 & 4 & 91.8 \\
\hline
\end{tabular}

a. The cut value is .500

Table 13

Model if Term Removed

\begin{tabular}{lcccc}
\hline \multicolumn{1}{c}{ Variable } & $\begin{array}{c}\text { Model log } \\
\text { likelihood }\end{array}$ & $\begin{array}{c}\text { Change in }-2 \\
\text { log likeliness }\end{array}$ & df & $\begin{array}{c}\text { Sig. of the } \\
\text { change }\end{array}$ \\
\hline Step 19 RN Comp B & -51.298 & 4.312 & 1 & .038 \\
Physiology & -52.237 & 6.191 & 1 & .013 \\
Communication3 & -53.377 & 8.471 & 1 & .004 \\
ATI Pharm II & -52.027 & 5.771 & 1 & .016 \\
\hline
\end{tabular}

The answer to research Question 3 is yes for the academic aptitude variables of communication 3 and physiology and for the nursing aptitude variables of RN comp B and pharmacology II.

This pilot study was completed to evaluate the data collection tool and the statistical analysis methods proposed for a doctoral dissertation study. The tool was found to contain all the desired variables needed for the study. The nursing aptitude variables of ATI comp A and B probability percentages and the levels for the ATI subject tests were found to be repetitive data and will not be used for the dissertation study. The academic aptitude variables of GPA before nursing and 
comprehensive TEAS were also repetitive data and will be excluded as well. The actual research study plan is to run the three statistical analysis used in this study to answer the three research questions proposed. The complete doctoral research will use four CSU universities who agreed to be part of the study.

\section{Procedures}

A request was made to each CSU nursing program in the study to complete the formatted data collection Excel tool for the students from that institution, which includes all variables, and is compatible with SPSS 19.0. Data were obtained from sources available to each CSU nursing program including, but not limited to (a) student reports per university archival sources, (b) nursing department records, (c) college transcripts, (d) ATI archival data, and (e) BRN NCLEX-RN pass rate data. As each CSU completed the data collection tool with data from the corresponding institution, the completed tool was electronically returned to the researcher. The completed individual university data files were merged into a file that was created for the statistical package used to analyze the data. SPSS 19.0 was used to perform the research calculations.

\section{Data Analysis}

Data were compiled completely into the research instrument. A file created in SPSS 19.0 statistical package was used to analyze the data and perform calculations. Descriptive Statistics, Correlational Analysis, Canonical Analysis, Regression Analysis, and Logistic Regression were run.

\section{Descriptive Statistics}

Descriptive Statistics are techniques used to summarize the data of individual dependent variable (Huck, 2008). This was used with mean and standard deviation data for variables per CSU program and total. 


\section{Correlation Analysis}

Correlational analysis is using statistical correlation to evaluate if there is a relationship between variables, and also Correlation also helps determine the strength of those relationships (Kerlinger \& Lee, 2000).

Canonical correlation analysis (CCA) is a multivariate statistical method used when the researcher wants to study relationships between two variable sets. Figure 6 is an "Illustration of the first function in a canonical correlation analysis with three predictors and two criterion variables. The canonical correlation is the simple Pearson $r$ between the two synthetic variables, which were linearly combined from the observed variables" (Sherry \& Henson, 2005).

Adaptation of CC (see Figure 7) demonstrates the plan for this research, as implemented in the CC illustration by Sherry and Henson (2005). For example (see Figure 8), predictor 1 would represent the 15 academic aptitude variables of this study, and predictor 2 would represent the 18 nursing aptitude variables. Likewise, criterion 1 would represent NLCEX-RN passing outcomes, and criterion 2 would represent NCLEX-RN failing outcomes.

This statistical method examines relationships between sets of criteria and predictor variables. In this dissertation study that would include academic aptitude, and nursing aptitude variables (Sherry \& Henson, 2005). A CCA statistical technique will limit error (Type I) probability throughout the study due to the simultaneous analysis of data.

\section{Logistic Regression}

Logistic regression uses several predictor variables to predict one dichotomous criterion (Huck, 2008). It is a type of multiple regression, "in which the outcome is a categorical variable" (Field, 2009, p. 265). Regression is a way of 


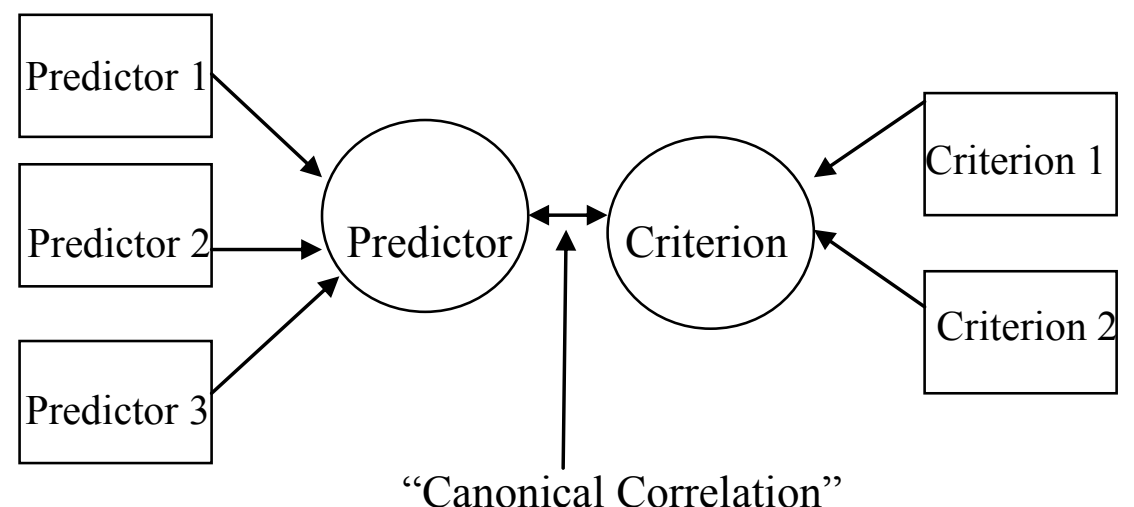

Figure 6. Canonical correlation.

(Sherry \& Henson, 2005, p. 39)

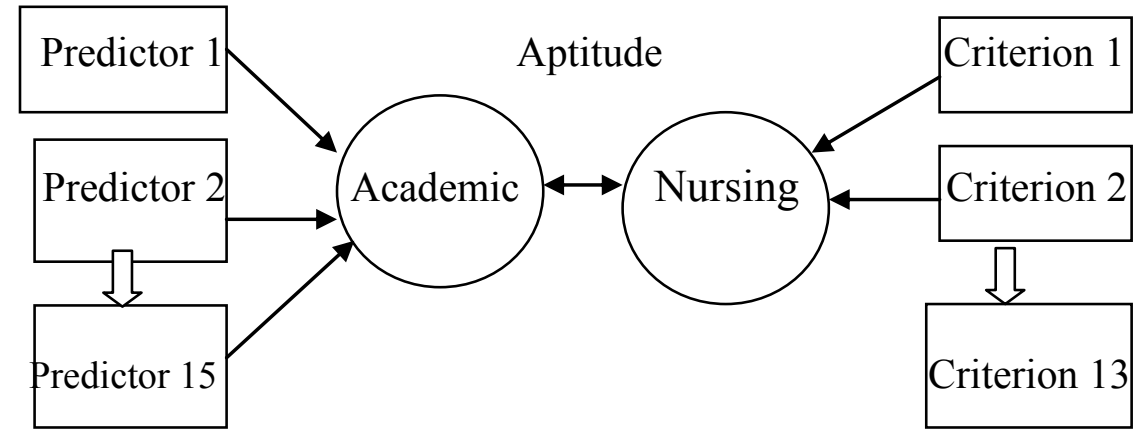

Figure 7. Adaptation of canonical correlation.

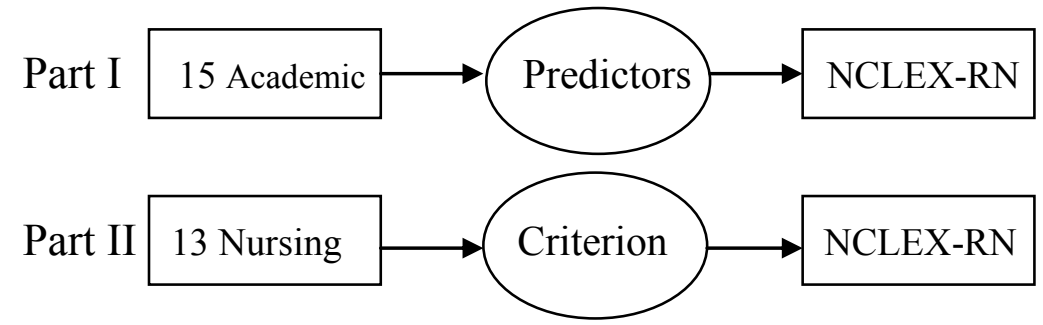

Figure 8. Parts of the analysis process. 
evaluating an outcome variable using one or more variables. Use of one variable would be referred to as simple regression as the use of more than one would be considered multiple regression. In this proposed study (see Figure 9), a type of multiple regression, Logistic Regression, is used since there are 28 predictor variables (Field, 2009).

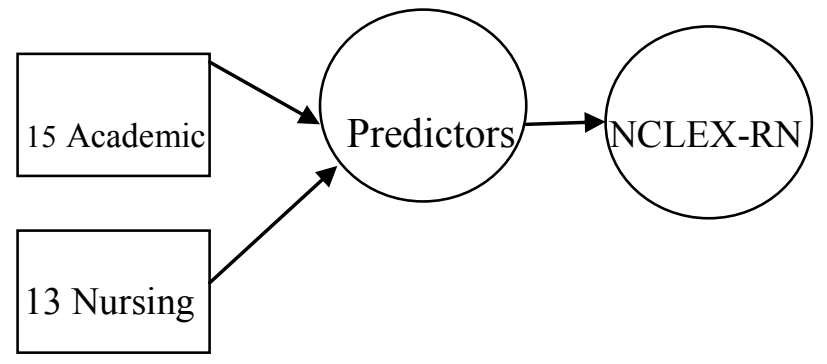

Figure 9. Adaptation of logistic regression.

This method will be used to estimate the probability of the predictor variables relating to the outcome of pass or fail on the NCLEX-RN. Logistic regression analysis "transforms the probability of an event occurring ... into its odds, that is, into the ratio of one event's probability relative to the probability of a second event" (Polit \& Hungler, 1995, p. 514). In logistic regression there can be multiple independent, predictor variables. These variables can be categorical or continuous; however, there is only one dependent or criterion variable. This variable is dichotomous (Huck, 2008). The level of significance for this study will be 0.05 .

\section{Limitations}

Limitations considered for this study.

1. The study is limited to students of baccalaureate nursing programs in the California State University system. California has other BSN programs not included in this study. The study of BSN nursing programs in the 
CSU system only affect the external validity of this study; therefore, the findings are not generalizable to other nursing programs throughout the nation.

2. The study does not look at other extraneous variables such as age, ethnicity, socioeconomic status, family status, job status, motivation, etc., which could have affected the study and lead to a Type I or Type II error.

\section{Delimitations}

Delimitations imposed by the researcher.

1. The findings of this study are only generalized to the schools who agreed to participate in the study due to only four willing programs with data available.

2. In the pilot study an attempt was made to gather information related to other extraneous variables.

\section{Summary}

This correlational, retrospective, nonexperimental, research was conducted to assess the relationship between multiple variables, before admission to a nursing program and during nursing school, to each other, and their effects on the dichotomous pass/fail criterion variable the NCLEX-RN. The researcher used traditional baccalaureate nursing programs in the CSU system. Data were obtained from the academic records of the students and the ATI database. CC and logistic regression analysis were proposed to examine the data using SPSS. Chapter 4 will follow and present the findings of this data analysis. 


\section{CHAPTER 4: RESULTS/OUTCOMES}

\section{Review of Methodology}

A retrospective quantitative study was completed to analyze predictors of first-try success of 4-year degree nursing students on the NCLEX-RN. All nursing students graduating in the two academic years of 2009-10 and 2010-11 from four nursing programs in the California State University system were considered for the study. These universities included CSU Fresno, CSU Sacramento, CSU Bakersfield, and CSU Fullerton. Out of the four universities, 794 participants met criteria to be included in the study. Demographic information was obtained from each university statistical department and variable data from the nursing departments. This estimated sample was 794 nursing graduates posted as statistical data on the CSU website; however, when the data were collected including the academic years of 2009-10 and 2010-11 for students who completed the NCLEXRN exam once, not all data were complete from each school. The demographic data provided by the universities was complete; however, nursing departments had missing data. The findings of this research will be presented as a summary and results of the three research questions.

The purpose of this study was to explore whether scholastic aptitude and nursing aptitude are correlated with each other and with first-attempt pass rates on the NCLEX-RN in baccalaureate nursing programs. Specifically, this research was completed to identify correlations between academic aptitude and nursing aptitude and to assess how well preadmission academic aptitude variables correlate with first-try NCLEX-RN pass rates of nursing students in the California State University system. 
The three research questions posed were (a) How do academic aptitude and nursing aptitude correlate? (b) How does nursing aptitude predict with first-try NCLEX-RN pass rates when controlling for academic aptitude of BSN students? and (c) How do academic aptitude and nursing aptitude predict first-try NCLEXRN pass rates for BSN students in the CSU system? Frequencies, means, and standard deviations were reported. $\mathrm{CC}$ was used to determine correlations between the two variable groups. Linear and logistic regression analysis was used to develop models to predict success on the NCLEX-RN.

\section{Summary of Findings}

\section{Demographics}

The sample (see Table 14) was made up of females $(n=659,83 \%)$ and males $(n=135,17 \%)$. The majority ethnic groups represented were White $(n=326$, 41.1\%), Mexican ( $\mathrm{n}=89,11.2 \%)$, Other Asian $(\mathrm{n}=88,11.1 \%)$, and Filipino $(\mathrm{n}=50$, $6.3 \%$ ). Over $9 \%$ of the population did not respond to the ethnicity question. The remaining $20.7 \%$ fell between $0.1 \%$ and $3 \%$ of the remaining CSU system ethnic classification choices.

For the variable of students' mother's education, most responded that their mothers had completed a bachelor's degree ( $\mathrm{n}=134,16.9 \%)$.

In the category of father's education, most responded that their fathers were high school graduates $(\mathrm{n}=127,16 \%)$.

\section{Data}

The data collected and variables available at each CSU nursing program were very different. All four schools did not collect all of the same data and although an Excel data collection tool was provided, there were still missing data. Of the 13 prenursing variables and the 9 in-program variables, CSU Fresno was 


\section{Table 14}

\section{Demographic Information}

\begin{tabular}{|c|c|c|}
\hline Category & $\mathrm{N}$ & $\%$ \\
\hline \multicolumn{3}{|l|}{ Gender } \\
\hline Male & 135 & 17 \\
\hline Female & 659 & 83 \\
\hline \multicolumn{3}{|l|}{ Ethnic group } \\
\hline Amer Indian/Alaskan & 7 & 0.9 \\
\hline African American & 20 & 2.5 \\
\hline Mexican & 89 & 11.2 \\
\hline Other Caribbean & 5 & 0.6 \\
\hline Other Asian & 88 & 11.1 \\
\hline Other Pacific Island & 23 & 2.9 \\
\hline White & 326 & 41.1 \\
\hline Other & 20 & 2.5 \\
\hline No response & 76 & 9.6 \\
\hline Chinese & 14 & 1.8 \\
\hline Decline to state & 24 & 3.0 \\
\hline Filipino & 50 & 6.3 \\
\hline Japanese & 4 & 0.5 \\
\hline Korean & 5 & 0.6 \\
\hline Laotian & 3 & 0.4 \\
\hline Puerto Rican & 2 & 0.3 \\
\hline Asian Indian & 11 & 1.4 \\
\hline Other SE Asian & 7 & 0.9 \\
\hline Thai & 1 & 0.1 \\
\hline Vietnamese & 12 & 1.5 \\
\hline \multicolumn{3}{|l|}{ Mother education } \\
\hline No high school & 57 & 7.2 \\
\hline Some high school & 34 & 4.3 \\
\hline High school grad & 124 & 15.6 \\
\hline Some college & 96 & 12.1 \\
\hline 2-year college grad & 71 & 8.9 \\
\hline 4-year college grad & 134 & 16.9 \\
\hline Post graduate & 55 & 6.9 \\
\hline No response & 33 & 4.2 \\
\hline \multicolumn{3}{|l|}{ Father education } \\
\hline No high school & 59 & 7.4 \\
\hline Some high school & 32 & 4.0 \\
\hline High school grad & 127 & 16.0 \\
\hline Some college & 117 & 14.7 \\
\hline 2- year college grad & 39 & 4.9 \\
\hline 4- year college grad & 125 & 15.7 \\
\hline Post graduate & 70 & 8.8 \\
\hline No response & 34 & 4.3 \\
\hline
\end{tabular}


the only program to have data for each category. CSU Sacramento did not have prerequisite nursing course grades, $\mathrm{RN}$ comprehensive $\mathrm{A}$, and had only one of the two pharmacology test scores. CSU Bakersfield had missing data in the variables of RN comprehensive B and only one of the two pharmacology test scores. CSU Fullerton did not have data in prenursing GPA, RN comprehensive A and B, and only one of the two pharmacology test scores. With this in mind, the academic and nursing variables with the most complete data were used to answer the three research questions. The missing data reduced prenursing variables from 13 variables to 6 , and nursing variables from 9 variables to 5 . The academic variables included prenursing GPA, communication, reading TEAS, math TEAS, science TEAS, English TEAS. The nursing variables included ATI fundamentals score, ATI medical surgical score, ATI pediatrics score, ATI psychology score, and ATI maternal child score. The NCLEX-RN remained the dichotomous dependent variable (see Table 15).

\section{Correlation}

Correlation coefficients were run between all the academic aptitude independent variables of (a) preprogram GPA, (b) communication, (c) TEAS reading, (d) TEAS math, (e) TEAS science, (f) TEAS English; with the nursing independent variables of (a) ATI fundamental score, (b) ATI medical/surgical score, (c) ATI pediatrics, (d) ATI psychology score, (e) ATI maternal child score, and the dichotomous dependent variable NCLEX-RN coded $0=$ fail, $1=$ pass (see Tables 16, 17, 18). 
Table 15

Data Available for Each CSU Nursing Program

\begin{tabular}{lcccc}
\hline \multicolumn{1}{c}{ Preprogram } & Fresno & Sacramento & Bakersfield & Fullerton \\
\hline Prenursing GPA & $\mathrm{X}$ & $\mathrm{X}$ & $\mathrm{X}$ & \\
Chemistry & $\mathrm{X}$ & & $\mathrm{X}$ & $\mathrm{X}$ \\
Anatomy & $\mathrm{X}$ & & $\mathrm{X}$ & $\mathrm{X}$ \\
Physiology & $\mathrm{X}$ & & $\mathrm{X}$ & $\mathrm{X}$ \\
Microbiology & $\mathrm{X}$ & & $\mathrm{X}$ & $\mathrm{X}$ \\
Communication & $\mathrm{X}$ & & $\mathrm{X}$ & $\mathrm{X}$ \\
English & $\mathrm{X}$ & & $\mathrm{X}$ & $\mathrm{X}$ \\
Math & $\mathrm{X}$ & & $\mathrm{X}$ & $\mathrm{X}$ \\
Critical Thinking & $\mathrm{X}$ & & $\mathrm{X}$ & $\mathrm{X}$ \\
TEAS Reading & $\mathrm{X}$ & $\mathrm{X}$ & $\mathrm{X}$ & $\mathrm{X}$ \\
TEAS Math & $\mathrm{X}$ & $\mathrm{X}$ & $\mathrm{X}$ & $\mathrm{X}$ \\
TEAS Science & $\mathrm{X}$ & $\mathrm{X}$ & $\mathrm{X}$ & $\mathrm{X}$ \\
TEAS English & $\mathrm{X}$ & $\mathrm{X}$ & $\mathrm{X}$ & $\mathrm{X}$ \\
\multicolumn{1}{c}{ In-program } & & & & \\
RN Comp A & $\mathrm{X}$ & & $\mathrm{X}$ & \\
RN Comp B & $\mathrm{X}$ & $\mathrm{X}$ & & $\mathrm{X}$ \\
ATI Fundamentals & $\mathrm{X}$ & $\mathrm{X}$ & $\mathrm{X}$ & $\mathrm{X}$ \\
ATI Pharm I & $\mathrm{X}$ & $\mathrm{X}$ & & $\mathrm{X}$ \\
ATI Pharm II & $\mathrm{X}$ & $\mathrm{X}$ & $\mathrm{X}$ & $\mathrm{X}$ \\
ATI Medical/Surg & $\mathrm{X}$ & $\mathrm{X}$ & $\mathrm{X}$ & $\mathrm{X}$ \\
ATI Pediatrics & $\mathrm{X}$ & $\mathrm{X}$ & $\mathrm{X}$ & $\mathrm{X}$ \\
ATI Psychology & $\mathrm{X}$ & $\mathrm{X}$ & $\mathrm{X}$ & $\mathrm{X}$ \\
ATI Maternal/Child & $\mathrm{X}$ & $\mathrm{X}$ & \\
\hline
\end{tabular}


Table 16

Correlations Among NCLEX and Academic Variables

\begin{tabular}{|c|c|c|c|c|c|c|c|c|}
\hline Variables & & \multicolumn{3}{|c|}{ Pre Nsg } & $\begin{array}{c}\text { Reading } \\
\text { TEAS }\end{array}$ & $\begin{array}{l}\text { Math } \\
\text { TEAS }\end{array}$ & $\begin{array}{c}\text { Science } \\
\text { TEAS }\end{array}$ & $\begin{array}{c}\text { English } \\
\text { TEAS }\end{array}$ \\
\hline & $r$ & .146 & & & & & & \\
\hline Pre Nsg GPA & $p$ & $<.001$ & & & & & & \\
\hline & $r$ & .126 & -.034 & & & & & \\
\hline Communication & $p$ & .001 & .409 & & & & & \\
\hline & $r$ & .197 & .232 & .139 & & & & \\
\hline Reading TEAS & $p$ & $<.001$ & $<.001$ & .001 & & & & \\
\hline & $r$ & .158 & .295 & .075 & .515 & & & \\
\hline Math TEAS & $p$ & $<.001$ & $<.001$ & .063 & $<.001$ & & & \\
\hline & $r$ & .171 & .210 & .086 & .506 & .565 & & \\
\hline Science TEAS & $p$ & $<.001$ & $<.001$ & .032 & $<.001$ & $<.001$ & & \\
\hline & $r$ & .103 & .166 & .078 & .564 & .500 & .483 & \\
\hline English TEAS & $p$ & .008 & $<.001$ & .051 & $<.001$ & $<.001$ & $<.001$ & \\
\hline
\end{tabular}

\section{Table 17}

Correlations Among NCLEX and Nursing Variables

\begin{tabular}{|c|c|c|c|c|c|c|c|}
\hline Variables & & NCLEX & $\begin{array}{l}\text { ATI } \\
\text { Fund }\end{array}$ & $\begin{array}{c}\text { ATI } \\
\text { Med/Surg }\end{array}$ & $\begin{array}{c}\text { ATI } \\
\text { Pediat }\end{array}$ & $\begin{array}{c}\text { ATI } \\
\text { Psych }\end{array}$ & $\begin{array}{c}\text { ATI } \\
\text { Mat/Child }\end{array}$ \\
\hline ATI Fundamentals & $\begin{array}{l}r \\
p\end{array}$ & $\begin{array}{r}.225 \\
<.001\end{array}$ & & & & & \\
\hline ATI Med/Surg & $\begin{array}{l}r \\
p\end{array}$ & $\begin{array}{r}.257 \\
<.001\end{array}$ & $\begin{array}{r}.494 \\
<.001\end{array}$ & & & & \\
\hline ATI Pediatrics & $\begin{array}{l}r \\
p\end{array}$ & $\begin{array}{r}.270 \\
<.001\end{array}$ & $\begin{array}{r}.506 \\
<.001\end{array}$ & $\begin{array}{r}.565 \\
<.001\end{array}$ & & & \\
\hline ATI Psychology & $\begin{array}{l}r \\
p\end{array}$ & $\begin{array}{r}.236 \\
<.001\end{array}$ & $\begin{array}{r}.210 \\
<.001\end{array}$ & $\begin{array}{r}.570 \\
<.001\end{array}$ & $\begin{array}{r}.559 \\
<.001\end{array}$ & & \\
\hline ATI Mat/Child & $\begin{array}{l}r \\
p\end{array}$ & $\begin{array}{r}.225 \\
<.001 \\
\end{array}$ & $\begin{array}{r}.577 \\
<.001 \\
\end{array}$ & $\begin{array}{r}\quad .568 \\
<.001 \\
\end{array}$ & $\begin{array}{r}.565 \\
<.001 \\
\end{array}$ & $\begin{array}{r}.493 \\
<.001 \\
\end{array}$ & \\
\hline
\end{tabular}


Table 18

Correlations Among Academic and Nursing Variables

\begin{tabular}{llrcccc}
\hline \multicolumn{1}{c}{ Variables } & & $\begin{array}{c}\text { ATI } \\
\text { Fund }\end{array}$ & $\begin{array}{c}\text { ATI } \\
\text { Med/Surg }\end{array}$ & $\begin{array}{c}\text { ATI } \\
\text { Pediatrics }\end{array}$ & $\begin{array}{c}\text { ATI } \\
\text { Psychology }\end{array}$ & $\begin{array}{c}\text { ATI } \\
\text { Mat/Child }\end{array}$ \\
\hline Pre Nsg GPA & $r$ & .239 & .289 & .325 & .237 & .345 \\
& $p$ & $<.001$ & $<.001$ & $<.001$ & $<.001$ & $<.001$ \\
Communication & $r$ & .162 & .128 & .113 & .146 & .108 \\
& $p$ & $<.001$ & .001 & .003 & $<.001$ & .001 \\
Reading TEAS & $r$ & .487 & .404 & .292 & .457 & .407 \\
& $p$ & $<.001$ & $<.001$ & $<.001$ & $<.001$ & $<.001$ \\
Math TEAS & $r$ & .436 & .417 & .417 & .481 & .371 \\
& $p$ & $<.001$ & $<.001$ & $<.001$ & $<.001$ & $<.001$ \\
Science TEAS & $r$ & .463 & .377 & .383 & .437 & .350 \\
& $p$ & $<.001$ & $<.001$ & $<.001$ & $<.001$ & $<.001$ \\
English TEAS & $r$ & .390 & .324 & .277 & .374 & .293 \\
& $p$ & $<.001$ & $<.001$ & $<.001$ & $<.001$ & $<.001$ \\
\hline
\end{tabular}

The NCLEX-RN correlates low and positive with all prenursing variables and all are significant. Most variables are a positive correlation, and all are significant. In the prenursing GPA variable, the range of $r$ is -.034 to .295 . For communication the range is -.034 to .139 . The range for reading TEAS is -.034 to .564 , math TEAS is -.034 to .565 , and English TEAS is -.034 to .483 .

The NCLEX-RN correlation with all nursing variables is also positive, and all are significant except one. For the in-program nursing variable ATI fundamentals, the range of $r$ is .225 to .270 . The range for medical/surgical is .210 to .577 , ATI pediatrics is .506 to 570 , ATI psychology is .210 to .570 , and for ATI Maternal/Child .493 to .577 .

Correlations among prenursing and nursing variables are all positive, and all are significant. For ATI fundamentals the $r$ range is .162 to .487 , ATI 
medical/surgical .128 to .417 , ATI pediatrics .113 to .417 , ATI psychology .146 to .481 , and maternal/child .108 to .407 .

\section{Canonical Correlation}

Question 1 - How do academic aptitude and nursing aptitude correlate? CC analysis was conducted using the five nursing aptitude criterion variables and the six academic aptitude variables as predictors. $\mathrm{CC}$ evaluates the multivariate shared relationship between the two variable sets. The canonical correlation analysis yields a number of functions, for whichever is smaller, the number of predictors or the number or criterion variables. It also provides a test of the overall model. Collectively, the model across all functions was statistically significant using the Wilk's Lambda criterion (Wilk's Lambda $=.464, F(30,2214)=15.64, p<.001)$. Because Wilk's Lambda represents the variance unexplained by the model, 1Lambda yields the full model effect size in an $r^{2}$ metric. Thus for this set of canonical functions, the $r^{2}$ type effect size was 1-.464 $=.536$, which indicates that the full model explained a substantial portion, about $54 \%$, of the variance shared between the sets of predictor variables and criterion variables. Although this canonical correlation yielded five functions, a decision must be made about whether these are all interpretable. This subjective decision is based on the significance of each of the five functions, the amount of variance each function accounts for, and the magnitude of the structure coefficients.

The dimension reduction analysis allowed the researcher to test the hierarchal arrangement of functions for statistical significance. The models for the first two functions were significant. The model functions one to five were statistically significant $(F(30,2214.00)=15.64, p<.001)$. The model for functions $2-5$ was significant $(F(20,1838.36)=2.70, p<.001)$. The next three functions were not statistically significant. 
$\operatorname{CCs}\left(R_{c}\right)$ of $.700, .239, .159, .093$, and .050 for each successive functions. The $\left(R_{c}^{2}\right)$ for the five functions were $.49, .06, .03, .01$, and .002 . The first function was considered noteworthy in the context of this study, as it explains $49 \%$ of the variance. The remaining function for the variable sets after the extraction of the first function dropped off and did not explain much of the variance. Therefore, only one function is reported for these data.

Table 19 presents the standardized canonical functions coefficient and structure coefficients for all variables across function 1 . The standardized canonical function coefficients are used to weight the variables, and the structure coefficients can be used to show the importance of variables in this function. The squared structure coefficients $\left(r_{s}^{2}\right)$ are also given, which is the index of the percentage of shared variance between a predictor or criterion variable and the remaining predictor or criterion variables in the variable set. Structure coefficients above .40 are underlined as are communalities above $40 \%$ to reveal the variables with the highest usefulness in the model.

In function 1 coefficients, the salient predictor variable with the highest structure coefficients were prenursing GPA, reading TEAS, math TEAS, science TEAS, and English TEAS. On the criterion side of Function 1, all five criterion variables had high structure coefficients: ATI fundamentals, ATI medical/surgical, ATI pediatrics, ATI psychology, and ATI maternal child.

Since all the structure coefficients in function 1 are positive, it is known that if students score high on predictor variables, they will also score high on criterion variables because the sign for all structure coefficients is the same. Prenursing GPA and all TEAS subscores are good predictors of ATI tests scores or nursing criterion. 
Table 19

Canonical Solution for Nursing Aptitude Predicting Academic Aptitude Function 1

\begin{tabular}{lccc}
\hline \multirow{1}{*}{\multicolumn{1}{c}{ Variable }} & \multicolumn{3}{c}{ Function 1} \\
\cline { 2 - 4 } Prenursing GPA & Coefficient & $\mathrm{r}_{\mathrm{s}}$ & $\mathrm{r}_{\mathrm{s}}^{2}(\%)$ \\
Communication & .242 & $\underline{.523}$ & .274 \\
Reading TEAS &. .016 & .099 & .010 \\
Math TEAS & .320 & $\underline{.794}$ & .561 \\
Science TEAS & .349 & $\underline{.844}$ & .712 \\
English TEAS & .335 & $\underline{.791}$ & .626 \\
$\mathrm{R}_{\mathrm{c}}{ }^{2}$ & .092 & $\underline{.661}$ & .437 \\
ATI Fundamentals & .409 & $\underline{.490}$ & \\
ATI Med/Surg & .268 & $\underline{.763}$ & .719 \\
ATI Pediatrics & .125 & $\underline{.698}$ & .487 \\
ATI Psychology & .324 & $\underline{.826}$ & .682 \\
ATI Mat/Child & .131 & $\underline{.719}$ & .517 \\
\hline
\end{tabular}

\section{Linear Regression}

Question 2 - How does nursing aptitude correlate with first-try NCLEX$\mathrm{RN}$ pass rates controlling for academic aptitude of BSN students? To answer Question 2, linear regression analysis was run. To test for this question, three multiple linear regression models were run. The first model included all academic and nursing variables. The second model controlled for academic variables, so the regression weights for those academic variables were set equal to zero. The restricted model included only the nursing variables. The $R^{2}$ values from these two models are then used to calculate a change $F$ as follows: 
Where

$$
F=\frac{\left(R^{2}{ }_{F}-\frac{R^{2}}{R}\right) /\left(m_{1}-\frac{m_{2}}{2}\right)}{\left(1-R^{2}{ }_{F}\right) /\left(N-m_{1}\right)}
$$

$m_{1}=$ the number of weights in the full model

$m_{2}=$ the number of weights in the restricted model

$R_{F}^{2}=R^{2}$ in the full model

$R_{R}^{2}=R_{\Sigma}^{2}$ in the restricted model

This $F$ tests for the effects of the nursing variables controlling for the academic variables (McNeil et al., 1996).

The full, restricted, and change models appear in Table 20. The full model, the restricted model, and the change model are significant. The change model, which answers the research question, is significant because when the change model removes the variance of the academic aptitude, it is still significant in predicting NCLEX-RN for nursing aptitude. This means the NCLEX-RN can be predicted from academic and nursing variables together (full model), from the academic variables only (restricted model), and for nursing variables controlling for prenursing variables (change model).

Table 20

Results of Full, Restricted, and Change Model to Predict NCLEX-RN

\begin{tabular}{lrrrrr}
\hline \multicolumn{1}{c}{ Model } & \multicolumn{1}{c}{$\mathrm{df}$} & $\mathrm{F}$ & $\mathrm{p}$ & $\mathrm{R}^{2}$ & $\Delta \mathrm{R}^{2}$ \\
\hline Full (Academic + Nursing) & 11,552 & 6.747 & $<.001$ & .119 & \\
Restricted (Academic) & 6,557 & 6.436 & $<.001$ & .065 & \\
Change (Nursing) & 5,552 & 6.723 & $<.001$ & & .054 \\
\hline
\end{tabular}

\section{Logistic Regression}

Question 3 - How do academic aptitude and nursing aptitude predict firsttry NCLEX-RN pass rates for BSN students in the CSU system? Finally, to answer research Question 3, a logistic regression analysis was run. Logistic 
regression allows for several variables, six academic aptitude variables, and five nursing aptitude variables to predict one dichotomous pass/fail criterion, NCLEX$\mathrm{RN}$. To determine the best model, the predictors were included in the model and then a backwards conditional stepwise solution was run to determine the best model.

When all 11 variables are included, the model is significant $\left(\chi^{2}=62.72, d f=\right.$ $11, p<.001)$ and the Nagelkerke $R^{2}$, which explains the amount of variance accounted for in the model was .298; however, all variables are not significant. Table 21 presents the Wald statistical degrees of freedom and probability values for all 11 variables in this model. The significant variables included communication, ATI medical/surgical, and ATI psychology.

Table 21

Variables in Model

\begin{tabular}{lrrr}
\hline \multicolumn{1}{c}{ Step $1^{\text {a }}$} & Wald & df & \multicolumn{1}{c}{ Sig } \\
\hline Pre Nsg GPA & .523 & 1 & .470 \\
Communication 3 & 3.868 & 1 & $\underline{.049}$ \\
Reading TEAS & .090 & 1 & .764 \\
Math TEAS & 1.002 & 1 & .317 \\
Science TEAS & .049 & 1 & .825 \\
English TEAS & 3.117 & 1 & .075 \\
ATI Fundamentals & .001 & 1 & .971 \\
ATI Med/Surg & 4.706 & 1 & $\underline{.030}$ \\
ATI Pediatrics & 1.018 & 1 & .313 \\
ATI Psychology & 5.593 & 1 & $\underline{.018}$ \\
ATI Maternal Child & 2.243 & 1 & .134 \\
\hline
\end{tabular}


Also, the classifications appear in Table 22. When using all 11 independent variables, all students were predicted to pass the NCLEX-RN, yet 32 failed for an 94.3 correct percentage.

Table 22

Classification Table $e^{\mathrm{a}, \mathrm{b}}$

Predicted

\begin{tabular}{rccc} 
Observed & \multicolumn{2}{c}{ NCLEX 1st } & Percentage correct \\
\hline Step 0 NCLEX 1st Pass & 532 & 0 & \\
\cline { 2 - 3 } Fail & 32 & 0 & 100.0 \\
& & Fass & .0 \\
\hline
\end{tabular}

Overall percentage

94.3

a. Constant is included in the model

b. The cut value is .500

To control for an inflated Type I error rate, the Bonferroni technique was used (Mundfrom, Perrett, Schaffer, Piccone, \& Roozeboom, 2006). The technique divides the alpha $\alpha=.05$, by 11 , the number of independent variables, so the new Type I error rate is .05 divided by 11 which equals .0045 . This value was entered into SPSS at the probability for allowing variables in and out of the model (see Table 23).

Table 23

Variables in Model

\begin{tabular}{cccc}
\hline Step $10^{\mathrm{a}}$ & Wald & df & Sig \\
\hline ATI medical surgical & 12.23 & 1 & $\leq .001$ \\
ATI psychology & 12.62 & 1 & $\leq .001$ \\
\hline
\end{tabular}


The final classification appears in Table 24 and shows that 530 students were predicted to pass the NCLEX-RN and 30 predicted to fail. In the overall model, correct percent was $94.3 \%$. The percentage correct is the same for both step zero and step 10; however, more of the students who failed were correctly classified in step 10 .

Table 24

Classification Table ${ }^{\mathrm{a}}$

Predicted

\begin{tabular}{|c|c|c|c|}
\hline Observed & \multicolumn{2}{|c|}{ NCLEX 1st } & Percentage correct \\
\hline \multirow[b]{2}{*}{ Step 10 NCLEX 1st Pass } & Pass & Fail & \\
\hline & 530 & 2 & 99.6 \\
\hline Fail & 30 & 2 & 6.3 \\
\hline Overall percentage & & & 94.3 \\
\hline
\end{tabular}

a. The cut value is .500

\section{Results of Research Questions}

Chapter 4 presented statistical analysis of variables purposed to answer three research questions addressing the relationship of predictor and criterion variables with first-try NCLEX-RN pass rates. Tables presenting correlation, canonical correlation, linear regression, and logistic regression results were provided.

Correlation results revealed significance for almost all prenursing or academic variables with the NCLEX-RN. It also revealed all nursing variables with the NCLEX-RN to be significant, as well as significance among academic and nursing variables. 
$\mathrm{CC}$ was used to answer Question 1. How do academic aptitude and nursing aptitude correlate? The results revealed a strong correlation between academic and nursing aptitudes. If students score high on predictor variables, they will also score high on criterion variables. Prenursing GPA and all TEAS subscores, reading, math, science, and English taken together are good predictors of ATI tests scores or nursing criterion, ATI fundamentals, ATI medical surgical, ATI pediatrics, ATI psychology, and ATI maternal child taken together.

In Question 2, How does nursing aptitude correlate with first-try NCLEXRN pass rates controlling for academic aptitude of BSN students?, linear regression revealed that the NCLEX-RN can be predicted from academic and nursing variables together and separately when controlling for academic aptitude. Finally, to answer Question 3, Do academic aptitude and nursing aptitude predict first-try NCLEX-RN pass rates for BSN students in the CSU system?, using logistic regression the answer is yes for the nursing aptitude variables of ATI medical surgical, and ATI psychology.

The question could be asked why linear regression would reveal all models as significant and logistic regression would determine only two ATI standardized nursing tests as significant. The response is in the analysis itself. Multiple linear regression determines significance in models or sets of variables. Stepwise backward logistic regression starts with step zero and analyzes step by step until only the variables with the most significance remain. In this study the analysis included 10 steps with the final and most significance revealed with the ATI medical surgical test and the ATI psychology test. These two standardized tests revealed a significance of $<.001$.

Chapter 5 will discuss the research findings, recommendations, implications for practice, and implications for further research. 


\section{CHAPTER 5: DISCUSSION/SUMMARY/CONCLUSION}

The purpose of this study was to explore whether academic aptitude and nursing aptitude are correlated with each other and with first-attempt pass rates and whether NCLEX-RN success could be predicted using standardized testing variables in baccalaureate nursing programs. Dreyfus and Dreyfus's (1980) and Benner's (2001) Novice to Expert model theories were adapted for use as the guiding theoretical framework for this study. Three areas of learning were emphasized in the study framework: (a) academic aptitude (which included variables prior to admission to the nursing program), prenursing GPA, a communication prerequisite course, and the four TEAS composite subset scores of reading, math, science, and English; (b) nursing variables (which included the standardized testing completed throughout the program of ATI fundamentals of

nursing), ATI medical/surgical nursing, ATI pediatrics, ATI psychology, and ATI maternal child; and (c) first-try NLCEX-RN success rates for this dichotomous pass/fail variable.

$\mathrm{CC}$, multiple linear regression, and backward stepwise logistic regression were run to analyze the data. $\mathrm{CC}$, a multivariate statistical method used when the researcher wants to study relationships between two variable sets, was used to analyze the variable sets of prenursing academic predictor variables and the inprogram nursing criterion variables. The results of this analysis found significant correlation between all the academic variables of prenursing GPA, reading TEAS, math TEAS, science TEAS, and English TEAS. The only prenursing academic predictor variable that did not prove to be significant was the prerequisite course communication. The nursing variables of ATI fundamentals, ATI medical 
surgical, ATI pediatrics, ATI psychology, and ATI maternal child were all found to have significance in this correlation.

Multiple linear regression was used to determine nursing aptitude correlation with first-try NCLEX-RN pass rates controlling for academic aptitude. Linear regression was used to determine the significance of the models in the study. Three models were considered: The full module, which included all 11 variables in the study; The restricted module, which included only prenursing academic aptitude variables; and The change module, which included nursing, inprogram variables controlling for prenursing variables. The results revealed that the NCLEX-RN can be predicted from academic and nursing variables together, from the academic variables only, or from nursing variables only. Backward stepwise logistic regression was used to analyze all variables to predict one dichotomous pass-fail variable, NCLEX-RN. The results from this analysis revealed the nursing aptitude variables of ATI medical surgical and ATI psychology best predicted NCLEX-RN success.

\section{Discussion of Research Variables}

In discussing the research variables, one must consider that this study was based on what this researcher found as gaps in current research. Table 25 shows an analysis of the literature review and the added bold variables of this research study. The shaded areas demonstrate possible overlap in research that could support or dispute this research study. The use of ATI standardized testing throughout nursing education is not found in current research. 
Table 25

Meta-analysis of Current Literature Review and Research Study Variables

\begin{tabular}{|c|c|c|c|c|c|c|c|c|c|c|c|c|c|c|c|c|c|c|c|c|c|}
\hline Variables & 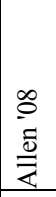 & 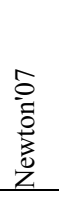 & 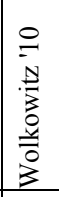 & $\begin{array}{l}1 \\
\infty \\
\omega \\
0 \\
0 \\
0\end{array}$ & 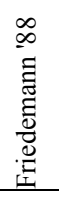 & 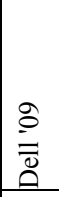 & $\begin{array}{l}\bar{a} \\
0 \\
0 \\
0 \\
\tilde{z}\end{array}$ & 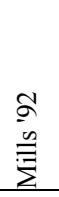 & $\begin{array}{l}\tilde{\rho} \\
\frac{\bar{\pi}}{\xi} \\
\xi\end{array}$ & \begin{tabular}{|l}
$\infty$ \\
0 \\
0 \\
.0 \\
.0 \\
0 \\
$\sum$
\end{tabular} & 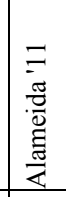 & 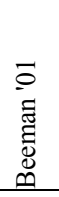 & 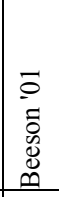 & 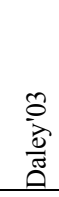 & 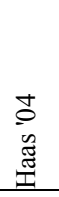 & t & 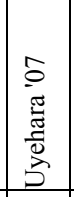 & 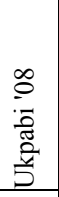 & 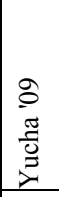 & $\begin{array}{l}0 \\
0 \\
0 \\
0 \\
\overline{0} \\
z\end{array}$ & 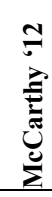 \\
\hline Yrs of educ post HS & & & & $\mathrm{X}$ & & & & & & & & & & & & & & & & & \\
\hline PGPA & $x$ & $\mathrm{x}$ & & & & & $\mathrm{x}$ & & & & & & $x$ & & $\mathrm{x}$ & & & & & & \\
\hline 1st semester GPA & & & & & & & & & & & & & & & & & & & & $\mathrm{X}$ & \\
\hline GPA (2nd yr prog) & & & & & & & $\mathrm{X}$ & $\mathrm{X}$ & $\mathrm{X}$ & $\mathrm{X}$ & & & & & & & & & & & \\
\hline GPA (program) & $\mathrm{X}$ & & & $\mathrm{x}$ & $\mathrm{x}$ & $\mathrm{x}$ & & & & & $\mathrm{x}$ & $\mathrm{x}$ & $\mathrm{x}$ & $\mathrm{X}$ & & & & & $\mathrm{X}$ & & \\
\hline ATI TEAS English & & & $x$ & & & & & & & & & & & & & & & & & & $x$ \\
\hline ATI TEAS reading & & & $\mathrm{X}$ & & & & & & & & & & & & & & & & & & $x$ \\
\hline ATI TEAS math & & & $\mathrm{x}$ & & & & & & & & & & & & & & & & & & $x$ \\
\hline ATI TEAS science & & & $x$ & & & & & & & & & & & & & & & & & & $x$ \\
\hline ATI TEAS composite & & $\mathrm{x}$ & $\mathrm{X}$ & & & & & & & & & & & & & & & & & & \\
\hline ATI in-prog tests & & & & & & & & & & & & & & & & & & $\mathrm{X}$ & & & $x$ \\
\hline ATI predict prob & & & & & & & & & & & $\mathrm{X}$ & & & & & & & & & & \\
\hline NLN verbal & & & & $\mathrm{X}$ & & & & & & & & & & & & & & & & & \\
\hline NLN math & & & & $\mathrm{X}$ & & & & & & & & & & & & & & & & & \\
\hline NLN science & & & & $\mathrm{X}$ & & & & & & & & & & & & & & & & & \\
\hline NLN composite & & & & $\mathrm{X}$ & & & & & & & & & & & & $\mathrm{X}$ & & & & & \\
\hline NLN in prog tests & & & & & & & & & & & & & & & & & $\mathrm{x}$ & $\mathrm{x}$ & & & \\
\hline MAT & & & & & & & & & & & & & $\mathrm{X}$ & & & & & & & & \\
\hline HESI & & & & & & & & & & & & & & $\mathrm{x}$ & & & & & & & \\
\hline NET & & & & & & & & & & & & & & & & & & & $x$ & & \\
\hline RN-CAT & & & & & & & & & & & & & & & & & & & $x$ & & \\
\hline Courses - med/surg & & & & & & & & & & & & & & $\mathrm{X}$ & & $\mathrm{X}$ & $\mathrm{x}$ & & & & \\
\hline Pathophysiology & & & & & & & & & & & & & & & & $\mathrm{X}$ & & & & & \\
\hline Prenursing GPA & & & & & & & & & & & & & & & & & & & & & $x$ \\
\hline
\end{tabular}




\section{Relevance to Literature}

Although this study is not a replica of any previous study, multiple studies in the literature review revealed data on one or more corresponding variables that may support or dispute this research. A discussion of these studies is presented in the following paragraphs.

In this study there was a significant relationship between the four TEAS subscores of reading, math, science, and English and the ATI standardized tests of fundamentals, medical surgical, pediatric, psychology, and maternal child. Wolkowitz and Kelley (2010) also looked at the four TEAS subscores to determine correlation between them, program success, and the ATI fundamentals assessment score. The results concluded that program success was best predicted by TEAS subscores in the order of science, reading, English, and math. There was a low to moderate correlation between the TEAS science score and the ATI fundamental exam (Wolkowitz \& Kelley, 2010).

Gross et al. (1987) used standardized testing via the NLN exam, which is similar to the ATI TEAS and has categories of verbal, math, science, and a composite score. These researchers found that this NLN exam was the best and only predictor of NCLEX pass rates. Since the TEAS and the NLN are both standardized prenursing academic aptitude tests, this study would support the finding that standardized testing prior to program admission helps predict NCLEX success.

Newton et al. (2007) looked at the composite TEAS score as a predictor of nursing program success and found it to be significant. The composite TEAS score supports the ATI TEAS test as a tool for admission and progression in a nursing program. Ukpabi (2008) also found significance in three of the four ATI subscores, including reading TEAS, math TEAS, and English TEAS. This study 
supports the significance of these prenursing standardized test scores in predicting NCLEX-RN success.

Morris and Hancock (2008) studied the HESI exam, which is an alternate standardized nursing exam, to determine NCLEX predictability. These significant results for the HESI exam support the prediction of students who would pass the NCLEX-RN. This would support the ATI testing system which is also a standardized evaluation of NCLEX-RN readiness.

Alameida et al. (2011) at San Francisco State University looked at predicting NCLEX-RN success using the ATI RN comprehensive predictor test score and the ATI predictor probability of first-time NCLEX-RN pass. These researchers found a significant relationship between NCLEX-RN success on the first try and the ATI variables. Although this study did not specifically look at the same ATI variables, the ATI system, standardized testing, comes up as significant in NCLEX success.

All five nursing variable ATI criteria (Fundamentals, Medical Surgical, Pediatrics, Psychology, and Maternal Child) in this study were found to have significance. The significance of these five nursing variable criteria is supported by similar findings revealed in a study by Ukpabi (2008). Included in the Ukpabi (2008) study were the criterion variables of ATI medical surgical, ATI community health, ATI psychology, ATI pharmacology, ATI fundamentals, and ATI pediatrics. Three of the six criterion variables, except ATI medical surgical, ATI community health, and ATI pediatrics were found to be significant. This supports the use of standardized in-program testing to predict NCLEX-RN success.

Crow et al. (2004) found that only the use of commercial review exams was significant in relationship to NCLEX-RN success. This study supported nursing program use of standardized entrance and exit exams to help assess NCLEX-RN 
success readiness. Newton and Moore (2009) also studied academic and nursing aptitude in regard to NCLEX success and found scholastic aptitude was predictive, but nursing aptitude was not.

\section{Pilot Study - Full Study}

In comparing the pilot study, completed on one of the four schools in the study, to the full study containing data from all four schools, a discussion will follow comparing the results for each analysis run. The pilot study included many more variables than the actual study due to missing data from several schools. Only the variables in both studies, that revealed significance, will be discussed here.

$\mathrm{CC}$ results in the pilot study revealed academic aptitude significance with the variables of the TEAS subscores of reading, math, science, and English. The pilot study also revealed significant correlation with the nursing aptitude variables of the ATI tests of medical surgical, pediatrics, psychology, and maternal child. The complete study revealed significance in the academic variables of GPA before nursing, the four TEAS subscores of reading, math, science, and English as well as in the nursing aptitude variables of ATI fundamentals, medical surgical, pediatrics, psychology, and maternal child. Therefore, there was significant correlation between these sets of academic variables.

Linear regression analysis included three models used to determine NCLEX-RN success. The first model included all academic and nursing variables. The second model controlled for academic variables, so the regression weights for those academic variables were set equal to zero. The restricted model only included the nursing variables. The pilot study revealed the NCLEX-RN is better predicted from both academic and nursing variables or from nursing variables 
only. The full study revealed that all three models, the full, restricted and the change model, are significant for predicting NCLEX-RN results.

Backward stepwise logistic regression revealed completely different results in the pilot study than in the actual study. This could be explained by including all 23 variables in the pilot study, whereas only 11 were variables were in the final study. In the pilot study, the backward stepwise regression continued to Step 19. At Step 19 the variables found to have the strongest predictors of the NCLEX-RN were the ATI comprehensive test B, prenursing courses of physiology and communication, and ATI pharmacology test II. The dissertation study continued to Step 11. At Step 11 the variables that best predicted NCLEX-RN success were the ATI tests of medical surgical and psychology.

$\mathrm{CC}$ and linear regression analysis results were similar in the pilot and the actual study. Logistic regression, however, did not have similar results. The difference in the variables used in each study could have an effect on the results obtained.

\section{Strengths}

This research provided valuable data for the nursing profession. Unique to this research was the analysis of data from four CSU nursing programs representing a large portion of California CSU Sacramento (Northern California), CSU Fresno (Central Valley), CSU Bakersfield (South Valley), and CSU Fullerton (Southern California). The analysis of gaps in the literature, the designing of a data gathering tool, and significant results regarding the prediction of NCLEX-RN success will benefit these nursing programs in ongoing outcome and evaluation development. Students will also benefit from this research. The financial commitment of the ATI, TEAS, resources, and standardized testing is supported with NCLEX-RN success. Passing the NCLEX-RN is the ultimate goal of each 
nursing student since practicing as a registered nurse is contingent upon this high stakes exam. Research results will be shared with these programs in the hopes that planning and implementation of interventions and remediation to assist student success not only on the NCLEX-RN but in nursing programs as well. Communication, collaboration, and collegiality with CSU Bakersfield, Fullerton, and Sacramento are also benefits of the research in expanding data collection and nursing research across the state and eventually throughout the nation.

\section{Recommendations}

Prediction of NCLEX-RN success would benefit nursing students, faculty, programs, and universities. Without success, graduates cannot enter the professional workforce; and nursing schools, departments, and programs fail to use resources appropriately, meet the needs of students, and the needs of healthcare in society.

In completing this research, data collection was more difficult and timeconsuming than expected within the CSU system. All three universities had demographic data collection; however, the access of these data was challenging. Although all schools in the study were in the state system, the IRB process for each was vastly different. No university would acknowledge the IRB process at any of the sister schools. Although these demographic data were difficult to attain, it was more uniformly complete than the nursing data.

In attempting to gather data from the CSU sites with nursing programs, several programs were unable to participate because of a data shortage or lack of data organization for access and retrieval. Even with the tool shared by this researcher for organizing and collecting data, some programs had no data or retrieval method. The tool was found to be useful for the schools that participated 
and made the research process more feasible; however, the process of data retrieval took many months and constant communication and follow-up.

It is recommended that this tool, which is in Excel format, be used as a data entering tool for CSU nursing programs. It is suggested that data be entered at the end of every semester or term to ensure complete data sets and the prevention of time-consuming retrieval difficulties of finding missing data in the future.

\section{Implications for Future Research}

The following recommendations are made for future research. The study should be replicated following the academic year of 2012-13 to determine if similar results are achieved. The four CSU nursing programs in this study will be invited to participate in the follow-up study when the participation thank you and executive summary of these study results are shared.

The data collection tool should be shared with all CSU nursing programs, and the study replicated with more schools and more variables as data become available. This will better determine if results are supported statewide.

This study should be replicated with more or all CSU nursing programs to determine if results are supported statewide. Replication will also help to support whether other standardized testing variables not included in this study, used within nursing programs, can predict NCLEX-RN success. Another study is also important to validate the logistic model derived with the stepwise procedure.

Demographic information could be added to future studies to determine if any demographic information analyzed with standardized testing would help predict NCLEX-RN success. Attrition statistics could also be analyzed with the current variables of the study to identify students at risk and lend information on providing mentoring, tutoring, intervention and remediation to these students. 
Future research could also be completed to look at these variables related to instructor impact, teaching strategies, and faculty support on NCLEX-RN success. Other programs such as associate degree programs (ADN), RN to BSN, accelerated, and entry-level masters programs (which all lead to the NCLEX-RN exam) could be used in comparative studies related to NCLEX-RN success.

A qualitative study could be completed by contacting those students who were unsuccessful on the NCLEX-RN on the first try. This interview process could gain some insight as to why students think they did not pass the first time and if any educational information is significant.

Finally, since standardized testing is available as a prerequisite to nursing programs, within nursing programs, and as postgraduation NCLEX-RN preparation courses, studies following students through this process including these postprogram courses could also be beneficial. Students take NCLEX preparations questions at the end of their nursing education. These programs are designed to assist students in the final preparation before taking this high stakes exam. 


\section{REFERENCES}

Alameida, M. D., Davis, H. C., \& Renwanz-Boyle, A. (2011). Predicting NCLEXRN success in diverse student population. Journal of Nursing Education, 50(5), 261-267. doi: 10.3928/01484834-20110228-01

Allen, C., Higgs, Z., \& Holloway, J. (1988). Identifying students at risk for academic difficulty. Journal of Professional Nursing, 4(2), 113-118. doi: 10.1016/S8755-7223(88)80033-4

American Association of Colleges of Nursing. (2010, July). Joint statement from the Tri-Council for Nursing on recent registered nurse supply and demand projections. Retrieved from http://www.aacn.nche.edu/Media/ NewsReleases/2010/tricouncil.html

American Association of Colleges of Nursing. (2011, April). Nursing shortage resource. Retrieved from http://www.aacn.nche.edu/Media/ shortageresource.htm

Amos, L. (2005). AACN education baccalaureate nursing programs. Retrieved from http://www.aacn.nche.edu/Education/nurse_ed/BSNArticle.htm Assessment Technologies Institute. (2007a). RN comprehensive predictor 2007. Retrieved from http://www.atitesting.com/ati_next_gen/Faculty/ FacultyLanding.aspx

Assessment Technologies Institute. (2007b). RN content mastery series online practice assessments. Retrieved from http://www.atitesting.com/ ati_next_gen/Faculty/FacultyLanding.aspx

Assessment Technologies Institute, LLC. (2009). Technical manual for the test of essential academic skills (TEAS®) Version 4.0: Reading, Mathematics, Science, and English. Stilwell, KS: Author. 
Assessment Technologies Institute. (2010). ATI testing nursing education NCLEX exam review TEAS testing. Retrieved from http://www.atitesting.com/ ati_next_gen/Faculty/FacultyLanding.aspx

Beeman, P., \& Waterhouse, J. (2001). NCLEX-RN performance: Predicting success on the computerized examination. Journal of Professional Nursing, 17(4), 158-165. doi: 10.1053/jpnu.2001.24860

Beeson, S., \& Kissling, G. (2001). Predicting success for baccalaureate graduates on the NCLEX-RN. Journal of Professional Nursing, 17(3), 121-127. doi: 10.1053/jpnu.2001.23382

Benner, P. E. (2001). From novice to expert: Excellence and power in clinical nursing practice. Upper Saddle River, NJ: Prentice Hall.

Benner, P. E., Sutphen, M., Leonard, V., \& Day, L. (2010). Educating nurses: A call for radical transformation. San Francisco, CA: Jossey-Bass.

Board of Registered Nursing. (2009). Board of registered nursing initial statement of reasons. Board of Registered Nursing. Retrieved from http://www.rn.ca. gov/pdfs/regulations/fsor8210.pdf

Board of Registered Nursing. (2010a). Steps to become a California registered nurse. Retrieved from http://rn.ca.gov/careers/steps.shtml

Board of Registered Nursing. (2010b). What is the board of registered nursing? Board of Registered Nursing. Retrieved from http://www.rn.ca.gov/ about_us/whatisbrn.shtml

Brinegar, P. (2005). The book of the states. Lexington, KY: Council of State Governments.

California State University. (n.d.). California State University campus websites. Retrieved from http://www.calstate.edu/search_find/ campus.shtml 
California State University. (2011, March). California state university fact book. Retrieved from http://www.calstate.edu/PA/2011Facts/facts2011.pdf Campbell, S. (1997). The role of nursing in primary health care. In Nursing in Europe: A resource for better health (pp. 209-236). Copenhagen, Denmark: WHO.

Crow, C., Handley, M., Shawmorrison, R., \& Shelton, M. (2004). Requirements and interventions used by BSN programs to promote and predict NCLEX-RN success: A national study. Journal of Professional Nursing, 20(3), 174-186. doi: 10.1016/j.profnurs.2004.04.004

Daley, L. K., Kirkpatrick, B. L., Frazier, S. K., Chung, M. L., \& Moser, D. K. (2003). Predictors of NCLEX-RN success in a baccalaureate nursing program as a foundation for remediation. Journal of Nursing Education, 42(9), 390-398.

Damgaard, G., Hohman, M., \& Karpiuk, K. (2000). History of nursing regulation. Retrieved from http://doh.sd.gov/boards/nursing/Documents/ WhitePaperHistory2000.pdf

Dell, M. S., \& Valine, W. J. (1990). Explaining differences in NCLEX-RN scores with certain cognitive and non-cognitive factors for new baccalaureate nurse graduates. Journal of Nursing Education, 24(4), 158-162. Retrieved from http://www.ncbi.nlm.nih.gov/pubmed/2159062

Dreyfus, S. E., \& Dreyfus, H. L. (1979). The scope, limits, and training implications of three models of aircraft pilot emergency response behavior. On Line Information for the Defense Community, 79(2), 1-35. Retrieved from http://www.dtic.mil/cgi-bin/GetTRDoc?AD=ADA071320\& Location $=\mathrm{U} 2 \& d o c=$ GetTRDoc.pdf 
Dreyfus, S. E., \& Dreyfus, H. L. (1980, February). A five stage model of the mental activities involved in directed skill acquisition. On Line Information for the Defense Community. Retrieved from http://www.dtic.mil/cgibin/GetTRDoc?AD=ADA084551\&Location=U2\&doc=GetTRDoc.pdf

Evangelist, T. A., Orr, T. B., \& Unrein, J. (2009). All about exams. In Nursing school entrance exams (pp. 13-27). New York, NY: McGraw-Hill.

Field, A. P. (2009). Discovering statistics using SPSS (3rd ed.). Los Angeles, CA: Sage.

Friedemann, M., \& Valentine, S. (1988). Success in old and new licensure examinations: Pre-admission factors and academic performance. Research in Nursing \& Health, 11(5), 343-350. doi: 10.1002/nur.4770110509

Gallagher, P., Bomba, C., \& Crane, L. (2001). Using an admissions exam to predict student success in an ADN program. Nurse Educator, 26(3), 132-135. Government Accountability Office. (2001, July). Nursing workforce: Emerging nurse shortages due to multiple factors (GAO-01-944). U.S. Government Accountability Office (U.S. GAO). Retrieved from http://www.gao.gov

Groot, A. D. (1978). Thought and choice in chess. The Hague, Netherlands: Mouton.

Gross, Y. T., Takazawa, E. S., \& Rose, C. L. (1987). Critical thinking and nursing education. Journal of Nursing Education, 26(8), 217-323.

Haas, R. H., Nugent, K. E., \& Rule, R. A. (2004). The use of discriminant function analysis to predict student success on the NCLEX -RN. Journal of Nursing Education, 43(10), 440-446.

Hader, R., Saver, C., \& Steltzer, T. (2006). No time to lose. Nursing Management, 37(7), 23-29. doi: 10.1097/00006247-200607000-00006 
Hodges, L., \& Williams, B. (2002, February). SREB study indicates serious shortage of nursing faculty. Southern Regional Board of Education. Retrieved from http://publications.sreb.org/2003/02N03-Nursing_Faculty.pdf Horns, P. N., O’Sullivan, P., \& Goodman, R. (1991). The use of progressive indicators as predictors of NCLEX-RN success and performance of BSN graduates. Journal of Nursing Education, 31(1), 9-14.

Huck, S. W. (2008). Reading statistics and research. Boston, MA: Pearson/Allyn \& Bacon.

Iowa Board of Nursing. (2003, December 30). Welcome to the official State of Iowa website. Retrieved from http://www.state.ia.us/nursing/ general_info/history.html

Kenward, K., Woo, A., Gross, L., \& Lui, W. (2010). NCSBN research brief: 2009 nurse licensee volume and NCLEX examination statistics. National Council of State Boards of Nursing, Inc. Retrieved from https://www. ncsbn.org/10_2009NCLEXExamStats_Vol50_web.pdf

Kerlinger, F. N., \& Lee, H. B. (2000). Foundations of behavioral research (4th ed.). Belmont, CA: Cengage Learning.

Konečni, V. J., \& Ebbesen, E. B. (1979). External validity of research in legal psychology. Law and Human Behavior, 3(1-2), 39-70. doi: 10.1007/ BF01039148

Korvick, L. M., Wisener, L. K., Loftis, L. A., \& Williamson, M. L. (2008). Comparing the academic performance of students in traditional and seconddegree baccalaureate programs. Journal of Nursing Education, 47(3), 139141. doi: 10.3928/01484834-20080301-10

Lave, J., \& Wenger, E. (2009). Situated learning: Legitimate peripheral participation. Cambridge, U.K.: Cambridge University Press. 
Matassarin-Jacobs, E. (1989). The nursing licensure process and the NCLEX-RN. Nurse Educator, 14(6), 32-34. doi: 10.1097/00006223-198911000-00008

McNeil, K. A., Newman, I., \& Kelly, F. J. (1996). Testing research hypotheses with the general linear model. Carbondale, IL: Southern Illinois University Press.

Mills, A. C., Sample, M. E., Pohlman, V. C., \& Becker, A. M. (1992). The odds for success on NCLEX-RN by nurse candidates from a four year baccalaureate nursing program. Journal of Nursing Education, 31(9), 403408.

Morris, T., \& Hancock, D. (2008). Program exit examinations in nursing education: Using a value added assessment as a measure of the impact of a new curriculum. Educational Research Quarterly, 32(2), 19-28.

Morrison, S., Free, K. W., \& Newman, M. (2002). Do progression and remediation policies improve NCLEX-RN pass rates? Nurse Educator, 27(2), 94-96. doi: 10.1097/00006223-200203000-00014

Mundfrom, D. J., Perrett, J. J., Schaffer, J., Piccone, A., \& Roozeboom, M. (2006). Bonferroni adjustments in tests for regression coefficients. Multiple Linear Regression Viewpoints, 32(1), 1-6.

National Council of State Boards of Nursing. (2010). History. Retrieved from https://www.ncsbn.org/181.htm

National League for Nursing. (2004). Assessment and evaluation. Retrieved from http://dev.nln.org/testproducts/pdf/963603P.pdf

National League for Nursing. (2006). Accreditation manual with interpretive guidelines by program type for postsecondary and higher degree programs in nursing. New York, NY: National League for Nursing Accrediting Commission. 
Newton, S. E., \& Moore, G. (2009). Use of aptitude to understand Bachelor of Science in nursing student attrition and readiness for the NCLEX-RN. Journal of Professional Nursing, 25(5), 273-278. doi: 10.1016/ j.profnurs.2009.01.016

Newton, S., Smith, L., Moore, G., \& Magnan, M. (2007). Predicting early academic achievement in a baccalaureate nursing program. Journal of Professional Nursing, 23(3), 144-149. doi: 10.1016/j.profnurs.2006.07.001

Nibert, A., Young, A., \& Adamson, C. (2008). Predicting NCLEX success with the HESI exit exam: Fourth annual validity study. CIN: Computers, Informatics, Nursing, 28-34.

Oermann, M. H., \& Gaberson, K. B. (2009). Test construction and preparation of students for licensure and certification examinations. In Evaluation and testing in nursing education (pp. 167-186). New York, NY: Springer.

Pedhazur, E. J., \& Schmelkin, L. P. (1991). Nonexperimental designs. In Measurement, design, and analysis: An integrated approach (pp. 304-317). Hillsdale, NJ: Lawrence Erlbaum.

Polit, D. F., \& Hungler, B. P. (1995). Nursing research: Principles and methods. Philadelphia, PA: Lippincott.

Potter, P. A., \& Perry, A. G. (2009). Nursing today. In Fundamentals of nursing (7th ed., pp. 1-14). St. Louis, MO: Mosby Elsevier.

Robert Wood Johnson Foundation. (2010, October). The future of nursing: Leading change, advancing health. Initiative on the Future of Nursing. Retrieved from http://thefutureofnursing.org Rother, J., \& Lavizzo-Mourey, R. (2009). Addressing the nursing workforce: A critical element for health reform. Health Affairs, 28(4), 620-624. 
Saxton, D. F., Green, J. S., \& Pelikan, P. K. (2000). Mosby's assess test: A practice exam for RN licensure. St. Louis, MO: Mosby.

Sayles, S., Shelton, D., \& Powell, H. (2003). Predictors of success in nursing education. The ABNF Journal, 14, 116-120.

Seldomridge, L. A., \& DiBartolo, M. C. (2004). Can success and failure be predicted for BSN grads on the computerized NCLEX. Journal of Professional Nursing, 20(6), 361-368.

Sherry, A., \& Henson, R. (2005). Conducting and interpreting canonical correlation analysis in personality research: A user-friendly primer. Journal of Personality Assessment, 84(1), 37-48. doi: 10.1207/s15327752jpa8401_09

Spurlock, D. R., \& Hunt, L. A. (2008). A study of the usefulness of the HESI exit exam in predicting NCLEX RN failure. Journal of Nursing Education, 47(4), 157-166.

Stone, R., \& Wiener, J. (2001, May). Who will care for us? Addressing the longterm care workforce crisis. Office of the Assistant Secretary for Planning and Evaluation, HHS. Retrieved from http://aspe.hhs.gov/daltcp/reports/ ltcwf.htm

Sudnow, D. (1978). Ways of the hand: The organization of improvised conduct. Cambridge, MA: MIT Press.

Sutherland, J. A., Hamilton, M. J., \& Goodman, N. (2007). Affirming at-risk minorities for success (ARMS): Retention graduation and success on the NCLEX - RN. Journal of Nursing Education, 46(8), 347-353.

Symes, L., Tart, K., \& Travis, L. (2005). An evaluation of the nursing success program: Reading comprehension, graduation, and diversity. Nurse Educator, 30, 217-220. 
Tracy, C., \& Fang, D. (2011). Special survey on vacant faculty positions for academic year 2010-2011. American Association of Colleges of Nursing. Retrieved from http://www.aacn.nche.edu/IDS/pdf/vacancy10.pdf Uhlenkamp, M., \& Fallis, E. (2011, June 30). 2011-12 state budget reduces funding to CSU by at least $\$ 650$ million. Retrieved from http://www. fresnostatenews.com/wp-content/uploads/Budget2011-12final.pdf

Ukpabi, C. V. (2008). Predictors of successful nursing education outcomes: A study of the North Carolina Central University's nursing program. Educational Research Quarterly, 32.2, 30-40.

University of Medicine and Dentistry of New Jersey. (n.d.). Staged models of skills acquisition. Retrieved from http://www.umdnj.edu/idsweb/ idst5340/models_skills_acquisition.htm

U.S. Department of Health and Human Services. (2000). U.S. Health Resources \& Services Administration. Retrieved from http://www.hrsa.gov/index.html U.S. Department of Health and Human Services. (2010, March). The registered nurse population: Initial findings from the 2008 national sample survey of registered nurses. Retrieved from http://bhpr.hrsa.gov/healthworkforce/ rnsurveys/rnsurveyinitial2008.pdf

U.S. Department of Labor, Bureau of Labor Statistics. (2010, December). Occupations with the Largest Job Growth. Retrieved from http://www. bls.gov/emp/ep_table_104.htm

U.S. Department of Labor, Bureau of Labor Statistics. (2011, May). Employment situation summary. Retrieved from http://www.bls.gov/news.release/ empsit.nr0.htm 
Uyehara, J., Magnussen, L., Itano, J., \& Zhang, S. (2007). Facilitating program and NCLEX-RN success in a generic BSN program. Nursing Forum, 42(1), 31-38. doi: 10.1111/j.1744-6198.2007.00063.x

Val Palumbo, M., McIntosh, B., Rambur, B., \& Naud, S. (2009). Retaining an aging nurse workforce: Perceptions of human resource practices. Nursing Economics, 27(4), 221-232.

Wall, B. M., Miller, D. E., \& Widerquist, J. G. (1993). Predictors of success on the newest NCLEX-RN. Western Journal of Nursing Research, 15(5), 628-643. doi: 10.1177/019394599301500509

Wendt, A., Kenny, L., \& Shultz, L. (2010). 2010 NLCEX-RN detailed test plan. National Council of State Boards of Nursing. Retrieved from https://www. NCSBN.org/1287.htm

Westra, M. (2006, January 9). Health education systems incorporated (HESI) joins Elsevier. Retrieved from http://www.elsevier.com/wps/find/ authored_newsitem.cws_home/companynews05_00378

Wolkowitz, A. A., \& Kelley, J. A. (2010). Academic predictors of success in a nursing program. Journal of Nursing Education, 49(9), 498-503. doi: 10.3928/01484834-20100524-09

Woo, A. (2011). Quarterly examination statistics. National Council of State Boards of Nursing. Retrieved from https://www.ncsbn.org/ NCLEX_Stats_2011.pdf

Yucha, C. B., Kowalski, S., \& Cross, C. (2009). Student stress and academic performance: Home hospital program. Jounal of Nursing Education, 48(11), 631-637. 
APPENDIX A: LITERATURE REVIEW FINDINGS

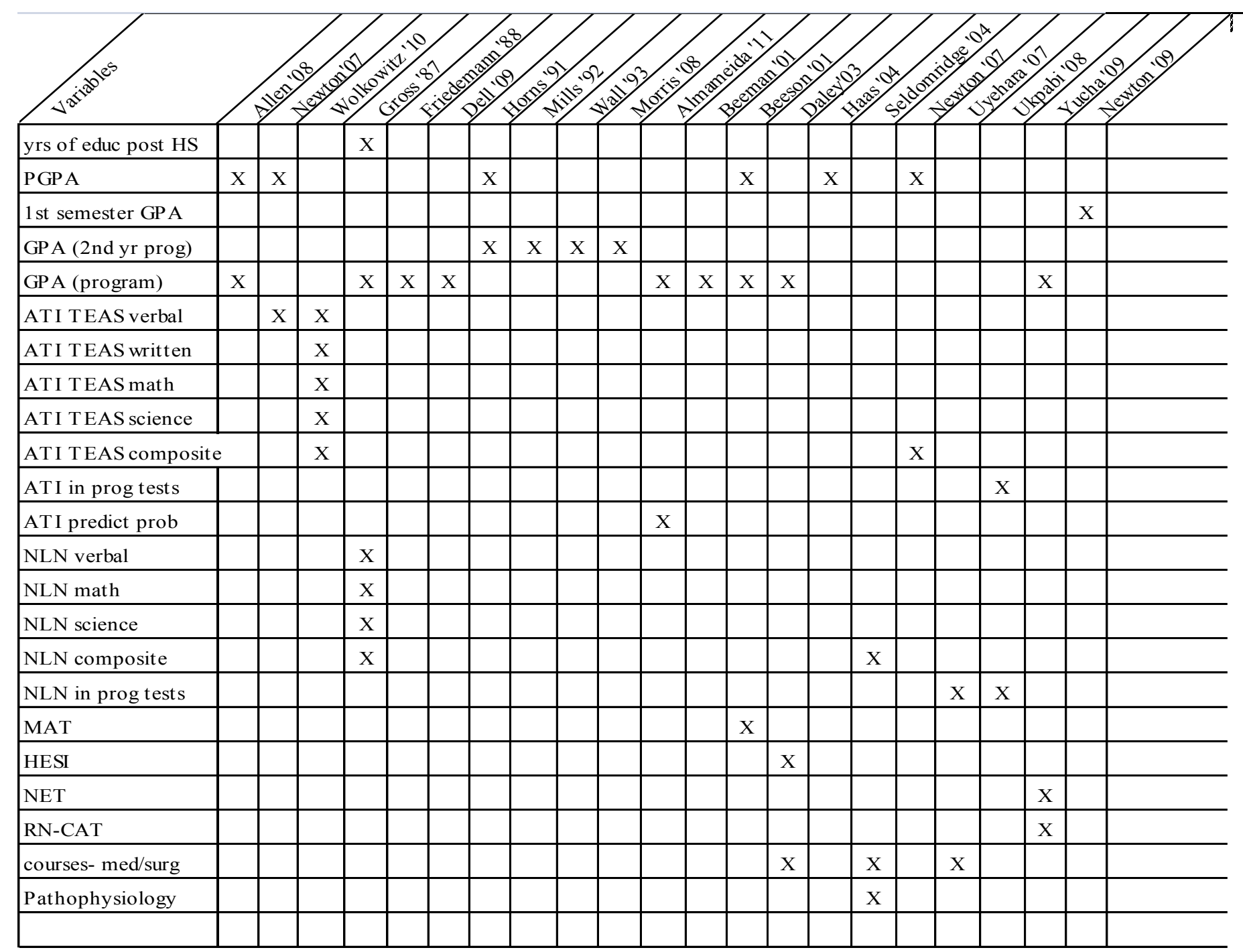




\section{APPENDIX B: PILOT STUDY COMPLETE CORRELATION}

Correlating these 34 variables resulted in 561 correlation coefficients that ranged from -.374 to -.798 .

\section{Correlations}

[DataSet1] E: \Documents and Settings\Susan Tracz.CSUFRESN-CBg0DE\My Documents Imary Ann Data 2-23-12, aลv

\begin{tabular}{|c|c|c|c|c|c|}
\hline \multicolumn{6}{|c|}{ Correlations } \\
\hline & & AtGPAb4Nsg & $\begin{array}{c}\text { A11CompTEA } \\
\mathrm{S}\end{array}$ & A12ReadTeas & A15EngTEAS \\
\hline \multirow[t]{3}{*}{ A1GPAb4Nsg } & Pearson Conrelation & 1 & $.150^{\circ}$ & .133 & 051 \\
\hline & Sig. (2-tailoc) & & .024 & .053 & 484 \\
\hline & $N$ & 231 & 228 & 211 & 210 \\
\hline \multirow[t]{3}{*}{ A11CompTEAS } & Pearson Correlation & $.150^{\circ}$ & 1 & $687^{11}$ & $798^{21}$ \\
\hline & Sig. (2-talieo) & .024 & & .000 & .000 \\
\hline & $\mathrm{N}$ & 228 & 241 & 223 & 222 \\
\hline \multirow[t]{3}{*}{ A12ReadTeas } & Pearson Correlation & .133 & $687^{2+}$ & 1 & $.578^{-4}$ \\
\hline & Sig. (2-tailed) & .053 & .000 & & .000 \\
\hline & $\mathrm{N}$ & 211 & 223 & 223 & 222 \\
\hline \multirow[t]{3}{*}{ A16EngTEAS } & Pearson Correlation & .051 & $798^{\circ}$ & $576^{4}$ & 1 \\
\hline & Sig. (2-tailed) & 464 & .000 &, 000 & \\
\hline & $N$ & 210 & 222 & 222 & 222 \\
\hline \multirow[t]{3}{*}{ A13MathTEAS } & Pearson Correlation & $145^{\circ}$ & $.752^{\prime \prime}$ & $401^{-1}$ & $412^{\prime \prime}$ \\
\hline & Sig (2-tailod) & .036 & .000 & .000 &, 000 \\
\hline & N & 211 & 223 & 223 & 222 \\
\hline \multirow[t]{3}{*}{ A14ScianTEAS } & Pearson Correlation & 108 & $701^{11}$ & $462^{\prime \prime}$ & $448^{\prime \prime}$ \\
\hline & Sig. (2-tailed) & .125 & .000 & .000 &., 000 \\
\hline & $\mathrm{N}$ & 210 & 222 & 222 & 222 \\
\hline \multirow[t]{3}{*}{ A3Chem3A } & Pearson Correlation & $308^{4-}$ & -.007 & -035 & -.058 \\
\hline & Shg. (2-talled) & .000 & .921 & .613 & .402 \\
\hline & $\mathrm{N}$ & 222 & 232 & 214 & 213 \\
\hline \multirow{3}{*}{ A4Anatomy } & Pearson Correlation & $243^{n}$ & .127 & .088 & .025 \\
\hline & Sig. (2-tailed) & .000 & .054 & 202 & .712 \\
\hline & $\mathrm{N}$ & 228 & 231 & 213 & 212 \\
\hline \multirow[t]{3}{*}{ A6Plyysidogy } & Pearson Correlatian & $.133^{\circ}$ & .001 & .001 & .0 .113 \\
\hline & Sig. (2-tailed) & .044 & 984 & 992 & .102 \\
\hline & $\mathrm{N}$ & 228 & 231 & 213 & 212 \\
\hline \multirow[t]{3}{*}{ Aetisicrobiology } & Pearson Corrsiation & $200^{\circ}$ & .072 & 049 & .007 \\
\hline & Sig. (2-tallod) & .002 & 277 & 480 & 914 \\
\hline & $\mathrm{N}$ & 228 & 231 & 213 & 212 \\
\hline \multirow[t]{3}{*}{ A7Comm 3} & Pearson Comblation & .012 & .060 & .090 & .087 \\
\hline & Sig, (2-tallod) & .854 & 364 & .192 & 330 \\
\hline & $\mathrm{N}$ & 228 & 231 & 213 & 212 \\
\hline
\end{tabular}

Page 1 
113

Correlations

\begin{tabular}{|c|c|c|c|c|c|}
\hline & & A13MathTEAS & $\begin{array}{c}\text { A14ScienTEA } \\
S\end{array}$ & A3Chem3A & AAAnatomy \\
\hline \multirow[t]{3}{*}{ A1GPAb4Nsg } & Pearson Correlation & -145 & .106 & $308^{21}$ & $243^{n}$ \\
\hline & Sig. (2-talled) & .036 & .125 &.$\infty 00$ & .000 \\
\hline & $\mathrm{N}$ & 211 & 210 & 229 & 228 \\
\hline \multirow[t]{3}{*}{ A11CompTEAS } & Pearson Correlation & $.752^{\prime \prime}$ & $.701^{-1}$ & -.007 & .127 \\
\hline & Sig. (2-tailed) & $\infty \infty$ & .000 & .921 & .054 \\
\hline & $\mathrm{N}$ & 223 & 222 & 232 & 231 \\
\hline \multirow[t]{3}{*}{ A12ReadTeas } & Pearson Correlation & $401^{\prime \prime}$ & $.462^{21}$ & -.035 & .088 \\
\hline & Sig. (2-talled) & .000 & .000 & 613 & .202 \\
\hline & $\mathrm{N}$ & 223 & 222 & 214 & 213 \\
\hline \multirow[t]{3}{*}{ A15EngTEAS } & Pearson Correlation & $412^{21}$ & $448^{21}$ & -.058 & .025 \\
\hline & Sig. (2-taied) & .000 & .000 & 402 & .712 \\
\hline & $\mathrm{N}$ & 222 & 222 & 213 & 212 \\
\hline \multirow[t]{3}{*}{ A13MathTEAS } & Pearson Correlation & 1 & $.447^{\prime \prime}$ & $=.052$ & $.212^{2}$ \\
\hline & Sig. (2-tailed) & & 000 & 453 & .002 \\
\hline & $\mathrm{N}$ & 223 & 222 & 214 & 213 \\
\hline \multirow[t]{3}{*}{ A14ScienTEAS } & Pearson Correlation & $447^{2 t}$ & 1 & .056 & $.139^{\circ}$ \\
\hline & Sig. (2-tailed) & .000 & & 420 & .043 \\
\hline & $\mathrm{N}$ & 222 & 222 & 213 & 212 \\
\hline \multirow[t]{3}{*}{ A3Chem $3 A$} & Pearson Correlation & -.052 & .056 & 1 & -.051 \\
\hline & Sig (2-tailed) & .453 & .420 & & .441 \\
\hline & $\mathrm{N}$ & 214 & 213 & 235 & 234 \\
\hline \multirow[t]{3}{*}{ A4Anatomy } & Pearson Correlation & $212^{\prime \prime}$ & .139 & .051 & 1 \\
\hline & Sig. (2-tailed) & .002 & .043 & 441 & \\
\hline & $\mathrm{N}$ & 213 & 212 & 234 & 234 \\
\hline \multirow[t]{3}{*}{ A5Physiology } & Pearson Correlation & .051 & -.002 & -040 & $230^{\circ+}$ \\
\hline & Sig. (2-tailed) & .458 & 980 & .544 & .000 \\
\hline & $\mathrm{N}$ & 213 & 212 & 234 & 234 \\
\hline \multirow[t]{3}{*}{ A6Microbiology } & Pearson Correlation & .120 & 095 & .071 & $.242^{21}$ \\
\hline & Sig. (2-tailed) & .081 & .166 & 281 & .000 \\
\hline & N & 213 & 212 & 234 & 234 \\
\hline \multirow[t]{3}{*}{ A7Comm3 } & Pearson Correlation & .057 & .104 & -.064 & -.065 \\
\hline & Sig (2-tailed) & 411 & 132 & 330 & .324 \\
\hline & $\mathrm{N}$ & 213 & 212 & 234 & 234 \\
\hline
\end{tabular}


Correlations

\begin{tabular}{|c|c|c|c|c|c|}
\hline & & AsPhysiology & $\begin{array}{c}\text { A6microbiclog } \\
y\end{array}$ & A7Comm3 & ABEng1A \\
\hline \multirow[t]{3}{*}{ A1GPAb4Nsg } & Pearson Correlation & .133 & $200^{\prime \prime}$ & .012 & .161 \\
\hline & Sig. (2.tailed) & 044 & .002 & .854 & .015 \\
\hline & $\mathrm{N}$ & 228 & 228 & 228 & 228 \\
\hline \multirow[t]{3}{*}{ A11CompTEAS } & Pearson Correlation & .001 & .072 & .080 & .085 \\
\hline & Sig. (2-tailed) & 984 & 277 & .364 & .199 \\
\hline & $\mathrm{N}$ & 231 & 231 & 231 & 231 \\
\hline \multirow[t]{3}{*}{ A12ReadTeas } & Pearson Correiation & .001 & .049 & .090 & .141 \\
\hline & Sig. (2-tailed) & .992 & .480 & .192 & .039 \\
\hline & $\mathrm{N}$ & 213 & 213 & 213 & 213 \\
\hline \multirow[t]{3}{*}{ A15EngTEAS } & Pearson Correlation & -113 & -007 & .067 & .169 \\
\hline & Sig. (2-tailed) & .102 & 914 & .330 & .014 \\
\hline & $\mathrm{N}$ & 212 & 212 & 212 & 212 \\
\hline \multirow[t]{3}{*}{ A13MathTEAS } & Pearson Correlation & .051 & .120 & .057 & .058 \\
\hline & Sig. (2-tailed) & .458 & 081 & .411 & .399 \\
\hline & $\mathrm{N}$ & 213 & 213 & 213 & 213 \\
\hline \multirow[t]{3}{*}{ A14ScienTEAS } & Pearson Correlation & -.002 & .095 & .104 & .013 \\
\hline & Sig (2-tailod) & 980 & .166 & 132 & .855 \\
\hline & $\mathrm{N}$ & 212 & 212 & 212 & 212 \\
\hline \multirow[t]{3}{*}{ A3Chem 3 A } & Pearson Correlation & .040 & .071 & -.064 & .004 \\
\hline & Sig. (2-tailed) & .544 & 281 & .330 & 947 \\
\hline & $\mathrm{N}$ & 234 & 234 & 234 & 234 \\
\hline \multirow[t]{3}{*}{ A4Anatomy } & Pearson Correlation & $230^{\circ}$ & $242^{2}$ & -.065 & -.049 \\
\hline & Sig, (2.tailed) & .000 & .000 & 324 & .452 \\
\hline & $\mathrm{N}$ & 234 & 234 & 234 & 234 \\
\hline \multirow[t]{3}{*}{ ASPhysiology } & Pearson Correlation & 1 & .110 & -.008 & -.117 \\
\hline & Sig (2-tailed) & & .093 & .898 & .073 \\
\hline & $\mathrm{N}$ & 234 & 234 & 234 & 234 \\
\hline \multirow[t]{3}{*}{ AGMicrobiology } & Pearson Comrelation & .110 & 1 & .033 & $=.010$ \\
\hline & Sig. (2-tailed) & 093 & & .618 & .879 \\
\hline & $\mathrm{N}$ & 234 & 234 & 234 & 234 \\
\hline \multirow[t]{3}{*}{ A7Comm3 } & Pearson Correlation & -.008 & .033 & 1 & .049 \\
\hline & Sig. (2-tailed) & 898 & .616 & & .453 \\
\hline & $\mathrm{N}$ & 234 & 234 & 234 & 234 \\
\hline
\end{tabular}




\begin{tabular}{|c|c|c|c|c|c|}
\hline \multicolumn{6}{|c|}{ Correlations } \\
\hline & & A10CriticalTh & A9Math11 & A2PrereqGPA & N1ATItund \\
\hline \multirow[t]{3}{*}{ A1GPAb4Nsg } & Pearson Correlation & $.170^{\circ}$ & .001 & $556^{\prime \prime}$ & $.152^{\circ}$ \\
\hline & Sig. (2-tailed) & .010 & .891 & .000 & .021 \\
\hline & N & 228 & 228 & 230 & 230 \\
\hline \multirow[t]{3}{*}{ A11CompTEAS } & Pearson Correlation & 052 & .035 & -.008 & $523^{-12}$ \\
\hline & Sig. (2-taled) & .438 & 599 & .906 & .000 \\
\hline & $\mathrm{N}$ & 231 & 231 & 233 & 240 \\
\hline \multirow[t]{3}{*}{ A12Reacteas } & Pearson Correlation & -.024 & .013 & .005 & $465^{2}$ \\
\hline & Sig. (2-tailed) & .732 & 847 & 947 & .000 \\
\hline & $\mathrm{N}$ & 213 & 213 & 215 & 222 \\
\hline \multirow[t]{3}{*}{ A15EngTEAS } & Pearson Correlation & .069 & 031 & -046 & $.373^{14}$ \\
\hline & Sig. (2-tailed) & .196 & .653 & .502 & .000 \\
\hline & $\mathrm{N}$ & 212 & 212 & 214 & 221 \\
\hline \multirow[t]{3}{*}{ A13MathTEAS } & Pearson Correlation & .046 & -.023 & -.019 & $343^{\prime \prime}$ \\
\hline & Sig. (2.tailed) & .505 & .734 & .780 & .000 \\
\hline & $\mathrm{N}$ & 213 & 213 & 215 & 222 \\
\hline \multirow[t]{3}{*}{ A14ScianTEAS } & Pearson Correlation & $.148^{\circ}$ & .014 & .020 & .454 \\
\hline & Sig. (2-tailed) & 031 & .835 & .771 & .000 \\
\hline & $\mathrm{N}$ & 212 & 212 & 214 & 221 \\
\hline \multirow[t]{3}{*}{ A3Chem3A } & Pearson Correlation & .103 & .002 & $.554^{2}$ & .015 \\
\hline & Sig. (2-tailed) & .115 & 976 & .000 & .815 \\
\hline & $\mathrm{N}$ & 234 & 234 & 235 & 234 \\
\hline \multirow[t]{3}{*}{ A4AAnatomy } & Pearson Correlation & .045 & -108 & $374^{12}$ & $236^{n}$ \\
\hline & Sig. (2-tailed) & 491 & 100 & .000 & .000 \\
\hline & $\mathrm{N}$ & 234 & 234 & 234 & 233 \\
\hline \multirow[t]{3}{*}{ A5Physiology } & Pearaon Correlation & .007 & .000 & $.487^{\circ}$ & .146 \\
\hline & Sig (2-talied) & $\$ 10$ & 1.000 & .000 & .026 \\
\hline & $\mathrm{N}$ & 234 & 234 & 234 & 233 \\
\hline \multirow[t]{3}{*}{ A6Microbiology } & Pearson Correlation & .032 & -.069 & $396^{2}$ & $.171^{\circ}$ \\
\hline & Sig (2-tailed) & .628 & .290 & .000 & .009 \\
\hline & $\mathrm{N}$ & 234 & 234 & 234 & 233 \\
\hline \multirow[t]{3}{*}{ A7Comm3 } & Pearson Correlation & -.058 & .004 & $.129^{\circ}$ & -.001 \\
\hline & Sig. (2-tailed) & .374 & .946 & .049 & .887 \\
\hline & $\mathrm{N}$ & 234 & 234 & 234 & 233 \\
\hline
\end{tabular}




\begin{tabular}{|c|c|c|c|c|c|}
\hline \multicolumn{6}{|c|}{ Correlations } \\
\hline & & Fundlevel & N2ATIPharm1 & Pharm1Level & N3ATIPharm2 \\
\hline \multirow[t]{3}{*}{ A1GPAb4Nsg } & Pearson Correlation & .068 & .135 & -.041 & $.165^{\circ}$ \\
\hline & Sig. (2-tailed) & 308 & .041 & .540 & .012 \\
\hline & $\mathrm{N}$ & 230 & 230 & 230 & 230 \\
\hline \multirow[t]{3}{*}{ A11CompTEAS } & Pearson Correlation & $-237^{\prime \prime}$ & $343^{2}$ & .042 & $.388^{\circ "}$ \\
\hline & Sig. (2-talled) & .000 & .000 & .622 & .000 \\
\hline & $\mathrm{N}$ & 240 & 238 & 238 & 240 \\
\hline \multirow[t]{3}{*}{ A12ReadTeas } & Pearson Correlation & $-.180^{\prime \prime}$ & $295^{\prime \prime}$ & .022 & $293^{\circ}$ \\
\hline & Sig. (2-tailed) & .007 & .000 & .741 & .000 \\
\hline & $\mathrm{N}$ & 222 & 220 & 220 & 222 \\
\hline \multirow[t]{3}{*}{ A15EngTEAS } & Pearson Correlation & $-.234^{\prime \prime}$ & $279^{\circ}$ & .008 & $.274^{2}$ \\
\hline & Sig- (2-tailed) & .000 &, 000 & 901 & .000 \\
\hline & $\mathrm{N}$ & 221 & 219 & 219 & 221 \\
\hline \multirow[t]{3}{*}{ A13MathTEAS } & Pearson Correlation & .006 & $.197^{\prime \prime}$ & .070 & $245^{\prime \prime}$ \\
\hline & Sig. (2-tailed) & .929 & .003 & 302 & .000 \\
\hline & $\mathrm{N}$ & 222 & 220 & 220 & 222 \\
\hline \multirow[t]{3}{*}{ A14ScienTEAS } & Pearson Correlation & -.118 & $.385^{\prime \prime}$ & -.102 & $.395^{21}$ \\
\hline & Sig. (2-tailed) & .080 & .000 & .133 & .000 \\
\hline & $\mathrm{N}$ & 221 & 219 & 219 & 221 \\
\hline \multirow[t]{3}{*}{ A3Chem $3 A$} & Pearson Comelation & -.039 & 011 & 109 & -.033 \\
\hline & Sig. (2-tailed) & .556 & .870 & .095 & .615 \\
\hline & $\mathrm{N}$ & 234 & 234 & 234 & 234 \\
\hline \multirow[t]{3}{*}{ A4AAnatomy } & Pearson Correlation & .099 & $.159^{\circ}$ & 114 & .147 \\
\hline & Sig. (2-tailed) & .173 & .015 & 082 & .025 \\
\hline & $\mathrm{N}$ & 233 & 233 & 233 & 233 \\
\hline \multirow[t]{3}{*}{ A5Physiology } & Pearson Correlation & .038 & $.158^{\circ}$ & .060 & 098 \\
\hline & Sig. (2-talled) & 596 & .018 & 362 & 135 \\
\hline & $\mathrm{N}$ & 233 & 233 & 233 & 233 \\
\hline \multirow[t]{3}{*}{ A6Microbiology } & Pearson Corretation & .005 & $.168^{\circ}$ & -074 & $201 "$ \\
\hline & Sig (2-tailed) & .934 & .010 & 260 & .002 \\
\hline & $\mathrm{N}$ & 233 & 233 & 233 & 233 \\
\hline \multirow[t]{3}{*}{ A7Comm 3} & Pearson Correlation & .063 & .124 & $-171^{t+}$ & .120 \\
\hline & Sig (2-tailed) & .337 & .058 & .009 & .067 \\
\hline & $\mathrm{N}$ & 233 & 233 & 233 & 233 \\
\hline
\end{tabular}


Correlations

\begin{tabular}{|c|c|c|c|c|c|}
\hline & & Pharmalevel & $\begin{array}{c}\text { NAATIMEdSur } \\
\mathrm{g}\end{array}$ & MedSurglevel & N5ATIPeds \\
\hline \multirow[t]{3}{*}{ A1GPAB4Nsg } & Pearson Correlation & .000 & .091 & $-163^{\circ}$ & $172^{\prime \prime}$ \\
\hline & Sig. (2-tailed) & .996 & .172 & .014 & .009 \\
\hline & $\mathrm{N}$ & 230 & 226 & 226 & 231 \\
\hline \multirow[t]{3}{*}{ A11CompTEAS } & Pearson Correlation &,- 101 & $439^{\circ}$ &. $.374^{\circ}$ & $295^{n}$ \\
\hline & Sig. (2-tailed) & .119 & .000 & .000 & .000 \\
\hline & $\mathrm{N}$ & 240 & 236 & 236 & 241 \\
\hline \multirow[t]{3}{*}{ A12ReadTeas } & Pearson Correlation & -.029 & $341^{2}$ & $-248^{\circ}$ & $.323^{\prime \prime}$ \\
\hline & Sig. (2-tailed) & .669 & .000 & 000 & .000 \\
\hline & $\mathrm{N}$ & 222 & 218 & 218 & 223 \\
\hline \multirow[t]{3}{*}{ A15EngTEAS } & Pearson Correlation & .006 & $301^{\prime \prime}$ & $-.216^{\mathrm{H}}$ & 105 \\
\hline & Sig. (2-tailed) & 935 & .000 & .001 & 117 \\
\hline & $\mathrm{N}$ & 221 & 217 & 217 & 222 \\
\hline \multirow[t]{3}{*}{ A13MathTEAS } & Pearson Correlation & .041 & $313^{21}$ & $-249^{27}$ & $168^{\circ}$ \\
\hline & Sig. (2-tailed) & .548 & .000 & .000 & .012 \\
\hline & $\mathrm{N}$ & 222 & 218 & 218 & 223 \\
\hline \multirow[t]{3}{*}{ A14ScienTEAS } & Pearson Correlation & .018 & $.390^{\circ /}$ & $-286^{21}$ & $236^{2}$ \\
\hline & Sig. (2-tailed) & .798 & .000 & .000 & .000 \\
\hline & $\mathrm{N}$ & 221 & 217 & 217 & 222 \\
\hline \multirow[t]{3}{*}{ A3Chem3A } & Pearson Correlation & -.018 &,- 085 & .036 & .081 \\
\hline & Sig (2-talled) & .784 & .328 & .588 & 213 \\
\hline & $\mathrm{N}$ & 234 & 230 & 230 & 235 \\
\hline \multirow[t]{3}{*}{ A4Anatomy } & Pearson Correlation & 111 & $.158^{\circ}$ & .070 & $220^{\circ}$ \\
\hline & Sig. (2-tailed) & .090 & .016 & 288 & .001 \\
\hline & $\mathrm{N}$ & 233 & 229 & 229 & 234 \\
\hline \multirow[t]{3}{*}{ A5Physiology } & Pearson Correlation & $=.048$ & .105 & .012 & .116 \\
\hline & Sig. (2-tailod) & 467 & .115 & .852 & .076 \\
\hline & $\mathrm{N}$ & 233 & 229 & 229 & 234 \\
\hline \multirow[t]{3}{*}{ A6Microbiology } & Pearson Correlation & .070 & $216^{2}$ &., 121 & $238^{\prime \prime}$ \\
\hline & Sig. (2-tailed) & .288 & .001 & .068 & .000 \\
\hline & $\mathrm{N}$ & 233 & 228 & 229 & 234 \\
\hline \multirow[t]{3}{*}{ A7Comm3 } & Pearson Correlation & .112 & .081 & .000 & .071 \\
\hline & Sig. (2-tailed) & .089 & .220 & .996 & .278 \\
\hline & $\mathrm{N}$ & 233 & 229 & 220 & 234 \\
\hline
\end{tabular}




\begin{tabular}{|c|c|c|c|c|c|}
\hline \multicolumn{6}{|c|}{ Correlations } \\
\hline & & PedsLovel & nGATIP syche & PsychLavel & $\begin{array}{c}\text { N7ATIMatChil } \\
d\end{array}$ \\
\hline \multirow[t]{3}{*}{ A1GPAb4Nsg } & Pearson Correlation & -.112 & .110 & -124 & $207^{\prime \prime}$ \\
\hline & Sig. (2-tailed) & .091 & 094 & .060 & .002 \\
\hline & $\mathrm{N}$ & 229 & 231 & 231 & 230 \\
\hline \multirow[t]{3}{*}{ A11CompTEAS } & Pearson Correlation &, 083 & $481^{\prime \prime}$ & $.258^{\prime \prime}$ & $333^{11}$ \\
\hline & Sig. (2-tailed) & 200 & .000 & $\infty$ & .000 \\
\hline & $\mathrm{N}$ & 239 & 241 & 241 & 240 \\
\hline \multirow[t]{3}{*}{ A12Readteas } & Pearson Correlation & $-.170^{\circ}$ & $314^{-1}$ & -.110 & $365^{* 1}$ \\
\hline & Sig. (2-tailed) & .011 & .000 & .101 & .000 \\
\hline & $\mathrm{N}$ & 221 & 223 & 223 & 222 \\
\hline \multirow[t]{3}{*}{ A15EngTEAS } & Pearson Correlation & .089 & $303^{\prime \prime}$ & $-158^{\circ}$ & $.159^{\circ}$ \\
\hline & Sig- (2-tailed) & 311 & .000 & .020 & .018 \\
\hline & N & 220 & 222 & 222 & 221 \\
\hline \multirow[t]{3}{*}{ A13MathTEAS } & Pearson Correlation & -.012 & $419^{-}$ & $-.157^{\circ}$ & $.199^{\prime \prime}$ \\
\hline & Sig (2-tailed) & 859 & .000 & .019 & .003 \\
\hline & N & 221 & 223 & 223 & 222 \\
\hline \multirow[t]{3}{*}{ A14ScienTEAS } & Pearson Correlation & .068 & $434^{21}$ & $-208^{\prime \prime}$ & $231^{1 "}$ \\
\hline & Sig (2-talled) & 328 & .000 & .002 & .001 \\
\hline & $\mathrm{N}$ & 220 & 222 & 222 & 221 \\
\hline \multirow[t]{3}{*}{ A3Chem 3 A } & Pearson Correlation & -101 & -019 & -.123 & .010 \\
\hline & Sig. (2-tailed) & .124 & .776 & .060 & 873 \\
\hline & N & 233 & 235 & 235 & 234 \\
\hline \multirow[t]{3}{*}{ A4Anatomy } & Pearson Correlation & $-.137^{\circ}$ & $218^{21}$ & .049 & .089 \\
\hline & Sig (2-tailed) & .037 & .001 & 459 & 174 \\
\hline & N & 232 & 234 & 234 & 233 \\
\hline \multirow[t]{3}{*}{ A5Physiology } & Pearson Correlation & $-180^{\circ}$ & $.214^{4}$ & -012 & .110 \\
\hline & Sig. (2-talled) & .006 & .001 & .851 & .093 \\
\hline & $\mathrm{N}$ & 232 & 234 & 234 & 233 \\
\hline \multirow[t]{3}{*}{ A6Microbiology } & Pearson Correlation & .037 & .109 & -.027 & .119 \\
\hline & Sig. (2-tailed) & .575 & .096 & .681 & .068 \\
\hline & N & 232 & 234 & 234 & 233 \\
\hline \multirow[t]{3}{*}{ A7Comm3 } & Pearson Correlation & .025 & .023 & .049 & $.130^{\circ}$ \\
\hline & Sig. (2-tailed) & .706 & .728 & .452 & .047 \\
\hline & $\mathrm{N}$ & 232 & 234 & 234 & 233 \\
\hline
\end{tabular}




\begin{tabular}{|c|c|c|c|c|c|}
\hline \multicolumn{6}{|c|}{ Correlations } \\
\hline & & MatChildtevel & RNcompA2 & Probability4A & RNCompB \\
\hline \multirow[t]{3}{*}{ A1GPADANsg } & Pearson Correlation & -.080 & .103 & $.148^{\circ}$ & $.185^{\prime \prime}$ \\
\hline & Sig (2-tailed) & 229 & .129 & .028 & .005 \\
\hline & $\mathrm{N}$ & 228 & 217 & 222 & 231 \\
\hline \multirow[t]{3}{*}{ A11CompTEAS } & Pearson Correlation & $-240^{27}$ & $370^{\prime \prime}$ & $.516^{-}$ & $.530^{\circ}$ \\
\hline & Sig. (2-tailed) & .000 & .000 & .000 & .000 \\
\hline & N & 239 & 227 & 232 & 240 \\
\hline \multirow[t]{3}{*}{ A12Readteas } & Pearson Correlation & $-286^{-1}$ & $244^{-1}$ & $.425^{\prime \prime}$ & $.480^{\prime \prime}$ \\
\hline & Sig (2-tailod) & .000 & .000 & .000 & .000 \\
\hline & $\mathrm{N}$ & 220 & 209 & 214 & 222 \\
\hline \multirow[t]{3}{*}{ A15EngTEAS } & Pearson Correlation & -.078 & $238^{2}$ & $.339^{2}$ & .392 \\
\hline & Sig. (2-tailed) & 248 & .001 & .000 & .000 \\
\hline & $\mathrm{N}$ & 219 & 208 & 213 & 221 \\
\hline \multirow[t]{3}{*}{ A13MathTEAS } & Pearson Correlation & $-136^{\circ}$ & $266^{\prime \prime}$ & $.322^{2}$ & .332 \\
\hline & Sig (2-tailed) & .044 & .000 & .000 & .000 \\
\hline & $\mathrm{N}$ & 220 & 209 & 214 & 222 \\
\hline \multirow[t]{3}{*}{ A14ScienTEAS } & Pearson Correlation & $-.149^{\circ}$ & $283^{\prime \prime}$ & $390^{\prime \prime}$ & $.531^{12}$ \\
\hline & Sig. (2-tailed) & .027 & .000 & .000 & .000 \\
\hline & $\mathrm{N}$ & 219 & 208 & 213 & 221 \\
\hline \multirow[t]{3}{*}{ A3Chem3A } & Pearson Correlation & .001 & -.039 & -.014 & .042 \\
\hline & Sig. (2-taled) & 990 & 560 & .832 & .521 \\
\hline & $\mathrm{N}$ & 232 & 221 & 226 & 235 \\
\hline \multirow[t]{3}{*}{ A4Aanatomy } & Pearson Correlation & .014 & .131 & $.158^{\circ}$ & .122 \\
\hline & Sig (2-tailed) & .831 & .053 & .018 & .082 \\
\hline & $\mathrm{N}$ & 231 & 220 & 225 & 234 \\
\hline \multirow[t]{3}{*}{ A5Physiology } & Pearson Correlation & .055 & .068 & .059 & .003 \\
\hline & Sig. (2-tailed) & .403 & .396 & .379 & .987 \\
\hline & $\mathrm{N}$ & 231 & 220 & 225 & 234 \\
\hline \multirow[t]{3}{*}{ A6GMcrobiology } & Pearson Correlation & .087 & -026 & .077 & .104 \\
\hline & Sig. (2-tailed) & 187 & 697 & 247 & .112 \\
\hline & $\mathrm{N}$ & 231 & 220 & 225 & 234 \\
\hline \multirow[t]{3}{*}{ A7Comm3 } & Pearson Correlation & -.097 & .072 & .076 & .009 \\
\hline & Sig. (2-tailed) & .141 & .291 & 259 & 889 \\
\hline & $\mathrm{N}$ & 231 & 220 & 225 & 234 \\
\hline
\end{tabular}




\begin{tabular}{|c|c|c|c|}
\hline & & Con & ons \\
\hline & & Probability4B & NCLEX1st \\
\hline A1GPAb4Nsg & Pearson Correlation & $.169^{\circ}$ & -.043 \\
\hline & Sig (2-tailed) & .010 & .514 \\
\hline & $\mathrm{N}$ & 231 & 231 \\
\hline A11CompTEAS & Pearson Comelation & $.503^{\prime \prime}$ & $.201^{12}$ \\
\hline & Sig. (2-tailed) & $\infty 00$ & .002 \\
\hline & N & 240 & 241 \\
\hline A12ReadTeas & Pearson Correlation & $441^{2+}$ & $-176^{4}$ \\
\hline & Sig. (2-tailed) & .000 & .009 \\
\hline & N & 222 & 223 \\
\hline A15EngTEAS & Pearson Correlation & $.382^{\prime \prime}$ & -.054 \\
\hline & Sig. (2-tailed) & .000 & .424 \\
\hline & $\mathrm{N}$ & 221 & 222 \\
\hline A13MathTEAS & Pearson Correlation & $289^{\prime \prime}$ & $-150^{\circ}$ \\
\hline & Sig. (2-tailed) & $\infty$ & .025 \\
\hline & $\mathrm{N}$ & 222 & 223 \\
\hline A14SoienTEAS & Pearson Comrelation & $492^{\prime \prime}$ & $-215^{-1}$ \\
\hline & Sig. (2-tailed) & .000 & .001 \\
\hline & $\mathrm{N}$ & 221 & 222 \\
\hline A3Chem $3 \mathrm{~A}$ & Pearson Correlation & .004 & -.061 \\
\hline & Sig. (2-tailed) & 945 & .354 \\
\hline & N & 235 & 235 \\
\hline A4Anatomy & Pearson Correlation & .071 & -.008 \\
\hline & Sig (2-tailed) & 281 & 931 \\
\hline & N & 234 & 234 \\
\hline A5Physiology & Pearson Correlation & -.029 & -.106 \\
\hline & Sig. (2-tailed) & .664 & .107 \\
\hline & N & 234 & 234 \\
\hline A6Microbiology & Pearson Correlation & .073 & .082 \\
\hline & Sig (2-tailed) & 268 & .213 \\
\hline & $\mathrm{N}$ & 234 & 234 \\
\hline A7Cornm3 & Pearson Correlation & -.007 & $-204^{4+}$ \\
\hline & Sig (2-tailed) & .919 & .002 \\
\hline & $\mathrm{N}$ & 234 & 234 \\
\hline
\end{tabular}


Correlations

\begin{tabular}{|c|c|c|c|c|c|}
\hline & & A1GPAb4Nsg & $\begin{array}{c}\text { A11CompTEA } \\
\mathrm{S}\end{array}$ & A12Readteas & A15EngTEAS \\
\hline \multirow[t]{3}{*}{ ABEng1A } & Pearson Correlation & $-161^{7}$ & .085 & .141 & 169 \\
\hline & Sig. (2-tailed) & .015 & 199 & .039 & .014 \\
\hline & $\mathrm{N}$ & 228 & 231 & 213 & 212 \\
\hline \multirow[t]{3}{*}{ A10CriticalTh } & Pearson Correlation & $170^{\circ}$ & .052 & -.024 & 099 \\
\hline & Sig (2-tailed) & .010 & 436 & .732 & .186 \\
\hline & N & 228 & 231 & 213 & 212 \\
\hline \multirow[t]{3}{*}{ A9Math11 } & Pearson Correlation & -.001 & .035 & .013 & .031 \\
\hline & Sig. (2-taled) & .991 & 599 & .847 & .653 \\
\hline & $\mathrm{N}$ & 228 & 231 & 213 & 212 \\
\hline \multirow[t]{3}{*}{ A2PrereqGPA } & Pearson Correlation & $.556^{\prime \prime}$ & $=.008$ & .005 & -.046 \\
\hline & Sig. (2-talled) & .000 & .906 & 947 & .502 \\
\hline & N & 230 & 233 & 215 & 214 \\
\hline \multirow[t]{3}{*}{ N1ATIfund } & Pearson Correlation & $.152^{\circ}$ & $.523^{\prime \prime}$ & $465^{\prime \prime}$ & $.373^{\prime \prime}$ \\
\hline & Sig. (2-tailed) & .021 & .000 & .000 & .000 \\
\hline & $\mathrm{N}$ & 230 & 240 & 222 & 221 \\
\hline \multirow[t]{3}{*}{ Fundlevel } & Pearson Correlation & -.068 & $-.237^{\circ}$ & $-180^{\circ}$ & $-234^{\prime \prime}$ \\
\hline & Sig. (2-tailed) & .308 & .000 & .007 & .000 \\
\hline & $\mathrm{N}$ & 230 & 240 & 222 & 221 \\
\hline \multirow[t]{3}{*}{ N2ATIPharm1 } & Pearson Correlation & $.135^{\circ}$ & $.343^{2}$ & $.295^{21}$ & $279^{2}$ \\
\hline & Sig. (2-tailed) & .041 & .000 & .000 & .000 \\
\hline & $\mathrm{N}$ & 230 & 238 & 220 & 219 \\
\hline \multirow[t]{3}{*}{ Pharm1Level } & Pearson Correlation & -.041 & -.042 & -.022 & .008 \\
\hline & Sig. (2-taled) & 540 & 522 & .741 & .901 \\
\hline & $\mathrm{N}$ & 230 & 238 & 220 & 219 \\
\hline \multirow[t]{3}{*}{ N3ATIPharm2 } & Pearson Correlation & $-165^{\circ}$ & $.368^{\circ}$ & .293 & $274^{\prime \prime}$ \\
\hline & Sig. (2-tailed) & .012 & .000 & .000 & .000 \\
\hline & $\mathrm{N}$ & 230 & 240 & 222 & 221 \\
\hline \multirow[t]{3}{*}{ Pharm2Level } & Pearson Correlation & .000 & -101 & -029 & -.008 \\
\hline & Sig. (2-tailed) & .896 & 119 & 689 & .935 \\
\hline & $\mathrm{N}$ & 230 & 240 & 222 & 221 \\
\hline \multirow[t]{3}{*}{ N4ATIMedSurg } & Pearson Correlation & .091 & $.439^{\circ}$ & $.341^{\prime \prime}$ & $301^{11}$ \\
\hline & Sig. (2-tailed) & -172 & .000 & .000 & .000 \\
\hline & $\mathrm{N}$ & 226 & 236 & 218 & 217 \\
\hline \multirow[t]{3}{*}{ MedSurgLevel } & Pearson Correlation & $-163^{\circ}$ & -.374 & $.248^{\prime \prime}$ & $-.218^{\prime \prime}$ \\
\hline & Sig. (2-tailed) & .014 & .000 & .000 & .001 \\
\hline & $\mathrm{N}$ & 228 & 236 & 218 & 217 \\
\hline \multirow[t]{3}{*}{ N5ATIPeds } & Pearson Correlation & $.172^{* 1}$ & $.295^{4}$ & $.323^{4}$ & .105 \\
\hline & Sig. (2-tailed) & .009 & .000 & .000 & .117 \\
\hline & $\mathrm{N}$ & 231 & 241 & 223 & 222 \\
\hline
\end{tabular}


Correlations

\begin{tabular}{|c|c|c|c|c|c|}
\hline & & A13MathTEAS & $\begin{array}{c}\text { A14ScienTEA } \\
\text { S }\end{array}$ & A3Chem3A & A4Anatorny \\
\hline \multirow[t]{3}{*}{ ABEng1A } & Pearson Correlation & .068 & .013 & .004 & -.049 \\
\hline & Sig. (2-tailed) & 399 & 855 & .947 & 452 \\
\hline & $\mathrm{N}$ & 213 & 212 & 234 & 234 \\
\hline \multirow[t]{3}{*}{ A10CriticalTh } & Pearson Correlation & .046 & $148^{\circ}$ & .103 & -.045 \\
\hline & Sig. (2-talled) & .505 & .031 & 115 & 491 \\
\hline & $\mathrm{N}$ & 213 & 212 & 234 & 234 \\
\hline \multirow[t]{3}{*}{ AgMath11 } & Pearson Correlation & -023 & $=014$ &,- 002 &,- 108 \\
\hline & Sig. (2-tailed) & .734 & .835 & 978 & 100 \\
\hline & $\mathrm{N}$ & 213 & 212 & 234 & 234 \\
\hline \multirow[t]{3}{*}{ A2PrereqGPA } & Pearson Correlation & -.019 & .020 & $.554^{-1}$ & $.374^{\prime \prime}$ \\
\hline & Sig. (2-tailed) & .780 & .771 & .000 & .000 \\
\hline & $\mathrm{N}$ & 215 & 214 & 235 & 234 \\
\hline \multirow[t]{3}{*}{ N1ATifund } & Pearson Correlation & $.343^{11}$ & $.454^{\prime \prime}$ & .015 & $.236^{11}$ \\
\hline & Sig. (2-tailed) & .000 & .000 & .815 & .000 \\
\hline & $\mathrm{N}$ & 222 & 221 & 234 & 233 \\
\hline \multirow[t]{3}{*}{ FundLevel } & Pearson Correlation & .006 & -118 & -.038 & .089 \\
\hline & Sig. (2-tailed) & .929 & .080 & .556 & .173 \\
\hline & $\mathrm{N}$ & 222 & 221 & 234 & 233 \\
\hline \multirow[t]{3}{*}{ N2ATIPharm1 } & Pearson Correlation & $.197^{\prime \prime}$ & $395^{\prime \prime}$ & .011 & $.159^{\circ}$ \\
\hline & Sig. (2-talled) & .003 & .000 & .870 & 015 \\
\hline & N & 220 & 219 & 234 & 233 \\
\hline \multirow[t]{3}{*}{ Pharm1Level } & Pearson Correlation & .070 & $<102$ & -109 & .114 \\
\hline & Sig. (2-tailed) & .302 & 133 & .095 & .082 \\
\hline & $\mathrm{N}$ & 220 & 219 & 234 & 233 \\
\hline \multirow[t]{3}{*}{ N3ATIPharm2 } & Pearson Correlation & $245^{-1}$ & $395^{\prime \prime}$ & -.033 & $.147^{\circ}$ \\
\hline & Sig (2-tailed) & .000 & .000 & .615 & .025 \\
\hline & $\mathrm{N}$ & 222 & 221 & 234 & 233 \\
\hline \multirow[t]{3}{*}{ Pharm2Level } & Pearson Correlation & .041 & .018 &, 018 & .111 \\
\hline & Sig. (2-tailed) & .548 & .796 & .784 & .090 \\
\hline & $\mathrm{N}$ & 222 & 221 & 234 & 233 \\
\hline \multirow[t]{3}{*}{ NAATIMedSurg } & Pearson Correlation & $.313^{1+}$ & $390^{\prime \prime}$ & -065 & $158^{\circ}$ \\
\hline & Sig. (2-tailod) & .000 & .000 & .328 & .016 \\
\hline & $\mathrm{N}$ & 218 & 217 & 230 & 229 \\
\hline \multirow[t]{3}{*}{ MedSurgLevel } & Peirson Correlation & $-.249^{\circ}$ & $-286^{2 \prime}$ & .036 & -.070 \\
\hline & Sig. (2-tailed) & .000 & .000 & .588 & .288 \\
\hline & $\mathrm{N}$ & 218 & 217 & 230 & 229 \\
\hline \multirow[t]{3}{*}{ N5ATIPeds } & Pearson Correlation & $.168^{\circ}$ & $236^{\prime \prime}$ & .081 & $220^{\circ}$ \\
\hline & Sig- (2-tailed) & .012 & .000 & .213 & .001 \\
\hline & $\mathrm{N}$ & 223 & 222 & 235 & 234 \\
\hline
\end{tabular}


Correlations

\begin{tabular}{|c|c|c|c|c|c|}
\hline & & A5Physiology & $\begin{array}{c}\text { A6Microbiolog } \\
y \\
\end{array}$ & A7Comm3 & A.8Eng1A \\
\hline \multirow{3}{*}{ ABEng1A } & Pearson Correlation &,- 117 & .010 & .049 & 1 \\
\hline & Sig. (2-tailed) & .073 & 879 & .453 & \\
\hline & $\mathrm{N}$ & 234 & 234 & 234 & 234 \\
\hline \multirow[t]{3}{*}{ A10Critica/Th } & Pearson Correlation & .007 & -032 &,- 058 & .092 \\
\hline & Sig. (2-taled) & .910 & 628 & 374 & .160 \\
\hline & $\mathrm{N}$ & 234 & 234 & 234 & 234 \\
\hline \multirow[t]{3}{*}{ AgMath11 } & Pearson Correlation & 000 & .069 & 004 & .035 \\
\hline & Sig. (2-tailed) & 1,000 & .290 & 946 & .591 \\
\hline & $\mathrm{N}$ & 234 & 234 & 234 & 234 \\
\hline \multirow[t]{3}{*}{ A2PrereqGPA } & Pearson Correlation & $487^{* 1}$ & $396^{2+}$ & $129^{\circ}$ & $.316^{2 \pi}$ \\
\hline & Sig. (2-tailed) & .000 & .000 & 049 & .000 \\
\hline & $\mathrm{N}$ & 234 & 234 & 234 & 234 \\
\hline \multirow[t]{3}{*}{ N1ATlfund } & Pearson Correlation & $.146^{\circ}$ & $.171^{-1}$ & -.001 & .021 \\
\hline & Sig. (2-taled) & .026 & .009 & .987 & .754 \\
\hline & $\mathrm{N}$ & 233 & 233 & 233 & 233 \\
\hline \multirow[t]{3}{*}{ FundLevel } & Pearson Correlation & .038 & .005 & .063 & .052 \\
\hline & Sig (2-tailed) & 566 & .934 & 337 & 430 \\
\hline & $\mathrm{N}$ & 233 & 233 & 233 & 233 \\
\hline \multirow[t]{3}{*}{ N2ATIPharm1 } & Pearson Correlation & $158^{\circ}$ & $.168^{\circ}$ & 124 & .001 \\
\hline & Sig-(2-talled) & .016 & .010 & .058 & .994 \\
\hline & $\mathrm{N}$ & 233 & 233 & 233 & 233 \\
\hline \multirow[t]{3}{*}{ Pham1Level } & Pearson Correlation & .060 & .074 & $-.171^{-1}$ & .022 \\
\hline & Sig (2-tailed) & 362 & .260 & .009 & .738 \\
\hline & $\mathrm{N}$ & 233 & 233 & 233 & 233 \\
\hline \multirow[t]{3}{*}{ N3ATIPharm2 } & Pearson Correlation & .098 & $201^{21}$ & .120 & .037 \\
\hline & Sig. (2-tailed) & 135 & .002 & .087 & 577 \\
\hline & $\mathrm{N}$ & 233 & 233 & 233 & 233 \\
\hline \multirow[t]{3}{*}{ Pharm2Level } & Pearson Correlation & -.048 & .070 & .112 & .029 \\
\hline & Sig. (2-tailed) & -467 & .288 & .089 & 658 \\
\hline & $\mathrm{N}$ & 233 & 233 & 233 & 233 \\
\hline \multirow[t]{3}{*}{ MAATIMedSurg } & Pearson Correlation & .105 & $216^{\pi}$ & .081 & .030 \\
\hline & Sig. (2-tailed) & .115 &, 001 & 220 & .649 \\
\hline & $\mathrm{N}$ & 229 & 229 & 229 & 229 \\
\hline \multirow[t]{3}{*}{ MedSurglevel } & Pearson Correlation & 012 & -.121 & .000 & .040 \\
\hline & Sig- (2-tailed) & .852 & .068 & .996 & .548 \\
\hline & $\mathrm{N}$ & 229 & 229 & 229 & 229 \\
\hline \multirow[t]{3}{*}{ N5ATIPEds } & Pearson Correlation & .116 & $236^{\circ+1}$ & .071 & -.094 \\
\hline & Sig. (2-tailed) & .076 & .000 & 276 & .154 \\
\hline & $\mathrm{N}$ & 234 & 234 & 234 & 234 \\
\hline
\end{tabular}




\begin{tabular}{|c|c|c|c|c|c|}
\hline \multicolumn{6}{|c|}{ Correlations } \\
\hline & & AtocriticalTh & A9Math11 & A2PrereqGPA & N1ATifund \\
\hline \multirow[t]{3}{*}{ A8Eng1A } & Pearson Correlation & .092 & .035 & $316^{2}$ & .021 \\
\hline & Sig. (2-tailed) & .160 & .591 & .000 & .754 \\
\hline & $\mathrm{N}$ & 234 & 234 & 234 & 233 \\
\hline \multirow[t]{3}{*}{ A10CriticalTh } & Pearson Correlation & 1 & 100 & $248^{\prime \prime}$ & .060 \\
\hline & Sig. (2-tailed) & & .127 & .000 & 380 \\
\hline & $\mathrm{N}$ & 234 & 234 & 234 & 233 \\
\hline \multirow[t]{3}{*}{ A9Meth11 } & Pearson Correlation & .100 & 1 & $.133^{\circ}$ & -013 \\
\hline & Sig. (2-tailed) & .127 & & .042 & .844 \\
\hline & $\mathrm{N}$ & 234 & 234 & 234 & 233 \\
\hline \multirow[t]{3}{*}{ A2PrereqGPA } & Pearson Correlation & $248^{11}$ & $133^{\circ}$ & 1 & .065 \\
\hline & Sig (2-tailed) & .000 & .042 & & .323 \\
\hline & $\mathrm{N}$ & 234 & 234 & 236 & 235 \\
\hline \multirow[t]{3}{*}{ N1ATlifund } & Pearson Correlation & .060 & -.013 & .065 & 1 \\
\hline & Sig. (2-talled) & .360 & .844 & .323 & \\
\hline & $\mathrm{N}$ & 233 & 233 & 235 & 244 \\
\hline \multirow[t]{3}{*}{ Fundlevel } & Pearson Correlation & -.001 & -.040 & .009 & $-223^{\prime \prime}$ \\
\hline & Sig. (2-tailed) & .989 & .548 & 890 & .000 \\
\hline & $\mathrm{N}$ & 233 & 233 & 236 & 244 \\
\hline \multirow[t]{3}{*}{ N2ATIPharm1 } & Pearson Correlation & $.157^{\circ}$ & .076 & .115 & $515^{\prime \prime}$ \\
\hline & Sig. (2-tailed) & .017 & .247 & 079 & .000 \\
\hline & $\mathrm{N}$ & 233 & 233 & 235 & 241 \\
\hline \multirow[t]{3}{*}{ Pharm1Level } & Pearson Correlation & -.093 & -.096 & -.057 & -.032 \\
\hline & Sig. (2-talled) & -156 & .144 & .385 & .617 \\
\hline & $\mathrm{N}$ & 233 & 233 & 235 & 241 \\
\hline \multirow[t]{3}{*}{ N3ATiPharm2 } & Pearson Correlation & 119 & $.149^{\circ}$ & .080 & $.448^{\prime \prime}$ \\
\hline & Sig. (2-tailed) & .070 & .023 & .359 & .000 \\
\hline & $\mathrm{N}$ & 233 & 233 & 235 & 243 \\
\hline \multirow[t]{3}{*}{ Pharmzlevel } & Pearson Correlation & .011 & $-172^{2}$ & .005 & .063 \\
\hline & Sig (2-talled) & 866 & .008 & .933 & .330 \\
\hline & $\mathrm{N}$ & 233 & 233 & 235 & 243 \\
\hline \multirow[t]{3}{*}{ N4ATIMedSurg } & Pearson Correlation & .010 & .105 & .022 & $505^{\prime \prime}$ \\
\hline & Sig. (2-tailed) & 881 & .113 & .740 & .000 \\
\hline & $\mathrm{N}$ & 229 & 229 & 231 & 239 \\
\hline \multirow[t]{3}{*}{ MedSurgLevel } & Pearson Correlation & .030 & .048 & -.009 & .322 \\
\hline & Sig (2-tailed) & .847 & .468 & 889 & .000 \\
\hline & $\mathrm{N}$ & 229 & 229 & 231 & 239 \\
\hline \multirow[t]{3}{*}{ N5ATIPeds } & Pearson Correlation & .045 & .079 & .118 & $5077^{\prime \prime}$ \\
\hline & Silg (2-talled) & .496 & .231 & .070 & 000 \\
\hline & $\mathrm{N}$ & 234 & 234 & 236 & 244 \\
\hline
\end{tabular}




\begin{tabular}{|c|c|c|c|c|c|}
\hline \multicolumn{6}{|c|}{ Corrolations } \\
\hline & & Fundlewel & N2ATIPharm1 & Pharm1Level & N3ATIPharm2 \\
\hline \multirow[t]{3}{*}{ ABEng1A } & Pearson Correlation & -.052 & .001 & .022 & .037 \\
\hline & Sig. (2-tailed) & .430 & .994 & .738 & .577 \\
\hline & $\mathrm{N}$ & 233 & 233 & 233 & 233 \\
\hline \multirow[t]{3}{*}{ A10CriticalTh } & Pearson Cocrelation &., 001 & $.157^{\circ}$ & .093 & .119 \\
\hline & Sig (2-tailed) & 989 & .017 & .158 & .070 \\
\hline & $\mathrm{N}$ & 233 & 233 & 233 & 233 \\
\hline \multirow[t]{3}{*}{ A9Math11 } & Pearson Correlation & -.040 & .076 & -.096 & $.149^{\circ}$ \\
\hline & Sig. (2-tailed) & .548 & 247 & .144 & .023 \\
\hline & $\mathrm{N}$ & 233 & 233 & 233 & 233 \\
\hline \multirow{3}{*}{ A2PrereqGPA } & Pearson Correlation & .009 & .115 & .067 & .060 \\
\hline & Sig. (2-tailed) & 890 & .079 & 386 & .359 \\
\hline & $\mathrm{N}$ & 235 & 235 & 235 & 235 \\
\hline \multirow[t]{3}{*}{ N1ATIFund } & Pearson Correlation & $-223^{27}$ & $.515^{\prime \prime}$ & .032 & $446^{\circ}$ \\
\hline & Sig, (2-tailed) & .000 & .000 & 617 & .000 \\
\hline & $\mathrm{N}$ & 244 & 241 & 241 & 243 \\
\hline \multirow[t]{3}{*}{ Fundlevel } & Pearson Correlation & 1 & -.096 & .053 & .007 \\
\hline & Sig. (2-tailed) & & .136 & .415 & .912 \\
\hline & $\mathrm{N}$ & 244 & 241 & 241 & 243 \\
\hline \multirow[t]{3}{*}{ N2ATIPharm1 } & Pearson Correlation & -096 & 1 & $.231^{\prime \prime}$ & $.657^{4}$ \\
\hline & Sig. (2-tailed) & .136 & & .000 & .000 \\
\hline & $\mathrm{N}$ & 241 & 242 & 242 & 241 \\
\hline \multirow[t]{3}{*}{ PharmiLevel } & Pearson Correlation & .053 & $-231^{2 \prime}$ & 1 & -.112 \\
\hline & Sig. (2-tailed) & 415 & .000 & & .083 \\
\hline & $\mathrm{N}$ & 241 & 242 & 242 & 241 \\
\hline \multirow[t]{3}{*}{ N3ATIPharm2 } & Pearson Correlation & .007 & $.657^{n}$ & -.112 & 1 \\
\hline & Sig, (2-tailed) & 912 & .000 & .083 & \\
\hline & $\mathrm{N}$ & 243 & 241 & 241 & 244 \\
\hline \multirow[t]{3}{*}{ Pharm2Lewel } & Pearson Corrolation & $.152^{\circ}$ & .094 & $.53 B^{2}$ & .005 \\
\hline & Sig. (2-tailed) & .018 &, 145 & .000 & .937 \\
\hline & $\mathrm{N}$ & 243 & 241 & 241 & 244 \\
\hline \multirow[t]{3}{*}{ NAATIMedSurg } & Pearson Correlation & -.021 & $455^{\prime \prime}$ & .006 & $.531^{4}$ \\
\hline & Sig. (2-talled) & .752 & .000 & .929 & .000 \\
\hline & $\mathrm{N}$ & 239 & 237 & 237 & 239 \\
\hline \multirow[t]{3}{*}{ MedSurgLevei } & Pearson Correlation & .094 & $.231^{\prime \prime}$ & .020 & -.407 \\
\hline & Sig (2-tailed) & .146 & .000 & .781 & .000 \\
\hline & $\mathrm{N}$ & 239 & 237 & 237 & 239 \\
\hline \multirow[t]{3}{*}{ N5ATIPeds } & Poarson Correlation & -088 & $472^{21}$ &., 066 & $.538^{\circ}$ \\
\hline & Sig: (2-tailed) & .172 & .000 & 303 & .000 \\
\hline & $\mathrm{N}$ & 244 & 242 & 242 & 244 \\
\hline
\end{tabular}


Correlations

\begin{tabular}{|c|c|c|c|c|c|}
\hline & & Pharm2Level & $\begin{array}{l}\text { NAATIMedSur } \\
\mathrm{g}\end{array}$ & MedSurglevel & NSATIPeds \\
\hline \multirow[t]{3}{*}{ ABEng1A } & Pearson Correlation & .029 & .030 & .040 & .094 \\
\hline & Sig. (2-tailed) & 658 & .649 & .548 & .154 \\
\hline & $\mathrm{N}$ & 233 & 229 & 229 & 234 \\
\hline \multirow[t]{3}{*}{ As0CriticalTh } & Pearson Correlation & .011 & .010 & .030 & 045 \\
\hline & Sig. (2-tailed) & 866 & 881 & .647 & .496 \\
\hline & $\mathrm{N}$ & 233 & 229 & 229 & 234 \\
\hline \multirow[t]{3}{*}{ A9Math11 } & Pearson Correlation & $-172^{2+}$ & .106 & .048 & .079 \\
\hline & Sig. (2-tailed) & .008 & 113 & .466 & .231 \\
\hline & $\mathbf{N}$ & 233 & 229 & 229 & 234 \\
\hline \multirow[t]{3}{*}{ A2PrereqGPA } & Pearson Correlation & .005 & .022 & $=009$ & .118 \\
\hline & Sig (2-tailed) & .933 &, 740 & 889 & .070 \\
\hline & $\mathrm{N}$ & 235 & 231 & 231 & 238 \\
\hline \multirow[t]{3}{*}{ N1ATifund } & Pearson Correlation & .063 & $.505^{2 \pi}$ & $-322^{\prime \prime}$ & $507^{\circ}$ \\
\hline & Sig- (2-tailed) & 330 & .000 & .000 & .000 \\
\hline & $\mathrm{N}$ & 243 & 239 & 239 & 244 \\
\hline \multirow[t]{3}{*}{ FundLevel } & Pearson Correlation & $.152^{\circ}$ & -.021 & .094 & .088 \\
\hline & Sig. (2-tailed) & .018 & .752 & .146 & -172 \\
\hline & $\mathrm{N}$ & 243. & 239 & 239 & 244 \\
\hline \multirow[t]{3}{*}{ N2ATIPharm1 } & Pearson Correlation & -.094 & $455^{n}$ & $-231^{27}$ & $472^{21}$ \\
\hline & Sig. (2-talled) & .145 & .000 & .000 & .000 \\
\hline & $\mathrm{N}$ & 241 & 237 & 237 & 242 \\
\hline \multirow[t]{3}{*}{ Pharm1Level } & Pearson Correlation & $538^{2+}$ & .006 & .020 & .066 \\
\hline & Sig. (2-tailed) &, 000 & .929 & .761 & 303 \\
\hline & $\mathrm{N}$ & 241 & 237 & 237 & 242 \\
\hline \multirow[t]{3}{*}{ N3ATIPharm2 } & Pearson Correlation & -.005 & $531^{\prime \prime}$ & $-407^{21}$ & $.538^{21}$ \\
\hline & Sig. (2-tailed) & .937 & .000 & .000 & .000 \\
\hline & $\mathrm{N}$ & 244 & 239 & 239 & 244 \\
\hline \multirow[t]{3}{*}{ Pharm2Level } & Pearson Correlation & 1 & .011 & $.147^{\circ}$ & .004 \\
\hline & Sig. (2-tailed) & & 866 & .023 & .949 \\
\hline & $\mathrm{N}$ & 244 & 239 & 239 & 244 \\
\hline \multirow[t]{3}{*}{ N4ATIMedSurg } & Pearson Correlation & .011 & 1 & $-.504^{21}$ & $458^{\circ}$ \\
\hline & Sig. (2-tailod) & 866 & & .000 & .000 \\
\hline & $\mathrm{N}$ & 239 & 240 & 240 & 240 \\
\hline \multirow[t]{3}{*}{ MedSurgLevel } & Pearson Correlation & $.147^{\circ}$ & -.504 & 1 & $-318^{\prime \prime}$ \\
\hline & Sig. (2-tailed) & .023 & .000 & & .000 \\
\hline & $\mathrm{N}$ & 239 & 240 & 240 & 240 \\
\hline \multirow[t]{3}{*}{ N5ATIPeds } & Pearson Correlation & .004 & $458^{-7}$ & $-318^{2}$ & 1 \\
\hline & Sig-(2-tailed) & 949 & .000 & .000 & \\
\hline & $\mathrm{N}$ & 244 & 240 & 240 & 245 \\
\hline
\end{tabular}




\begin{tabular}{|c|c|c|c|c|c|}
\hline \multicolumn{6}{|c|}{ Correlations } \\
\hline & & Pedslevel & n6ATIPsyche & PsychLevel & $\begin{array}{c}\text { N7ATIMatChil } \\
d\end{array}$ \\
\hline \multirow[t]{3}{*}{ A8Eng1A } & Pearson Correlation & .112 & -.014 & $=.070$ & 034 \\
\hline & Sig (2-tailed) & .089 & .833 & .288 & 607 \\
\hline & $\mathrm{N}$ & 232 & 234 & 234 & 233 \\
\hline \multirow[t]{3}{*}{ A10CriticalTh } & Pearson Correlation & .062 & $.140^{\circ}$ & -.045 & -.059 \\
\hline & Sig. (2-tailed) & .346 & .033 & .495 & 372 \\
\hline & $\mathrm{N}$ & 232 & 234 & 234 & 233 \\
\hline \multirow[t]{3}{*}{ AgMath11 } & Pearson Correlation & -.110 & .047 & .072 & $.216^{\prime \prime}$ \\
\hline & Sig. (2-tailed) & .095 & 470 & 275 & .001 \\
\hline & $\mathrm{N}$ & 232 & 234 & 234 & 233 \\
\hline \multirow[t]{3}{*}{ A2PrerogGPA } & Pearson Correlation & -.071 & .040 & -.053 & .100 \\
\hline & Sig. (2.tailed) & .278 & .544 & 418 & 128 \\
\hline & $\mathrm{N}$ & 234 & 236 & 236 & 235 \\
\hline \multirow[t]{3}{*}{ N1ATifund } & Pearson Correlation & $-295^{\circ}$ & $.554^{\circ}$ & $-.180^{-1}$ & $466^{2-}$ \\
\hline & Sig. (2-talled) & .000 & .000 & .003 & .000 \\
\hline & $\mathrm{N}$ & 242 & 244 & 244 & 243 \\
\hline \multirow[t]{3}{*}{ FundLevel } & Pearson Correlation & 125 & -.083 & 089 & $=.137$ \\
\hline & Sig. (2-tailed) & .053 & .197 & 164 & .032 \\
\hline & $\mathrm{N}$ & 242 & 244 & 244 & 243 \\
\hline \multirow[t]{3}{*}{ N2ATIPharm1 } & Pearson Correlation & -.192 & $-454^{\prime \prime}$ & $-232^{n}$ & $.361^{2 \pi}$ \\
\hline & Sig. (2-tailed) & .003 & .000 & .000 & .000 \\
\hline & $\mathrm{N}$ & 240 & 242 & 242 & 241 \\
\hline \multirow[t]{3}{*}{ Pharm1Level } & Pearson Correlation & .047 & -.080 & $217^{\circ}$ & -.051 \\
\hline & Sig- (2-tailed) & .471 & 216 & .001 & .431 \\
\hline & $\mathrm{N}$ & 240 & 242 & 242 & 241 \\
\hline \multirow[t]{3}{*}{ N3ATIPharm2 } & Pearson Correlation & $-.229^{2}$ & $411^{2}$ &,$+ 188^{\prime \prime}$ & $-408^{\prime \prime}$ \\
\hline & Sig. (2-tailed) & .000 &.$\infty 0$ & .003 & .000 \\
\hline & $\mathrm{N}$ & 242 & 244 & 244 & 243 \\
\hline \multirow[t]{3}{*}{ Pharm2Level } & Pearson Correlation & .077 & -.059 & $.267^{-7}$ & -.038 \\
\hline & Sig. (2-tailed) & .235 & 357 & .000 & 554 \\
\hline & $\mathrm{N}$ & 242 & 244 & 244 & 243 \\
\hline \multirow[t]{3}{*}{ N4ATIMedSurg } & Pearson Correlation & $-243^{N+}$ & $420^{2}$ &,$- 131^{\circ}$ & $.460^{\circ}$ \\
\hline & Sig. (2-tailed) & .000 & .000 & 043 & .000 \\
\hline & $\mathrm{N}$ & 238 & 240 & 240 & 240 \\
\hline \multirow[t]{3}{*}{ MedSurgLewel } & Pearson Correlation & $168^{\prime \prime}$ & $-.260^{\prime \prime}$ & $234^{2 \pi}$ & $.341^{2}$ \\
\hline & Sig. (2-tailed) & .009 & .000 & .000 & 000 \\
\hline & $\mathrm{N}$ & 238 & 240 & 240 & 240 \\
\hline \multirow[t]{3}{*}{ N5ATIPeds } & Pearson Correlation & $-.650^{\prime \prime}$ & $498^{\prime \prime}$ & -.096 & $584^{\prime \prime}$ \\
\hline & Sig. (2-tailed) & .000 & .000 & .133 & .000 \\
\hline & $\mathrm{N}$ & 243 & 245 & 245 & 244 \\
\hline
\end{tabular}




\begin{tabular}{|c|c|c|c|c|c|}
\hline \multicolumn{6}{|c|}{ Correlations } \\
\hline & & MatChildLevel & RNcompA2 & Probability4A & RNCompB \\
\hline \multirow{3}{*}{ ABEng1A } & Pearson Correlation & .077 & .035 & .035 & .017 \\
\hline & Sig (2-taled) & .243 & .603 & 606 & .792 \\
\hline & $\mathrm{N}$ & 231 & 220 & 225 & 234 \\
\hline \multirow[t]{3}{*}{ A10CriticalTh } & Pearson Correlation & .042 & .070 & .020 & .083 \\
\hline & Sig. (2-tailed) & .525 & .300 & .769 & .206 \\
\hline & $\mathrm{N}$ & 231 & 220 & 225 & 234 \\
\hline \multirow[t]{3}{*}{ A9Math11 } & Pearson Correlation &,$- 185^{\circ}$ & .048 & .079 & .083 \\
\hline & Sig. (2-tailed) & .012 & .483 & .236 & 203 \\
\hline & $\mathrm{N}$ & 231 & 220 & 225 & 234 \\
\hline \multirow[t]{3}{*}{ A2PrereqGPA } & Pearson Correlation & .012 & -.043 & .034 & .016 \\
\hline & Sig. (2-tailed) & .852 & .519 & .613 & 810 \\
\hline & $\mathrm{N}$ & 233 & 222 & 227 & 236 \\
\hline \multirow[t]{3}{*}{ N1ATifund } & Pearson Correlation & $.246^{27}$ & $.375^{-1}$ & $.498^{\prime \prime}$ & $.625^{n+}$ \\
\hline & Sig, (2-tailed) & .000 & .000 & .000 & .000 \\
\hline & $\mathrm{N}$ & 241 & 231 & 236 & 243 \\
\hline \multirow[t]{3}{*}{ Fundlevel } & Pearson Corrclation & $.167^{4}$ & .043 &,$- 184^{\circ}$ & -100 \\
\hline & Sig. (2-tailed) & .010 & .514 & .012 & .121 \\
\hline & $\mathrm{N}$ & 241 & 231 & 236 & 243 \\
\hline \multirow[t]{3}{*}{ N2ATIPharm1 } & Pearson Correlation & $-.239^{\prime \prime}$ & $337^{\prime \prime}$ & $.465^{+1}$ & $.570^{\circ 1}$ \\
\hline & Sig. (2-tailed) & .000 & .000 & .000 & .000 \\
\hline & N & 239 & 228 & 233 & 242 \\
\hline \multirow[t]{3}{*}{ Pharm1Level } & Pearson Correlation & .102 & .042 &,- 121 & $-129^{\circ}$ \\
\hline & Sig. (2-tailed) & .118 & .525 & .065 & .045 \\
\hline & N & 239 & 228 & 233 & 242 \\
\hline \multirow[t]{3}{*}{ N3ATIPharm2 } & Pearson Correlation & $-244^{-1}$ & $423^{27}$ & $561^{2}$ & $612^{2}$ \\
\hline & Sig. (2-tailed) & .000 & .000 & .000 & .000 \\
\hline & $\mathrm{N}$ & 241 & 230 & 235 & 243 \\
\hline \multirow[t]{3}{*}{ Pharm2Level } & Pearson Correlation & .078 & .027 & -.085 & -.072 \\
\hline & Sig. (2-tailed) & .229 & 681 & .193 & .260 \\
\hline & $\mathrm{N}$ & 241 & 230 & 235 & 243 \\
\hline \multirow[t]{3}{*}{ N4ATIMedSurg } & Pearson Correlation & $-268^{21}$ & $426^{27}$ & $650^{\prime \prime}$ & $619^{\prime \prime}$ \\
\hline & Sig (2-tailed) & .000 & $\infty, \infty$ & .000 & .000 \\
\hline & $\mathrm{N}$ & 238 & 230 & 234 & 239 \\
\hline \multirow[t]{3}{*}{ MedSurgLevel } & Pearson Correlation & $300^{\prime \prime}$ & $-.304^{\prime \prime}$ & $-496^{\prime \prime}$ & -436 \\
\hline & Sig. (2-tailed) & .000 & .000 & .000 & .000 \\
\hline & $\mathrm{N}$ & 238 & 230 & 234 & 239 \\
\hline \multirow[t]{3}{*}{ N5ATIPeds } & Pearson Correlation & $.299^{\prime \prime}$ & $.386^{11}$ & $540^{\circ}$ & $.561^{1 "}$ \\
\hline & Sig. (2-tailed) & .000 & .000 & .000 & .000 \\
\hline & $\mathrm{N}$ & 242 & 231 & 236 & 244 \\
\hline
\end{tabular}




\begin{tabular}{|c|c|c|c|}
\hline & & \multicolumn{2}{|c|}{ Corrolations } \\
\hline & & Probability 48 & NCLEX1st \\
\hline \multirow{3}{*}{ A.8Eng1A } & Pearson Correlation & -.023 & .069 \\
\hline & Sig. (2-taled) & .721 & .290 \\
\hline & $\mathrm{N}$ & 234 & 234 \\
\hline \multirow[t]{3}{*}{ A10CriticarTh } & Pearson Correlation & .056 & .001 \\
\hline & Sig. (2-tailed) & .390 & 984 \\
\hline & $\mathrm{N}$ & 234 & 234 \\
\hline \multirow[t]{3}{*}{ A9Math11 } & Pearson Correlation & .071 & -.076 \\
\hline & Sig (2-talled) & 278 & 248 \\
\hline & $\mathrm{N}$ & 234 & 234 \\
\hline \multirow[t]{3}{*}{ A2PrereqGPA } & Pearson Correlation & -.018 & .057 \\
\hline & Sig. (2-tailed) & .780 & .386 \\
\hline & $\mathrm{N}$ & 236 & 236 \\
\hline \multirow[t]{3}{*}{ N1ATItund } & Pearson Corretation & $.670^{\circ}$ & $-251^{2}$ \\
\hline & Sig. (2-tailed) & .000 & .000 \\
\hline & $\mathrm{N}$ & 243 & 244 \\
\hline \multirow[t]{3}{*}{ FundLevel } & Pearson Correlation & $-164^{\circ}$ & .085 \\
\hline & Sig. (2-talied) & .011 & .138 \\
\hline & $\mathrm{N}$ & 243 & 244 \\
\hline \multirow[t]{3}{*}{ N2ATIPharm1 } & Pearson Correlation & $.511^{21}$ & $.386^{\circ}$ \\
\hline & Sig. (2-tailed) & .000 & .000 \\
\hline & $\mathrm{N}$ & 242 & 242 \\
\hline \multirow[t]{3}{*}{ Pharm1Level } & Pearson Correlation & $-146^{\circ}$ & $344^{2}$ \\
\hline & Sig (2-tailed) & .023 & .000 \\
\hline & $\mathrm{N}$ & 242 & 242 \\
\hline \multirow[t]{3}{*}{ N3ATIPharm2 } & Pearson Correlation & $.549^{\prime \prime}$ & $-.357^{-1}$ \\
\hline & Sig. (2-talied) & .000 & .000 \\
\hline & $\mathrm{N}$ & 243 & 244 \\
\hline \multirow[t]{3}{*}{ Pharm2Level } & Pearson Correlation & -.111 & $.195^{4}$ \\
\hline & Sig, (2-tailed) & .085 & 002 \\
\hline & $\mathrm{N}$ & 243 & 244 \\
\hline \multirow[t]{3}{*}{ N4ATIMedSurg } & Pearson Correlation & $584^{2}$ & $-.282^{-1}$ \\
\hline & Sig. (2-tailed) & .000 & .000 \\
\hline & $\mathrm{N}$ & 239 & 240 \\
\hline \multirow[t]{3}{*}{ MedSurgLevel } & Pearson Correlation & $-.485^{\prime \prime}$ & $.172^{4}$ \\
\hline & Sig. (2-tailed) & .000 & .008 \\
\hline & $\mathrm{N}$ & 239 & 240 \\
\hline \multirow[t]{3}{*}{ N5ATIPeds } & Pearson Correlation & $.508^{21}$ & $.288^{\prime \prime}$ \\
\hline & Sig. (2-tailed) & .000 & 000 \\
\hline & $\mathrm{N}$ & 244 & 245 \\
\hline
\end{tabular}


Correlations

\begin{tabular}{|c|c|c|c|c|c|}
\hline & 4 & A1GPAb4Nsn & $\begin{array}{c}\text { A11CompTEA } \\
\mathrm{S}\end{array}$ & A12Readteas & A15EngTEAS \\
\hline \multirow[t]{3}{*}{ Pedslevel } & Pearson Correlation & -.112 & .083 & $-170^{\circ}$ & .069 \\
\hline & Sig. (2-tailed) & .091 & 200 & .011 & 311 \\
\hline & $\mathrm{N}$ & 229 & 239 & 221 & 220 \\
\hline \multirow[t]{3}{*}{ nEATIPsyche } & Pearson Correlation & 110 & $481^{\prime \prime}$ & $314^{2}$ & $303^{21}$ \\
\hline & Sig. (2-tailed) & .084 & .000 & .000 & .000 \\
\hline & $\mathrm{N}$ & 231 & 241 & 223 & 222 \\
\hline \multirow[t]{3}{*}{ PsychLevel } & Pearson Correlation & -.124 & $-258^{\prime \prime}$ & -.110 & $-.156^{\circ}$ \\
\hline & Sig. (2-tailed) & .060 & .000 & .101 & .020 \\
\hline & $\mathrm{N}$ & 231 & 241 & 223 & 222 \\
\hline \multirow[t]{3}{*}{ N7ATIMatChild } & Pesrson Correlation & $207^{m}$ & $333^{21}$ & $365^{21}$ & $.159^{\circ}$ \\
\hline & Sig. (2-tailed) & .002 &, 000 & .000 & .018 \\
\hline & $\mathrm{N}$ & 230 & 240 & 222 & 221 \\
\hline \multirow[t]{3}{*}{ MatChildLevel } & Pearson Correlation & -.080 & $-240^{-1}$ & $-.286^{21}$ & -.078 \\
\hline & Sig, (2-tailed) & 229 & .000 &, 000 & 248 \\
\hline & $\mathrm{N}$ & 228 & 238 & 220 & 219 \\
\hline \multirow[t]{3}{*}{ RNcompA2 } & Pearson Correlation & .103 & $370^{\prime \prime}$ & $244^{27}$ & $236^{12}$ \\
\hline & Sig. (2-tailed) & .129 & .000 & 000 & .001 \\
\hline & $\mathrm{N}$ & 217 & 227 & 209 & 208 \\
\hline \multirow[t]{3}{*}{ Probabdity4A } & Pearson Correlation & $.148^{2}$ & $.516^{2+}$ & $4255^{2+}$ & $339^{\circ}$ \\
\hline & Sig. (2-tailed) & .028 & .000 & 000 & .000 \\
\hline & $\mathrm{N}$ & 222 & 232 & 214 & 213 \\
\hline \multirow[t]{3}{*}{ RNCompB } & Pearson Correlation & $.185^{12}$ & $.530^{\prime \prime}$ & $480^{\prime \prime}$ & $.392^{\prime \prime}$ \\
\hline & Sig. (2-tailed) & .005 & .000 & 000 & .000 \\
\hline & $\mathrm{N}$ & 231 & 240 & 222 & 221 \\
\hline \multirow[t]{3}{*}{ Probability 48} & Pearson Correlation & $.169^{\prime}$ & $.503^{\prime \prime}$ & $441^{21}$ & $382^{12}$ \\
\hline & Sig- (2-tailed) & .010 & .000 & .000 & .000 \\
\hline & $N$ & 231 & 240 & 222 & 221 \\
\hline \multirow[t]{3}{*}{ NCLEX1st } & Pearson Correlation & -.043 & $-201^{-7}$ & $-176^{\circ}$ & -.054 \\
\hline & Sig. (2-tailed) & 514 & .002 & .009 & 424 \\
\hline & $N$ & 231 & 241 & 223 & 222 \\
\hline
\end{tabular}


Correlations

\begin{tabular}{|c|c|c|c|c|c|}
\hline & & A13MathTEAS & $\begin{array}{c}\text { A14ScienTEA } \\
\mathrm{S} \\
\end{array}$ & A3Chem $3 A$ & A.4Anatomy \\
\hline \multirow[t]{3}{*}{ PedsLevel } & Pearson Correlation & -.012 & -.066 & -.101 & $=137$ \\
\hline & Sig. (2-tailed) & .859 & .328 & 124 & 037 \\
\hline & $\mathrm{N}$ & 221 & 220 & 233 & 232 \\
\hline \multirow[t]{3}{*}{ nGATIPsyche } & Pearson Correlation & $.419^{\prime \prime}$ & $.434^{\prime \prime}$ & .019 & $218^{21}$ \\
\hline & Sig. (2-talied) & .000 & .000 & .776 & .001 \\
\hline & N & 223 & 222 & 235 & 234 \\
\hline \multirow[t]{3}{*}{ Psychlevel } & Pesrson Correlation &,$- 157^{\circ}$ & $-.208^{21}$ & -123 & .049 \\
\hline & Sig. (2-tailed) & 019 & .002 & .060 & 459 \\
\hline & $\mathrm{N}$ & 223 & 222 & 235 & 234 \\
\hline \multirow[t]{3}{*}{ N7ATIMatChild } & Pearson Correlation & $199^{\circ}$ & $.231^{* 1}$ & .010 & .089 \\
\hline & Sig. (2-tailed) & .003 & .001 & .873 & .174 \\
\hline & $\mathrm{N}$ & 222 & 221 & 234 & 233 \\
\hline \multirow[t]{3}{*}{ MatChildLevel } & Pearson Correlation & $=.136^{\prime}$ &,$- 149^{2}$ & .001 & .014 \\
\hline & Sig. (2-tailed) & .044 & .027 & .990 & 831 \\
\hline & $\mathrm{N}$ & 220 & 219 & 232 & 231 \\
\hline \multirow[t]{3}{*}{ RNoompA2 } & Pearson Correlation & $.266^{2+}$ & $283^{27}$ & -.039 & .131 \\
\hline & Sig. (2-tailed) & .000 & .000 & .560 & .053 \\
\hline & $\mathrm{N}$ & 209 & 208 & 221 & 220 \\
\hline \multirow[t]{3}{*}{ Probability $4 A$} & Pearson Correlation & 322 & $.390^{\prime \prime}$ & .014 & .158 \\
\hline & Sig. (2-tailed) & .000 & .000 & .832 & .018 \\
\hline & $\mathrm{N}$ & 214 & 213 & 226 & 225 \\
\hline \multirow[t]{3}{*}{ RNCompB } & Pearson Correlation & $.332^{2 \pi}$ & $.531^{21}$ & .042 & .122 \\
\hline & Sig-(2-tailed) & .000 & .000 & .521 & .062 \\
\hline & $\mathrm{N}$ & 222 & 221 & 235 & 234 \\
\hline \multirow[t]{3}{*}{ Probability $4 \mathrm{~B}$} & Pearson Correlation & $289^{*}$ & $.492^{-1}$ & .004 & .071 \\
\hline & Sig. (2-tailed) & .000 & .000 & .945 & .281 \\
\hline & $\mathrm{N}$ & 222 & 221 & 235 & 234 \\
\hline \multirow[t]{3}{*}{ NCLEX1st } & Pearson Correlation & $-150^{\circ}$ & $-.215^{\prime \prime}$ & .061 & .006 \\
\hline & Sig- (2-tailed) & .025 & .001 & 364 & .931 \\
\hline & $\mathrm{N}$ & 223 & 222 & 235 & 234 \\
\hline
\end{tabular}


Correlations

\begin{tabular}{|c|c|c|c|c|c|}
\hline & & A5Physiology & $\begin{array}{c}\text { AbAlicrobiolog } \\
y\end{array}$ & A7Comm3 & ABEng $1 \mathrm{~A}$ \\
\hline \multirow[t]{3}{*}{ PedsLevel } & Pearson Correlation & $-.180^{\circ}$ & -.037 & .025 & 112 \\
\hline & Sig- (2-tailed) & .006 & .575 & .706 & .089 \\
\hline & $N$ & 232 & 232 & 232 & 232 \\
\hline \multirow[t]{3}{*}{ n6ATIPsyche } & Pearson Correlation & $214^{\prime \prime}$ & 109 & .023 & .014 \\
\hline & Sig (2-tailed) & .001 & .096 & .728 & 833 \\
\hline & $\mathrm{N}$ & 234 & 234 & 234 & 234 \\
\hline \multirow[t]{3}{*}{ Psychlevel } & Pearson Correlation & -.012 & -.027 & .049 & -.070 \\
\hline & Sig. (2-tailed) & 851 & 681 & .452 & 288 \\
\hline & $\mathrm{N}$ & 234 & 234 & 234 & 234 \\
\hline \multirow[t]{3}{*}{ N7ATIMatChild } & Pearson Correlation & -110 & .119 & $.130^{\circ}$ & .034 \\
\hline & Sig. (2-tailed) & .093 & .069 & .047 & .607 \\
\hline & $\mathrm{N}$ & 233 & 233 & 233 & 233 \\
\hline \multirow[t]{3}{*}{ MatChildLevel } & Pearson Correlation & -.056 & .087 &,- 097 & .077 \\
\hline & Sig. (2-tailed) & .403 & 187 & 141 & 243 \\
\hline & $\mathrm{N}$ & 231 & 231 & 231 & 231 \\
\hline \multirow[t]{3}{*}{ RiNcompA2 } & Pearson Correlation & .058 & -.026 & .072 & .035 \\
\hline & Sig- (2-talled) & 396 & .697 & .291 & .603 \\
\hline & $N$ & 220 & 220 & 220 & 220 \\
\hline \multirow[t]{3}{*}{ Probability4A } & Pesrson Correlation & .059 & .077 & .076 & .035 \\
\hline & Sig- (2-tailed) & 379 & .247 & .259 & .608 \\
\hline & $\mathrm{N}$ & 225 & 225 & 225 & 225 \\
\hline \multirow[t]{3}{*}{ RNCompB } & Pearson Correlation & .003 & .104 & .009 & .017 \\
\hline & Sig- (2-tailed) & .967 & .112 & .889 & .792 \\
\hline & $N$ & 234 & 234 & 234 & 234 \\
\hline \multirow[t]{3}{*}{ Probablity48 } & Pearson Correlation & -.029 & .073 & -.007 & -.023 \\
\hline & Sig- (2-tailed) & .664 & .268 & .919 & .721 \\
\hline & $\mathrm{N}$ & 234 & 234 & 234 & 234 \\
\hline \multirow[t]{3}{*}{ NCLEX1st } & Pearson Correlation & -106 &,- 082 & $-204^{\prime \prime}$ & .069 \\
\hline & Sig. (2-tailed) & 107 & .213 & .002 & 290 \\
\hline & $\mathrm{N}$ & 234 & 234 & 234 & 234 \\
\hline
\end{tabular}




\begin{tabular}{|c|c|c|c|c|c|}
\hline \multicolumn{6}{|c|}{ Correlations } \\
\hline & & A10Criticalm & A9Math11 & A2PrereqGPA & N1ATIfund \\
\hline \multirow[t]{3}{*}{ PedsLevel } & Pearson Correlation & .062 & -1110 & -071 & $.295^{2}$ \\
\hline & Sig. (2-tailed) & 346 & .095 & 278 & .000 \\
\hline & $\mathrm{N}$ & 232 & 232 & 234 & 242 \\
\hline \multirow[t]{3}{*}{ neATIPsyche } & Pearson Correlation & $140^{\circ}$ & .047 & .040 & 554 \\
\hline & Sig (2-talled) & .033 & .470 & .544 & .000 \\
\hline & $\mathrm{N}$ & 234 & 234 & 236 & 244 \\
\hline \multirow[t]{3}{*}{ PsychLevel } & Pearson Correlation & .045 & .072 & .053 & $-.190^{4}$ \\
\hline & Sig (2-taied) & .495 & .275 & .418 &, 003 \\
\hline & $\mathrm{N}$ & 234 & 234 & 233 & 244 \\
\hline \multirow[t]{3}{*}{ N7ATIMatChild } & Pearson Correlation & -059 & $.216^{2 \pi}$ & .100 & .466 \\
\hline & Sig (2-tailed) & 372 & .001 & 128 & .000 \\
\hline & $\mathrm{N}$ & 233 & 233 & 235 & 243 \\
\hline \multirow[t]{3}{*}{ MatChildLevel } & Pearson Correlation & .042 &. $.165^{\circ}$ & .012 & $-246^{\prime \prime}$ \\
\hline & Sig. (2-tailed) & .525 & .012 & .852 & .000 \\
\hline & $\mathrm{N}$ & 231 & 231 & 233 & 241 \\
\hline \multirow[t]{3}{*}{ RNcompA2 } & Pearson Correlation & .070 & .048 & .043 & $375^{2}$ \\
\hline & Sig. (2-tailed) & 300 & .483 & .519 & .000 \\
\hline & $\mathrm{N}$ & 220 & 220 & 222 & 231 \\
\hline \multirow[t]{3}{*}{ Probability 4 A } & Pearson Corrolation & .020 & .079 & 034 & $.498^{\prime \prime}$ \\
\hline & Sig. (2-tailed) & .769 & .238 & .613 & .000 \\
\hline & $\mathrm{N}$ & 225 & 225 & 227 & 236 \\
\hline \multirow[t]{3}{*}{ RNCompB } & Pearson Correlation & .083 & .083 & 016 & $.625^{\circ}$ \\
\hline & Sig. (2-tailed) & .208 & .203 & 810 & .000 \\
\hline & $\mathrm{N}$ & 234 & 234 & 236 & 243 \\
\hline \multirow[t]{3}{*}{ Probsbility48 } & Pearson Correlation & .056 & .071 & .018 & $.570^{27}$ \\
\hline & Sig (2-tailed) & 390 & .278 & .780 & .000 \\
\hline & $\mathrm{N}$ & 234 & 234 & 236 & 243 \\
\hline \multirow[t]{3}{*}{ NCLEX1st } & Pearson Correlation & .001 & -.076 & -.057 & $-.251^{\prime \prime}$ \\
\hline & Sig. (2-tailed) & .984 & .248 & 386 & .000 \\
\hline & $\mathrm{N}$ & 234 & 234 & 236 & 244 \\
\hline
\end{tabular}




\begin{tabular}{|c|c|c|c|c|c|}
\hline \multicolumn{6}{|c|}{ Correlations } \\
\hline & & Fundlevel & N2ATIPharm1 & Pharm1Level & N3ATIPharm2 \\
\hline \multirow[t]{3}{*}{ PedisLevel } & Pearson Correlation & .125 & $-192^{\prime \prime}$ & 047 & $.229^{11}$ \\
\hline & Sig. (2-talled) & .053 & .003 & .471 & .000 \\
\hline & $\mathrm{N}$ & 242 & 240 & 240 & 242 \\
\hline \multirow[t]{3}{*}{ n6ATIPsyche } & Pearson Correlation & .003 & $454^{\prime \prime}$ & -.080 & $411^{2 \pi}$ \\
\hline & Sig. (2-tailed) & .197 & .000 & .215 & .000 \\
\hline & $\mathrm{N}$ & 244 & 242 & 242 & 244 \\
\hline \multirow[t]{3}{*}{ Psychlevel } & Pearson Correlation & .089 & $-232^{\prime \prime}$ & $217^{\prime \prime}$ & $-188^{\prime \prime}$ \\
\hline & Sig. (2-tailed) & .164 & .000 & .001 & .003 \\
\hline & $\mathrm{N}$ & 244 & 242 & 242 & 244 \\
\hline \multirow[t]{3}{*}{ N7ATIMatChild } & Pearson Comrelation & $-137^{\circ}$ & $361^{21}$ & -051 & $408^{-1}$ \\
\hline & Sig. (2-tailed) & .032 & .000 & .431 & .000 \\
\hline & $\mathrm{N}$ & 243 & 241 & 241 & 243 \\
\hline \multirow[t]{3}{*}{ MatChildLevel } & Pearson Cocrelation & $.167^{-2}$ & $-239^{\prime \prime}$ & .102 & $.244^{\prime \prime}$ \\
\hline & Sig. (2-tailed) & .010 & .000 & .118 & .000 \\
\hline & $\mathrm{N}$ & 241 & 239 & 239 & 241 \\
\hline \multirow[t]{3}{*}{ RNcompA2 } & Pearson Correlation & .043 & $.337^{\prime \prime}$ & .042 & $423^{m}$ \\
\hline & Sig. (2-tailed) & .514 & .000 & .525 & .000 \\
\hline & $\mathrm{N}$ & 231 & 228 & 228 & 230 \\
\hline \multirow[t]{3}{*}{ Probability4A } & Pearson Correlation & $-164^{4}$ & $465^{4}$ & -.121 & 5611 \\
\hline & Sig. (2-tailed) & .012 & .000 & .065 & .000 \\
\hline & $\mathrm{N}$ & 236 & 233 & 233 & 235 \\
\hline \multirow[t]{3}{*}{ RNCompB } & Pearson Correlation & -.100 & $.570^{\circ}$ & $-129^{\circ}$ & $.612^{\prime \prime}$ \\
\hline & Sig (2-tailed) & .121 & .000 & .045 & .000 \\
\hline & $\mathrm{N}$ & 243 & 242 & 242 & 243 \\
\hline \multirow[t]{3}{*}{ Probability48 } & Pearson Correlation & $-164^{\prime}$ & $.511^{2}$ & $-146^{\circ}$ & $549^{\prime \prime}$ \\
\hline & Sig- (2-tailed) & .011 & .000 & .023 & .000 \\
\hline & $\mathrm{N}$ & 243 & 242 & 242 & 243 \\
\hline \multirow[t]{3}{*}{ NCLEX1st } & Pearson Correlation & .095 & $-390^{2}$ & $.344^{-1}$ & $-357^{-1}$ \\
\hline & Sig. (2-tailed) & .138 & .000 & .000 & .000 \\
\hline & $\mathrm{N}$ & 244 & 242 & 242 & 244 \\
\hline
\end{tabular}


Correlations

\begin{tabular}{|c|c|c|c|c|c|}
\hline & & Pharm2Level & $\begin{array}{c}\text { N4ATIMedSur } \\
\mathrm{g}\end{array}$ & MedSurgLewel & N5ATIPeds \\
\hline \multirow[t]{3}{*}{ Pedslevel } & Pearson Correlation & .077 & $-243^{11}$ & $.168^{11}$ & $-.650^{\prime \prime}$ \\
\hline & Sig. (2-talled) & .235 & .000 & .009 & .000 \\
\hline & $\mathrm{N}$ & 242 & 238 & 238 & 243 \\
\hline \multirow[t]{3}{*}{ n6ATIPsyche } & Pearson Correlation &. .059 & $.420^{\prime \prime}$ & $.280^{\circ}$ & $498^{27}$ \\
\hline & Sig-(2-tailed) & .357 & .000 & .000 & .000 \\
\hline & $\mathrm{N}$ & 244 & 240 & 240 & 245 \\
\hline \multirow[t]{3}{*}{ Psychlevel } & Pearson Correlation & $.287^{+2}$ & $-.131^{\circ}$ & $.234^{+}$ & -.096 \\
\hline & Sig. (2-tailed) & .000 & .043 & .000 & .133 \\
\hline & $\mathrm{N}$ & 244 & 240 & 240 & 245 \\
\hline \multirow[t]{3}{*}{ N7ATIMatChild } & Pearson Correlation & -.038 & $.460^{\prime \prime}$ & $-341^{4}$ & $584^{2}$ \\
\hline & Sig- (2-tailed) & .554 &, 000 & .000 & 000 \\
\hline & $\mathrm{N}$ & 243 & 240 & 240 & 244 \\
\hline \multirow[t]{3}{*}{ MatChildLevel } & Pearson Correlation & .078 & $-268^{n}$ & $300^{-\pi}$ & $-299^{\prime \prime}$ \\
\hline & Sig (2-tailed) & .229 & .000 & .000 & .000 \\
\hline & $\mathrm{N}$ & 241 & 238 & 238 & 242 \\
\hline \multirow[t]{3}{*}{ RNiocmpA2 } & Pearson Correlation & -.027 & $.426^{N+}$ & $-304^{27}$ & $366^{2 \pi}$ \\
\hline & Sig. (2-talled) & 681 & .000 & .000 & .000 \\
\hline & $\mathrm{N}$ & 230 & 230 & 230 & 231 \\
\hline \multirow[t]{3}{*}{ Probability $4 \mathrm{~A}$} & Pearson Correlation & .086 & $650^{\mathrm{m}}$ & $.496^{24}$ & $540^{21}$ \\
\hline & Sig. (2-tailed) & 193 &, 000 & .000 & .000 \\
\hline & $\mathrm{N}$ & 235 & 234 & 234 & 236 \\
\hline \multirow[t]{3}{*}{ RNCompB } & Pearson Correlation & -.072 & $619^{\prime \prime}$ & $-436^{21}$ & $.561^{2 \pi}$ \\
\hline & Sig, (2-tailed) & 260 & .000 & .000 & .000 \\
\hline & $\mathrm{N}$ & 243 & 239 & 239 & 244 \\
\hline \multirow[t]{3}{*}{ Probability $4 \mathrm{~B}$} & Pearson Correlation & -111 & $.584^{\prime \prime}$ & $-.495^{\prime \prime}$ & $.508^{m}$ \\
\hline & Sig. (2-tailed) & .085 & .000 & .000 & .000 \\
\hline & $\mathrm{N}$ & 243 & 239 & 239 & 244 \\
\hline \multirow[t]{3}{*}{ NCLEX1st } & Pearson Correlation & $.196^{22}$ & $-282^{21}$ & $172^{27}$ & $-.288^{+7}$ \\
\hline & Sig. (2-tailed) & .002 & .000 &, 008 & .000 \\
\hline & $\mathrm{N}$ & 244 & 240 & 240 & 245 \\
\hline
\end{tabular}




\begin{tabular}{|c|c|c|c|c|c|}
\hline \multicolumn{6}{|c|}{ Correlations } \\
\hline & & PedsLevel & n6ATIPsyche & Psychlovel & $\begin{array}{c}\text { N7ATIMatChil } \\
d\end{array}$ \\
\hline \multirow[t]{3}{*}{ PedsLevel } & Pearson Correlation & 1 & -.278 & .036 & $-.385^{\prime \prime}$ \\
\hline & Sig (2-talled) & & .000 & .571 & .000 \\
\hline & $\mathrm{N}$ & 243 & 243 & 243 & 242 \\
\hline \multirow[t]{3}{*}{ nEATIPsyche } & Pearson Correlation & -.278 & 1 & $-279^{\prime \prime}$ & $.449^{\prime \prime}$ \\
\hline & Sig. (2-tailed) & .000 & & .000 & .000 \\
\hline & $\mathrm{N}$ & 243 & 246 & 245 & 244 \\
\hline \multirow[t]{3}{*}{ Psychleevel } & Pearson Correlation & .036 & $-279^{\prime \prime}$ & 1 & $-.165^{27}$ \\
\hline & Sig. (2-tailed) & .571 & .000 & & .010 \\
\hline & $\mathrm{N}$ & 243 & 245 & 245 & 244 \\
\hline \multirow[t]{3}{*}{ N7ATIMatChild } & Pearson Correlation & $-.385^{\prime \prime}$ & $449^{\prime \prime}$ & $-185^{2+}$ & 1 \\
\hline & Sig (2-tailed) & .000 & .000 & .010 & \\
\hline & $\mathrm{N}$ & 242 & 244 & 244 & 244 \\
\hline \multirow[t]{3}{*}{ MatChildLevel } & Pearson Correlation & 306 & $-.232^{\prime \prime}$ & .093 & -.505 \\
\hline & Sig (2-talied) & .000 & .000 & .150 & .000 \\
\hline & $\mathrm{N}$ & 240 & 242 & 242 & 242 \\
\hline \multirow[t]{3}{*}{ RNcompA2 } & Pearson Correlation &,$- 172^{\prime \prime}$ & $341^{\prime \prime}$ &,- 128 & $31 \theta^{\prime \prime}$ \\
\hline & Sig. (2-taled) & .009 & .000 & .052 & .000 \\
\hline & $\mathrm{N}$ & 229 & 231 & 231 & 231 \\
\hline \multirow[t]{3}{*}{ Probability4A } & Pearson Correlation & -364 & $453^{\prime \prime}$ &,$- 187^{-\infty}$ & $549^{*}$ \\
\hline & Sig (2-tailed) & .000 & .000 & 004 & .000 \\
\hline & $\mathrm{N}$ & 234 & 236 & 236 & 236 \\
\hline \multirow[t]{3}{*}{ RNCompB } & Pearson Correlation & $-.270^{4}$ & $520^{\circ}$ & $-228 "$ & $.543^{\prime \prime}$ \\
\hline & Sig. (2-tailed) & .000 & .000 & .000 & .000 \\
\hline & $\mathrm{N}$ & 242 & 244 & 244 & 243 \\
\hline \multirow[t]{3}{*}{ Probability4B } & Pearson Correlation & $-.254^{21}$ & $.458^{11}$ & $-251^{27}$ & $.516^{\prime \prime}$ \\
\hline & Sig (2-tailed) & .000 & .000 & .000 & .000 \\
\hline & $\mathrm{N}$ & 242 & 244 & 244 & 243 \\
\hline \multirow[t]{3}{*}{ NCLEX Ist } & Pearson Correlation & $.191^{\prime \prime}$ & $-.306^{\prime \prime}$ & $189^{\prime \prime}$ & $-283^{\prime \prime}$ \\
\hline & Sig. (2-talled) & .003 & .000 & .002 & .000 \\
\hline & $\mathrm{N}$ & 243 & 245 & 245 & 244 \\
\hline
\end{tabular}




\begin{tabular}{|c|c|c|c|c|c|}
\hline \multicolumn{6}{|c|}{ Correlations } \\
\hline & & MatChildLevel & RNoompA2 & Probability 4 A & RNCompB \\
\hline \multirow[t]{3}{*}{ Pedistevel } & Pearson Correlation & $306^{12}$ & $-.172^{\prime \prime}$ & $-.364^{2}$ & $-.270^{\circ}$ \\
\hline & Sig. (2-talled) & .000 & .009 & .000 & .000 \\
\hline & $\mathrm{N}$ & 240 & 229 & 234 & 242 \\
\hline \multirow[t]{3}{*}{ n6ATIPsyche } & Pearson Correlation & $-.232^{21}$ & $.341^{\prime \prime}$ & $.453^{2 \prime}$ & $.520^{\circ}$ \\
\hline & Sig. (2-talled) & .000 & .000 & .000 & .000 \\
\hline & $\mathrm{N}$ & 242 & 231 & 236 & 244 \\
\hline \multirow[t]{3}{*}{ Psychlevel } & Pearson Correlation & .093 & -.128 & $-.187^{4}$ & .228 \\
\hline & Sig. (2-tailed) & .150 & .052 & .004 & .000 \\
\hline & $\mathrm{N}$ & 242 & 231 & 236 & 244 \\
\hline \multirow[t]{3}{*}{ N7ATIMatChild } & Pearson Correlation & $-.505^{+1}$ & $.319^{\circ}$ & $.549^{-1}$ & $.543^{\prime \prime}$ \\
\hline & Sig. (2-talied) & .000 & .000 & .000 & .000 \\
\hline & $\mathrm{N}$ & 242 & 231 & 236 & 243 \\
\hline \multirow[t]{3}{*}{ MatChildLevel } & Pearson Correlation & 1 & $-.210^{-17}$ & $.410^{27}$ & $\cdot 333$ \\
\hline & Sig. (2-tailed) & & .001 & .000 & .000 \\
\hline & $\mathrm{N}$ & 242 & 230 & 235 & 241 \\
\hline \multirow[t]{3}{*}{ RNocmpA2 } & Pearson Correlation & $-210^{-1}$ & 1 & $481^{\prime \prime}$ & $4211^{2}$ \\
\hline & Sig. (2-tailed) & .001 & & .000 & .000 \\
\hline & $\mathrm{N}$ & 230 & 231 & 231 & 230 \\
\hline \multirow[t]{3}{*}{ Probablity4A } & Pearson Correlation & $-.410^{4}$ & 481 & 1 & $661^{2}$ \\
\hline & Sig. (2-tailed) & .000 & .000 & & .000 \\
\hline & $\mathrm{N}$ & 236 & 231 & 238 & 235 \\
\hline \multirow[t]{3}{*}{ RNCompB } & Pearson Correlation &., $333^{4}$ & $.421^{21}$ & $661^{21}$ & 1 \\
\hline & Sig. (2-tailed) & .000 & .000 & .000 & \\
\hline & $N$ & 241 & 230 & 235 & 244 \\
\hline \multirow[t]{3}{*}{ Probability 48} & Pearson Correlation & $-.371^{-1}$ & $.377^{\prime \prime}$ & $679^{\prime \prime}$ & $.824^{\prime \prime}$ \\
\hline & Sig. (2-tailed) & .000 & .000 & .000 & .000 \\
\hline & $\mathrm{N}$ & 241 & 230 & 235 & 244 \\
\hline \multirow[t]{3}{*}{ NCLEX1st } & Pearson Correlation & $291^{4}$ &,- 109 & $.323^{\prime \prime}$ & $.338^{\prime \prime}$ \\
\hline & Sig. (2-tailed) & .000 & .099 & .000 & .000 \\
\hline & $\mathrm{N}$ & 242 & 231 & 236 & 244 \\
\hline
\end{tabular}




\begin{tabular}{|c|c|c|c|}
\hline & & \multicolumn{2}{|c|}{ Corrolations } \\
\hline & & Probability4B & NCLEX1st \\
\hline \multirow[t]{3}{*}{ Pedslevel } & Pearson Conrelation & $-.254^{\prime \prime}$ & $-191^{\prime \prime}$ \\
\hline & Sig. (2-tailed) & .000 & .003 \\
\hline & $\mathrm{N}$ & 242 & 243 \\
\hline \multirow[t]{3}{*}{ nEATIPsyche } & Pearson Comrelation & $458^{2}$ & $-306^{2 \pi}$ \\
\hline & Sig. (2-tailed) & 000 & .000 \\
\hline & $\mathrm{N}$ & 244 & 245 \\
\hline \multirow[t]{3}{*}{ PsychLevel } & Pearson Comblation & $-.251^{2}$ & $.199^{\prime \prime}$ \\
\hline & Sig (2-tailod) & .000 & .002 \\
\hline & $\mathrm{N}$ & 244 & 245 \\
\hline \multirow[t]{3}{*}{ N7ATIMatChild } & Pearson Correlation & $.516^{\circ}$ & $-.283^{\prime \prime}$ \\
\hline & Sig. (2-tailed) & .000 & .000 \\
\hline & $\mathrm{N}$ & 243 & 244 \\
\hline \multirow[t]{3}{*}{ MatChildLevel } & Pearson Correlation & $-371^{2}$ & $291^{\prime \prime}$ \\
\hline & Sig (2-tailed) & 000 & .000 \\
\hline & $\mathrm{N}$ & 241 & 242 \\
\hline \multirow[t]{3}{*}{ RNoompA2 } & Pearson Correlation & $.377^{\circ}$ & -.109 \\
\hline & Sig. (2-talled) & .000 & .099 \\
\hline & N & 230 & 231 \\
\hline \multirow[t]{3}{*}{ Probability 4 A } & Pearson Correlation & $679^{\circ}$ & $.323^{21}$ \\
\hline & Sig. (2-tailed) & .000 & .000 \\
\hline & $\mathrm{N}$ & 235 & 236 \\
\hline \multirow[t]{3}{*}{ RNCompB } & Pearson Correlation & .924 & $-.338^{2 "}$ \\
\hline & Sig (2-tailed) & .000 & .000 \\
\hline & $\mathrm{N}$ & 244 & 244 \\
\hline \multirow[t]{3}{*}{ Probability $4 \mathrm{~B}$} & Pearson Correlation & 1 & $-337^{\circ}$ \\
\hline & Sig. (2-tailed) & & .000 \\
\hline & $\mathrm{N}$ & 244 & 244 \\
\hline \multirow[t]{3}{*}{ NCLEX1st } & Pearson Correlation &,$- 337^{27}$ & 1 \\
\hline & Sig. (2-tailed) & 000 & \\
\hline & $\mathrm{N}$ & 244 & 245 \\
\hline
\end{tabular}

- Correlation is significant at the 0.05 level (2-tailed).

$*$. Correlation is significant at the 0.01 level (2-tailed). 


\section{California State University, Fresno}

\section{Non-Exclusive Distribution License}

(to make your thesis/dissertation available electronically via the library's eCollections database)

By submitting this license, you (the author or copyright holder) grant to CSU, Fresno Digital Scholar the non-exclusive right to reproduce, translate (as defined in the next paragraph), and/or distribute your submission (including the abstract) worldwide in print and electronic format and in any medium, including but not limited to audio or video.

You agree that CSU, Fresno may, without changing the content, translate the submission to any medium or format for the purpose of preservation.

You also agree that the submission is your original work, and that you have the right to grant the rights contained in this license. You also represent that your submission does not, to the best of your knowledge, infringe upon anyone's copyright.

If the submission reproduces material for which you do not hold copyright and that would not be considered fair use outside the copyright law, you represent that you have obtained the unrestricted permission of the copyright owner to grant CSU, Fresno the rights required by this license, and that such third-party material is clearly identified and acknowledged within the text or content of the submission.

If the submission is based upon work that has been sponsored or supported by an agency or organization other than California State University, Fresno, you represent that you have fulfilled any right of review or other obligations required by such contract or agreement.

California State University, Fresno will clearly identify your name as the author or owner of the submission and will not make any alteration, other than as allowed by this license, to your submission. By typing your name and date in the fields below, you indicate your agreement to the terms of this distribution license.

$$
\text { Mary Ann McCarthy }
$$

Type full name as it appears on submission

$$
\text { June } 11,2012
$$

\section{Date}

